\title{
A Review of 50-Years of International Literature on the Internal Environment of Building Practice-Based Research Networks (PBRNs)
}

\author{
Anna Dania, MPH, Zsolt Nagykaldi, PhD, Ari Haaranen, PhD, \\ Jean W. M. Muris, MD, PhD, Philip H. Evans, FRCGP, MPhil, \\ Pekka Mäntyselkä, MD, PhD, and Chris van Weel, MD, PhD
}

Purpose: Practice-based research networks (PBRNs) have developed dynamically across the world, paralleling the emergence of the primary care discipline. While this review focuses on the internal environment of PBRNs, the complete framework will be presented incrementally in future publications.

Methods: We conducted a scoping review of the published and gray literature. Electronic databases, including MEDLINE (PubMed), OVID, CINAHL (EBSCOhost), Scopus, and SAGE Premier, were searched for publications between January 1, 1965 and December 31, 2020 for English-language articles. Rigorous inclusion/exclusion criteria were implemented to identify relevant publications, and inductive thematic analysis was applied to elucidate key elements, subthemes, and themes. Social network theory was used to synthesize findings.

Results: A total of 229 publications described the establishment of 93 PBRNs in 15 countries that met the inclusion criteria. The overall framework yielded 3 main themes, 12 subthemes, and 57 key elements. Key PBRN activities included relationship building between academia and practitioners and development of a learning environment through multidirectional communication.

Conclusions: PBRNs across many countries contributed significantly to shaping the landscape of primary health care and became an integral part of it. Many common features within the sphere of PBRNs can be identified that seem to promote their establishment across the world. (J Am Board Fam Med 2021;34:762-797.)

Keywords: Bibliometrics, Communication, Family Medicine, Practice-Based Research Network, Primary Health Care, Quality Improvement

\section{Introduction}

Practice-based research networks (PBRNs) are collaborations of researchers and primary care practitioners who are engaged in conducting health/care research, addressing questions and problems that emerge from daily practice, translating research

This article was externally peer reviewed.

Submitted 16 November 2020; revised 9 February 2021; accepted 10 February 2021.

From Department of Family Medicine/General Practice, CAPHRI Institute, Maastricht University, The Netherlands (AD, JWMM); University of Oklahoma Health Sciences Center, Department of Family and Preventive Medicine, Oklahoma City (ZN); Department of Nursing Science, University of Eastern Finland, Kuopio (AH); University of Exeter Medical School, Exeter, UK (PHE); Institute of Public Health and Clinical Nutrition, Unit of General Practice, University of Eastern Finland, Kuopio (PM); Kuopio University Hospital, Kuopio, Finland (PM); Department of Primary and Community Care, Radboud Institute of Health Sciences, Radboud University Nijmegen, The Netherlands $(\mathrm{CvW})$; Department of Health Services findings into evidence-based practice, and improving the quality of healthcare. ${ }^{1-4}$

The seminal idea of PBRNs was planted in the UK in the late 1800s, first by James Mackenzie, and later by Will Pickles and John Fry, who conducted research in their own practices. ${ }^{5}$ Starting in 1967 , this effort became more systematic through the Royal College of General Practitioners Weekly Returns Service in Birmingham, UK, which systematically gathered morbidity data from specific practices. ${ }^{6}$ In the USA, Curtis G. Hames conducted

Research and Policy, Australian National University, Canberra $(\mathrm{CvW})$.

Funding: None.

Conflicts of interest: None.

Corresponding author: Anna Dania, MPH, Department of Family Medicine/General Practice, CAPHRI Institute, Maastricht University, PO Box 616, 6200 MD Maastricht, The Netherlands (E-mail: a.dania@maastrichtuniversity.nl). 
observational studies in family practice settings in the early 1970 s, ${ }^{5}$ while A. Huygen initiated research activities at first in his practice just after World War II and soon engaged 4 Dutch family practices in the Nijmegen area in $1967 .^{7}$ Since these early experiences, primary care research has expanded to more countries and healthcare settings, and many PBRNs have sprung up worldwide. , $^{4-13}$

Through the course of 5 decades, PBRNs developed new scientific knowledge and various health care innovations, ${ }^{14-16}$ new research methodologies, ${ }^{17-19}$ innovative Health Information Technology (HIT), ${ }^{20-23}$ and healthcare improvement programs that were, in some cases, supported by national legislation. ${ }^{24-27}$

While several publications exist describing the development of individual PBRNs or geographically clustered PBRNs (eg, at the regional or national level), there is a paucity of information about the establishment of PBRNs across the world and over 5 decades. The purpose of this study was to address this gap by conducting a scoping review of the worldwide English literature to synthesize what is known about the establishment of PBRNs and by constructing an overarching thematic framework, which has not been established before. This also allowed us to map the facilitators and barriers of building PBRNs based on the entire discoverable body of PBRN literature.

Due to the extent of our findings, the focus of this article is on the internal environment of PBRNs. Results derived from other domains (eg, the external environment) will be presented in subsequent publications.

\section{Methods}

We conducted a scoping review of the literature following a methodological framework described by Arksey and O'Malley, ${ }^{28}$ which was appropriate to map the key elements that underpin our area of interest, spanning across a broad scale of source data. This method is particularly suitable to examine a comprehensive set of data sources and various types of evidence that may be available, such as electronic databases, reference lists, manual searches of individual journals, online information on existing networks, organizations, and conference proceedings. This allowed us to search across the "universe" of PBRNs and any information that was accessible on their establishment.

We then applied analytic stages suggested by the chosen method: (1) defining the research question,
(2) identifying relevant studies, (3) study selection, (4) charting the data, (5) collating and summarizing the findings, and (6) reporting the results. The purpose of conducting the scoping review was to identify key elements that were linked to the establishment of PBRNs and to create an overarching thematic framework that contextualizes the facilitators and barriers of this process. Our qualitative scoping review approach did not include a quality assessment of the examined articles, since we intended to incorporate any verifiable information available.

\section{Identifying Relevant Studies and Study Selection}

We identified relevant publications in 2 steps. In the first step, we searched the English-language literature systematically and reviewed publications listed in MEDLINE (PubMed), OVID, CINAHL (EBSCOhost), Scopus, and SAGE Premier, using the following search terms: "primary care," "family practice," "general practice"; in combination with: "practice-based," "research," "network," “data," and "infrastructure." We identified publications that contained information on the establishment of PBRNs between January 1, 1965 and December 31, 2020 to establish a primary group of article abstracts.

One of the authors (AD) reviewed the full-text articles and eliminated duplications and articles that were clearly irrelevant. Subsequently, 3 reviewers $(\mathrm{AD}, \mathrm{PM}$, and $\mathrm{AH})$ scrutinized all articles separately to ensure that they were relevant to the research question and applied rigorous inclusion/exclusion criteria. The inclusion/exclusion criteria are presented in Table 1 . The selection process yielded a total of 229 publications that included relevant information.

In the second step, we searched the "gray literature" for white papers, newsletters, conference abstracts, posters, proceedings, presentations, individual PBRN websites, editorials, and online materials published by national organizations; assessed the references in selected publications; and reviewed additional papers that emerged from bibliographic lists. An extended search was conducted using Google Scholar and public online sources. The lead author (AD) communicated with coauthors and colleagues to clarify ambiguities and bridge remaining gaps.

When there was any doubt about the relevance of a study, it was marked and remained in the list to 
1. Peer-reviewed journal articles published between 1/1/1965 and 12/31/2020 in English language that refer to one or more primary care PBRNs and include information about their establishment.

2. Articles that refer to research projects conducted by PBRNs that also provide information about their establishment.

3. Reports, editorials, letters, commentaries, conference papers, and web pages that may provide complementary information on an already identified PBRN.

4. Information on PBRN establishment was included after defining primary care-linked PBRNs based on the scope of primary care in each particular region or country.

Exclusion Criteria

1. Articles that focus on specific research studies, data collection, or database/technology development in PBRN settings, without providing information about the PBRN's establishment.

2. Articles in which the identity of the PBRN can't be determined (e.g., due to blinding).

PBRN, practice-based research network.

be evaluated by another reviewer (ZN), who had in-depth understanding of PBRN research on an international scale and maintained professional relationships with many included PBRNs. This helped the authors put information published in the literature into a more granular context and gain a deeper understanding about its relevance and meaning. A more detailed description of the review process is presented in Figure 1.

\section{Charting, Collating, and Summarizing Findings}

We explored the first 10 years of each PBRN's trajectory (when available) to capture all discoverable key actors and their attributes (interest, influence, goals), relationships and interactions between them, the nature of their relationships, and the resources contributed and properties of the PBRN that emerged during the establishment process. These key areas of our inquiry were anchored in social network theory. ${ }^{29,30}$ Four authors (AD, $\mathrm{AH}, \mathrm{ZN}$, JWMM) carefully reviewed selected publications, grouped those that referred to the same PBRNs, and implemented an iterative process to sort and characterize the material using a data charting form, including the following information: PBRN name, national affiliation, year of establishment, membership, information about PBRN leadership, geographical location and connection to other PBRNs, mission/ purpose/goals/objectives/aims (when available), and narratives that informed us about the distinct groups of main actors ("nodes" of the network) and their contributions ("network resources"), their relationships and interactions ("ties" between the "nodes"), their relationship "features," "properties" they developed, processes of establishment, and early operations. We considered "actors" to be individuals (eg, academics, clinician practitioners, practice facilitators) or groups (eg, PBRN members, boards of directors) who were interacting with each other. $^{29-31}$

An inductive thematic analysis approach ${ }^{32-34}$ was implemented to identify key elements gleaned from the literature to generate themes and subthemes related to the establishment of PBRNs.

Our iterative content analysis yielded converging observations (analytic components). These basic components were grouped according to their relevance to already known specific activities or functions that were foundational to the establishment of PBRNs (eg, recruitment, membership, governance, communication, learning environment, and so forth). This process yielded the conceptualization of 57 key elements. These key elements were then linked to 12 subthemes based on higher-level similarities. The subthemes captured the distinct groups of main "actors" (or "nodes") that contributed to the establishment of PBRNs.

We then developed the final theme structure in relation to specific environmental domains where the subthemes most fittingly belonged. Our analysis defined 3 themes, including the external, the internal, and the boundary between external and internal environments. This article focuses on the theme of the "Internal Environment," which consists of 25 key elements that can be grouped into 4 subthemes.

Some of the components from our review were then conceptualized as facilitators and barriers to establishing PBRNs, although not all components mapped to facilitators and barriers. In summary, our analytic pathway from data gathering to theme development can be described as follows:

Gathering original narratives from papers (relevant quotations) $\rightarrow$ Structuring and grouping narratives $\rightarrow$ 
Figure 1. Chart Flow Diagram. Abbreviation: PBRN, practice-based research network.

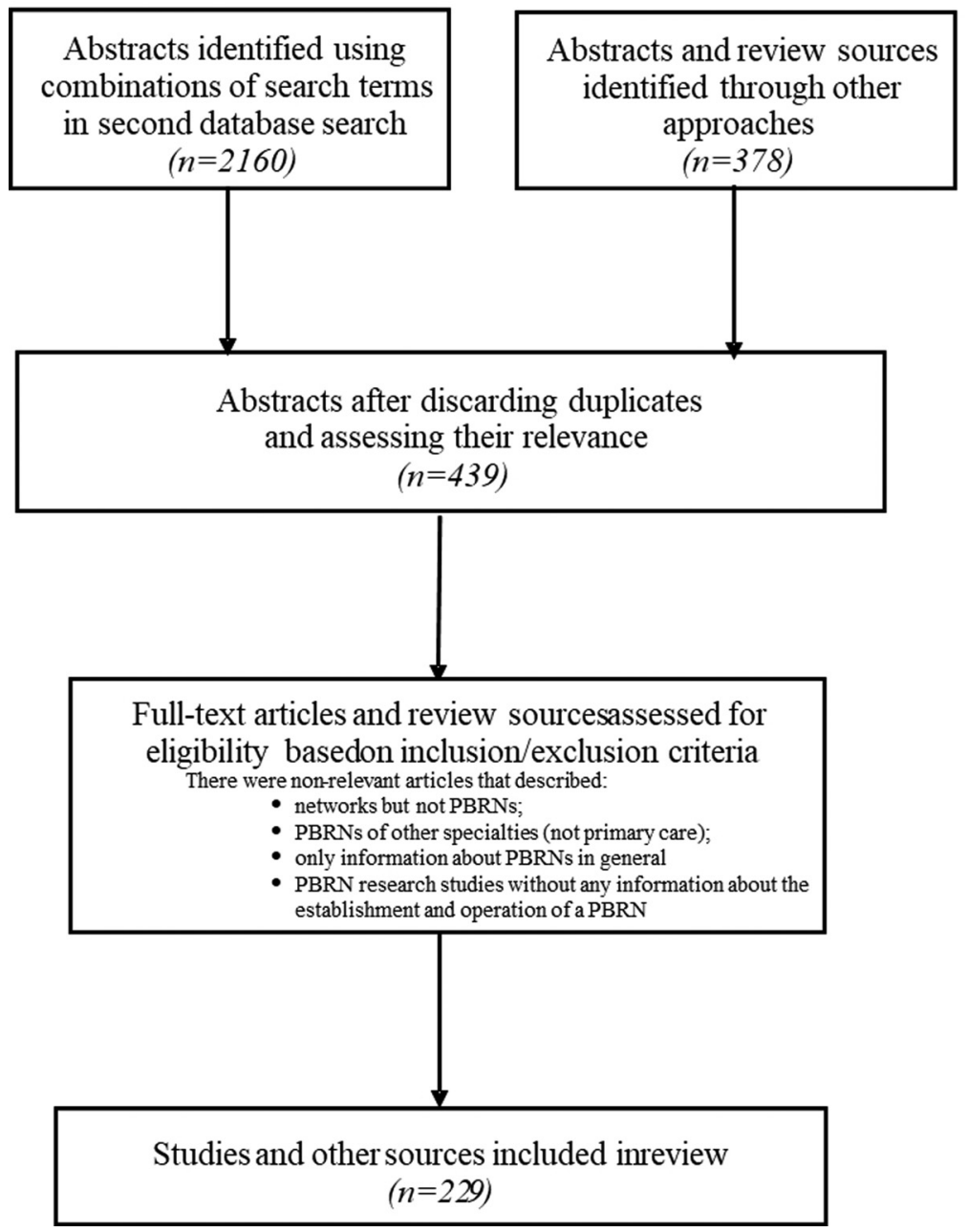

Developing components (eg, "Characteristics of a PBRN Leader") $\rightarrow$ Grouping components $\rightarrow$ Developing key elements from groups of relevant components (eg, "Organizational Leadership") $\rightarrow$ Grouping key elements $\rightarrow$ Developing subthemes from groups of relevant key elements (eg, "Network Infrastructure and Operations") $\rightarrow$ Grouping subthemes $\rightarrow$ Coalescing themes (eg, "Internal Environment")

Two examples of the methodological approach in synthesizing key elements, subthemes, and themes from the quotation level are presented in Appendix Tables 5 and 6 . An illustration of the subthemes and their connections to the themes is presented in Figure 2.

\section{Results}

Our database search identified 2160 publications. A further search of references and the "gray literature" resulted in 378 additional publications. Of these sources, 229 met the inclusion/exclusion criteria. Information gleaned about PBRNs was often variable across publications and individual PBRNs. Included PBRNs and related literature are presented in Table 2.

Ninety-three PBRNs from 15 countries met the inclusion criteria from publications spanning a period of more than 50 years. We evaluated 37 PBRNs from the USA, 15 from the UK, 10 from Australia, 4 from Belgium (of which 2 were pilot projects), 6 from the Netherlands, 3 from Ireland, 2 from Switzerland, 2 from New Zealand, 2 from Canada, and 1 PBRN from Finland, Germany, Italy, Singapore, South Africa, and Sweden. ASPN and e-PCRN were binational and were established with contributors from the USA/Canada, ${ }^{35-37}$ and $\mathrm{USA} / \mathrm{UK},{ }^{23,38-40}$ respectively and 4 were international networks. ${ }^{41-45}$ PBRNs could be characterized 
Figure 2. The Thematic Structure of PBRN Establishment. Abbreviation: PBRN, practice-based research network.

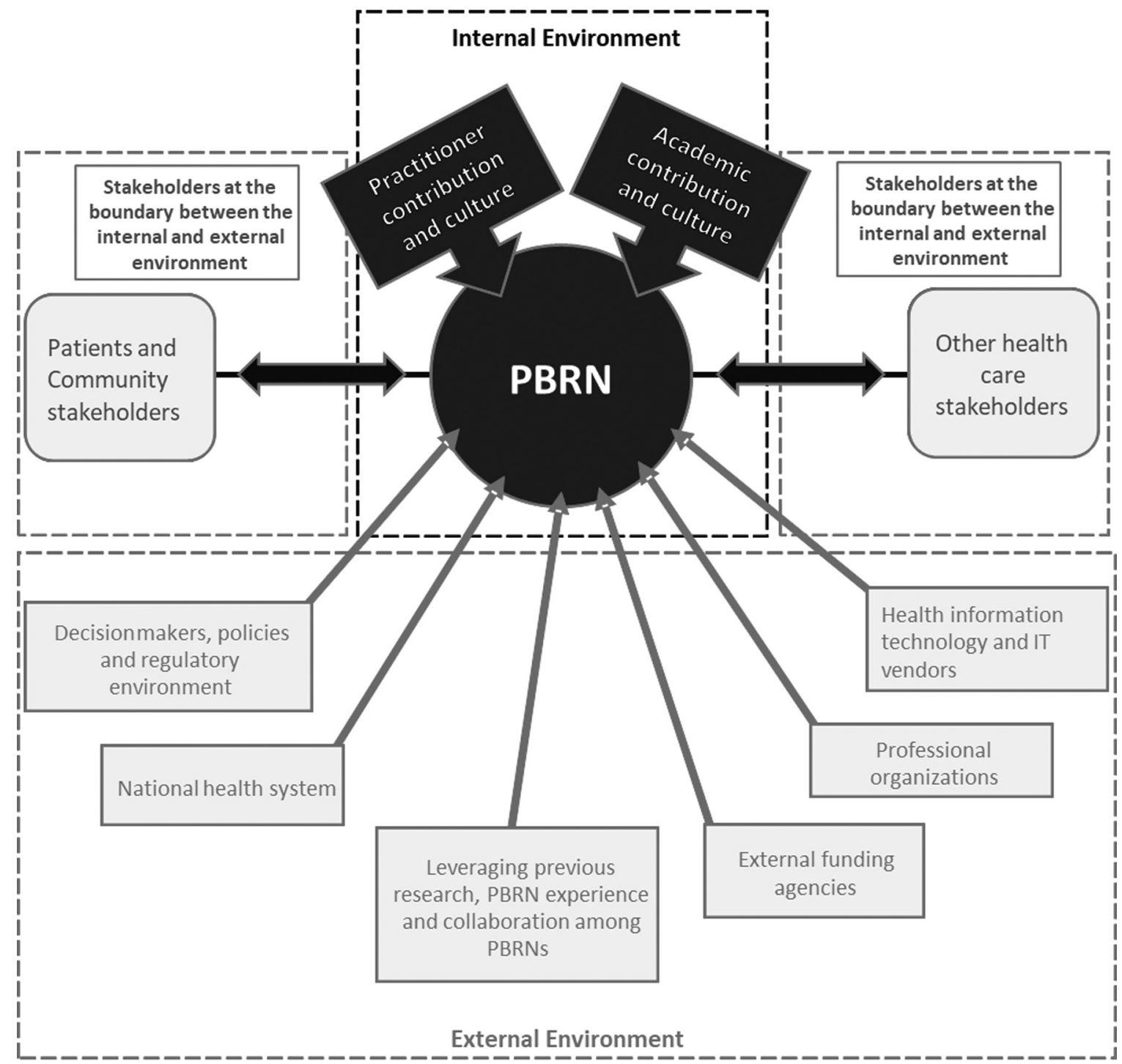

as local, regional, statewide, interstate, national, or international.

The synthesis of our results yielded 3 main themes, 12 subthemes, and 57 key elements (see Table 3). In this article, we present 25 key elements that constructed the 4 subthemes that are linked to the theme of "Internal Environment." An overarching thematic framework and thematic connections between its components are presented in Table 3.

\section{Foundation}

We found 1 key element linked to the subtheme of "Foundation" that we analyze below (see also Table 3).
Most PBRNs articulated their core mission, goals, objectives, and aims at the time of their establishment. Sentinel surveillance and the study of population morbidity patterns were often in the focus in early networks. ${ }^{7,46-49}$ Real-world problems emerging in primary care settings, and improving clinical practice and health care through practicebased evidence were central to the interest of most PBRNs. ${ }^{9,35,36,50-59}$ These suggest that PBRNs have a widely shared focus and mission for evidencebased practice and quality improvement (QI) of healthcare services. In addition, numerous PBRNs aimed at the enhancement of practitioner knowledge. ${ }^{36,52-55,61,70,76-78}$ This pattern has been 
Table 2. Included Practice-Based Research Networks, Peer-Reviewed Articles, and Review Sources

\begin{tabular}{|c|c|c|c|c|}
\hline & PBRN & Country & $\begin{array}{l}\text { Year of } \\
\text { Foundation }\end{array}$ & $\begin{array}{c}\text { Peer-Reviewed Articles and Review } \\
\text { Resources }\end{array}$ \\
\hline 1. & $\begin{array}{l}\text { Nijmegen Family Practice } \\
\text { Academic Network }\end{array}$ & The Netherlands & 1967 & $\begin{array}{l}\text { Van den Bosch } 1993^{223} \\
\text { Van Weel et al } 2000^{9} \\
\text { Gunn } 2002^{10} \\
\text { Schers et al } 2008^{136} \\
\text { Van Weel } 2008^{7}\end{array}$ \\
\hline 2. & Weekly Returns Service (WRS) & United Kingdom & 1967 & $\begin{array}{l}\text { Fleming and Crombie } 1985^{158} \\
\text { Fleming et al } 1991^{6} \\
\text { Fleming } 1999^{49}\end{array}$ \\
\hline 3. & $\begin{array}{l}\text { Dutch Sentinel General Practice } \\
\text { Network (SGPN) }\end{array}$ & The Netherlands & 1970 & Schweikardt et al $2016^{47}$ \\
\hline 4. & $\begin{array}{l}\text { Dartmouth-Northern New } \\
\text { England Primary Care } \\
\text { Cooperative Research } \\
\text { Network/COOP Project }\end{array}$ & USA & 1977 & $\begin{array}{l}\text { Nelson et al } 1981^{130} \\
\text { Nelson et al } 1981^{54} \\
\text { Nelson } 1983^{224} \\
\text { Mold and Peterson } 2005^{112}\end{array}$ \\
\hline 5 . & $\begin{array}{l}\text { Ambulatory Sentinel Practice } \\
\text { Network (ASPN) }\end{array}$ & USA-Canada & 1978 & $\begin{array}{l}\text { Green et al } 1984^{35} \\
\text { Iverson et al } 1988^{36} \\
\text { Rosser and Green } 1989^{37} \\
\text { Green et al } 1993^{180} \\
\text { Main et al } 1993^{225} \\
\text { Green et al } 1994^{104} \\
\text { Nutting et al } 1999^{181} \\
\text { Lindbloom et al } 2004^{164} \\
\text { Pearls of Research }\end{array}$ \\
\hline 6. & $\begin{array}{l}\text { Belgian Network of Sentinel } \\
\text { General Practices }\end{array}$ & Belgium & 1978 & $\begin{array}{l}\text { Lobet et al } 1987^{161} \\
\text { Boffin et al } 2010^{155} \\
\text { Boffin et al } 2013^{226}\end{array}$ \\
\hline 7. & $\begin{array}{l}\text { Minnesota Academy of Family } \\
\text { Physicians Research Network } \\
\text { (MAFPRN) }\end{array}$ & USA & 1978 & $\begin{array}{l}\text { Solberg et al } 1983^{171} \\
\text { Solberg et al } 1986^{56}\end{array}$ \\
\hline 8. & $\begin{array}{l}\text { Centro Studi e Ricerca in } \\
\text { Medicina Generale } \\
\text { (CSeRMeG PBRN) }\end{array}$ & Italy & 1983 & Visentin $2005^{76}$ \\
\hline 9. & $\begin{array}{l}\text { Pediatric Practice Research } \\
\text { Group (PPRG) }\end{array}$ & USA & 1984 & $\begin{array}{l}\text { Christoffel et al } 1988^{170} \\
\text { LeBailly et al } 2003^{167} \\
\text { Ariza et al } 2004^{227} \\
\text { LaBresh et al } 2014^{228}\end{array}$ \\
\hline 10. & $\begin{array}{l}\text { International Primary Care } \\
\text { Network (IPCN) }\end{array}$ & $\begin{array}{l}\text { National range PBRNs } \\
\text { of primary care } \\
\text { physicians from } \\
\text { Belgium, Canada, } \\
\text { England, the } \\
\text { Netherlands, } \\
\text { Switzerland, and USA }\end{array}$ & 1985 & $\begin{array}{l}\text { Culpepper and Froom } 1988^{41} \\
\text { Froom and Culpepper } 1991^{229}\end{array}$ \\
\hline 11. & $\begin{array}{l}\text { San Francisco Bay Area } \\
\text { Collaborative Research } \\
\text { Network (SFBayCRN, } \\
\text { previously UCSF PBRN) }\end{array}$ & USA & 1985 & $\begin{array}{l}\text { Osborn and Petitti } 1988^{138} \\
\text { Croughan-Minihane et al } 1999^{127} \\
\text { Pearls of Research } 1998^{125(\mathrm{p} 104)}\end{array}$ \\
\hline 12. & Transition project (Thanshis) & The Netherlands & 1985 & Okkes et al $2002^{230}$ \\
\hline 13. & $\begin{array}{l}\text { General Practice Information } \\
\text { Network }\end{array}$ & New Zealand & 1986 & $\begin{array}{l}\text { Kljakovic et al } 1992^{231} \\
\text { Leitch } 2016^{232}\end{array}$ \\
\hline & $\begin{array}{l}\text { Pediatric Research in Office } \\
\text { Settings (PROS) }\end{array}$ & USA & 1986 & $\begin{array}{l}\text { Wasserman et al } 1992^{160} \\
\text { Wasserman et al } 1998^{131}\end{array}$ \\
\hline
\end{tabular}




\begin{tabular}{|c|c|c|c|c|}
\hline & PBRN & Country & $\begin{array}{l}\text { Year of } \\
\text { Foundation }\end{array}$ & $\begin{array}{c}\text { Peer-Reviewed Articles and Review } \\
\text { Resources }\end{array}$ \\
\hline 15. & $\begin{array}{l}\text { Wisconsin Research Network } \\
(\text { WReN) }\end{array}$ & USA & 1987 & $\begin{array}{l}\text { Slora et al } 2006^{178} \\
\text { Slora and Wasserman } 2010^{96} \\
\text { Wasserman et al } 2011^{55} \\
\text { Pearls of Research } 1998^{125(\mathrm{p} 65-71)} \\
\text { Beasley et al } 1991^{124} \\
\text { Van Weel et al } 2000^{9}\end{array}$ \\
\hline 16. & University of Missouri PBRN & USA & 1987 & Williamson et al $1988^{131}$ \\
\hline 17. & $\begin{array}{l}\text { Harrisburg Area Research } \\
\text { Network (HARNET) }\end{array}$ & USA & 1988 & $\begin{array}{l}\text { Slawson et al } 1993^{189} \\
\text { Shaughnessy et al } 1999^{233}\end{array}$ \\
\hline 18. & (CumbReN) & United Kingdom & 1988 & Robertson et al $2005^{68}$ \\
\hline 19. & $\begin{array}{l}\text { Upper Peninsula Research } \\
\text { Network (UPRNet) }\end{array}$ & USA & 1988 & Pearls of Research $1998^{125(\mathrm{p} 72-5)}$ \\
\hline 20. & $\begin{array}{l}\text { Registration Network Family } \\
\text { Practices (RNH) }\end{array}$ & The Netherlands & 1988 & $\begin{array}{l}\text { Metsemakers et al } 1992^{109} \\
\text { Knottnerus et al } 1992^{234} \\
\text { Van den Akker et al } 1998^{182} \\
\text { de Lusignan and van Weel } 2006^{235}\end{array}$ \\
\hline 21. & $\begin{array}{l}\text { Royal New Zealand College of } \\
\text { General Practitioners } \\
\text { (RNZCGP CRN) }\end{array}$ & New Zealand & 1989 & $\begin{array}{l}\text { Tilyard et al } 1995^{236} \\
\text { Dovey and Tilyard } 1996^{84} \\
\text { Rodnick } 1999^{237} \\
\text { Hall and Martin } 2003^{238} \\
\text { Leitch } 2016^{232}\end{array}$ \\
\hline 22. & $\begin{array}{l}\text { Clinical Directors Network } \\
(\mathrm{CDN})\end{array}$ & USA & 1989 & Sardell $1996^{111}$ \\
\hline 23. & $\begin{array}{l}\text { General Practice Data Retrieval } \\
\text { Project (GPDRP) }\end{array}$ & United Kingdom & 1989 & Boydell et al $1995^{106}$ \\
\hline 24. & $\begin{array}{l}\text { Utrecht University General } \\
\text { Practices Network }\end{array}$ & The Netherlands & 1989 & $\begin{array}{l}\text { Hak et al } 1998^{239} \\
\text { Hak et al } 1998^{240} \\
\text { Venmans et al } 2009^{186}\end{array}$ \\
\hline 25. & $\begin{array}{l}\text { African Sentinel Practitioner } \\
\text { Research Network } \\
\text { (SASPREN) }\end{array}$ & South Africa & 1990 & $\begin{array}{l}\text { Volmink and Furman } 1991^{48} \\
\text { Volmink } 1996^{146} \\
\text { Volmink et al } 1996^{174} \\
\text { De Villiers } 1998^{179}\end{array}$ \\
\hline 26. & University of Adelaide PBRN & Australia & 1990 & Marley $1992^{145}$ \\
\hline 27. & $\begin{array}{l}\text { Rotterdam General Practitioners } \\
\text { Project (ROHAPRO) }\end{array}$ & The Netherlands & 1990 & $\begin{array}{l}\text { Middelkoop et al } 1994^{241} \\
\text { Middelkoop et al } 1995^{57}\end{array}$ \\
\hline 28. & $\begin{array}{l}\text { Australian Sentinel Practice } \\
\text { Research Network (ASPREN) }\end{array}$ & Australia & 1991 & $\begin{array}{l}\text { Gunn } 2002^{10} \\
\text { Clothier et al } 2005^{46}\end{array}$ \\
\hline 29. & $\begin{array}{l}\text { Northern Primary Care } \\
\text { Research Network (NoRen) }\end{array}$ & United Kingdom & 1991 & Carter $1998^{52(\mathrm{p} 77,79-83,86)}$ \\
\hline 30. & $\begin{array}{l}\text { South Texas Ambulatory } \\
\text { Research Network (STARNet) }\end{array}$ & USA & 1992 & $\begin{array}{l}\text { Noël et al } 2011^{242} \\
\text { Hayes and Burke } 2012^{243} \\
\text { STARNet }\end{array}$ \\
\hline 31. & $\begin{array}{l}\text { Medical Research Council } \\
\text { General Practice Research } \\
\text { Framework (MRC GPRF } \\
\text { GPRF) }\end{array}$ & United Kingdom & 1993 & $\begin{array}{l}\text { Carter } 1998^{52(\mathrm{p} 122-6)} \\
\text { Comino } 2002^{70}\end{array}$ \\
\hline & $\begin{array}{l}\text { Oklahoma Physicians Resource/ } \\
\text { Research Network (OKPRN) }\end{array}$ & USA & 1994 & $\begin{array}{l}\text { Mold and Barton } 1996^{113} \\
\text { Mold and Peterson } 2005^{112} \\
\text { Nagykaldi et al } 2005^{168} \\
\text { Mold and Gregory } 2003^{184}\end{array}$ \\
\hline
\end{tabular}




\begin{tabular}{|c|c|c|c|c|}
\hline & PBRN & Country & $\begin{array}{c}\text { Year of } \\
\text { Foundation }\end{array}$ & $\begin{array}{l}\text { Peer-Reviewed Articles and Review } \\
\text { Resources }\end{array}$ \\
\hline 33. & $\begin{array}{l}\text { Wessex Research Network } \\
\text { (WReN) }\end{array}$ & United Kingdom & 1994 & $\begin{array}{l}\text { Pearls of Research } 1998^{125(\mathrm{p} 85)} \\
\text { Nagykaldi et al } 2006^{245} \\
\text { Smith and Dunleavey } 1996^{78} \\
\text { Van Weel et al } 2000^{9} \\
\text { Gunn } 2002^{10}\end{array}$ \\
\hline 34. & Intego & Belgium & 1994 & $\begin{array}{l}\text { Truyers et al } 2014^{147} \\
\text { Van Casteren et al } 2015^{246}\end{array}$ \\
\hline 35. & $\begin{array}{l}\text { Practice Partner Research } \\
\text { Network (PPRNet) }\end{array}$ & USA & 1995 & $\begin{array}{l}\text { Ornstein and Jenkins } 1997^{91} \\
\text { Mold and Peterson } 2005^{112} \\
\text { Nemeth et al } 2007^{247} \\
\text { Wessell et al } 2008^{248}\end{array}$ \\
\hline 36. & $\begin{array}{l}\text { Virginia Ambulatory Care } \\
\text { Outcomes Research Network } \\
\text { (ACORN) }\end{array}$ & USA & 1996 & $\begin{array}{l}\text { Etz et al } 2015^{249} \\
\text { ACORN }^{250}\end{array}$ \\
\hline 37. & STaRNeT & United Kingdom & 1996 & $\begin{array}{l}\text { Carter } 1998^{52(\mathrm{p} 84-5,89-101)} \\
\text { Thiru et al } 2003^{251} \\
\text { Comino } 2002^{70(\mathrm{p} 12,23,29)}\end{array}$ \\
\hline 38. & $\begin{array}{l}\text { Residency Research Network of } \\
\text { Texas (RRNeT) }\end{array}$ & USA & 1997 & $\begin{array}{l}\text { Albright et al } 2001^{252} \\
\text { Hill et al } 2012^{253} \\
\text { Hayes and Burke } 2012^{243} \\
\text { Burge and Hill } 2014^{121} \\
\text { RRNeT }^{254}\end{array}$ \\
\hline 39. & $\begin{array}{l}\text { High Plains Research Network } \\
\text { (HPRN) }\end{array}$ & USA & 1997 & $\begin{array}{l}\text { Mold and Peterson } 2005^{112} \\
\text { Westfall et al } 2006^{255}\end{array}$ \\
\hline 40. & $\begin{array}{l}\text { Trent Focus Collaborative } \\
\text { Research Network }\end{array}$ & United Kingdom & 1995 & $\begin{array}{l}\text { Frew et al } 2001^{256} \\
\text { Cooke et al } 2002^{71} \\
\text { Comino } 2002^{70} \\
\text { Hammersley et al } 2002^{257} \\
\text { Trent Focus, Annual Report } 1996-97^{69} \\
\text { Trent Focus, Annual Report } 1998-99^{141} \\
\text { Trent Focus, Annual Report } 1999 \text { to } 2000^{141} \\
\text { Trent Focus, Annual Report } 2000 \text { to } 2001^{123} \\
\text { Trent Focus, Annual Report } 2001 \text { to } 2002^{258}\end{array}$ \\
\hline 41. & $\begin{array}{l}\text { East London and Essex Network } \\
\text { of Researchers (ELENoR) }\end{array}$ & United Kingdom & 1997 & $\begin{array}{l}\text { Davies et al } 2002^{58} \\
\text { Davies et al } 2002^{59} \\
\text { Graffy et al } 2002^{72} \\
\text { Graffy } 2003^{259} \\
\text { Abbott and Gunnell } 2005^{51}\end{array}$ \\
\hline 42. & $\begin{array}{l}\text { North Staffordshire General } \\
\text { Practice Research Network }\end{array}$ & United Kingdom & 1997 & $\begin{array}{l}\text { Porcheret et al } 2004^{74} \\
\text { Hayward et al } 2013^{260}\end{array}$ \\
\hline 43. & $\begin{array}{l}\text { West London Primary Care } \\
\text { Research Network } \\
\text { Community Interest Company } \\
\text { (WeLReN) }\end{array}$ & United Kingdom & 1997 & $\begin{array}{l}\text { Thomas and While } 2001^{86} \\
\text { Comino } 2002^{70}\end{array}$ \\
\hline 44. & TayRen & United Kingdom & 1998 & Pitkethly and Sullivan $2003^{73}$ \\
\hline 45. & $\begin{array}{l}\text { Scottish Primary Care Research } \\
\text { Network SPCRN (previously } \\
\text { SPPIRe) }\end{array}$ & United Kingdom & 1998 & $\begin{array}{l}\text { Zwar et al } 2006^{261} \\
\text { Sullivan et al } 2007^{75} \\
\text { Sullivan et al } 2014^{60}\end{array}$ \\
\hline
\end{tabular}




\begin{tabular}{|c|c|c|c|c|}
\hline & PBRN & Country & $\begin{array}{l}\text { Year of } \\
\text { Foundation }\end{array}$ & $\begin{array}{c}\text { Peer-Reviewed Articles and Review } \\
\text { Resources }\end{array}$ \\
\hline 46. & $\begin{array}{l}\text { American Academy of Family } \\
\text { Physicians National Research } \\
\text { Network (AAFP NRN) }\end{array}$ & USA & 1999 & $\begin{array}{l}\text { Lindbloom et al } 2004^{164} \\
\text { Graham et al } 2007^{120} \\
\text { AAFP National Research Network } \\
\text { Galliher et al } 2009^{177}\end{array}$ \\
\hline 47. & $\begin{array}{l}\text { Belgian Primary Care Data } \\
\text { Network }\end{array}$ & Belgium & 1999 & DeClerq et al $2002^{144}$ \\
\hline 48. & $\begin{array}{l}\text { Advanced Practice Registered } \\
\text { Nurse Network (APRNet) }\end{array}$ & USA & 1999 & $\begin{array}{l}\text { Deshefy-Longhi et al } 2002^{169} \\
\text { McCloskey et al } 2003^{97} \\
\text { Olsen et al } 2005^{262} \\
\text { Deshefy-Longhi et al } 2008^{263}\end{array}$ \\
\hline 49. & $\begin{array}{l}\text { ASPIRE (A Sign Health } \\
\text { Polyclinics Initiative for } \\
\text { Research Excellence) } \\
\text { (Singapore) }\end{array}$ & Singapore & 2000 & Chuan and Gan $2001^{264}$ \\
\hline 50. & $\begin{array}{l}\text { Dumfries and Galloway Primary } \\
\text { Care Research Network }\end{array}$ & United Kingdom & 2000 & Hannay $2006^{61}$ \\
\hline 51. & $\begin{array}{l}\text { General Practice Research } \\
\text { Network (GPRN) }\end{array}$ & Australia & 2000 & $\begin{array}{l}\text { Sayer et al } 2003^{129} \\
\text { Trinh et al } 2017^{265}\end{array}$ \\
\hline 52. & $\begin{array}{l}\text { Research Involving Outpatient } \\
\text { Settings Network (RIOS Net) }\end{array}$ & USA & 2000 & $\begin{array}{l}\text { Sinclair-Lian et al } 2008^{266} \\
\text { Williams et al } 2009^{267}\end{array}$ \\
\hline 53. & $\begin{array}{l}\text { Kentucky Ambulatory Network } \\
\text { (KAN) }\end{array}$ & USA & 2000 & $\begin{array}{l}\text { Pearce et al } 2004^{98} \\
\text { Love et al } 2006^{134}\end{array}$ \\
\hline 54. & $\begin{array}{l}\text { Southern Primary-Care Urban } \\
\text { Research Network (SPUR- } \\
\text { Net) }\end{array}$ & USA & 2000 & Kuo et al $2008^{99}$ \\
\hline 55. & $\begin{array}{l}\text { University Family Practice } \\
\text { Network (UFPN) }\end{array}$ & Australia & 2000 & $\begin{array}{l}\text { Laurence et al } 2001^{136} \\
\text { Gunn } 2002^{10}\end{array}$ \\
\hline 56. & $\begin{array}{l}\text { North Carolina Family Medicine } \\
\text { Research Network (NC-FM- } \\
\text { RN) (Now NCnet) }\end{array}$ & USA & 2001 & $\begin{array}{l}\text { Sloane et al } 2005^{268} \\
\text { Sloane et al } 2006^{140} \\
\text { Gourlay et al } 2010^{183}\end{array}$ \\
\hline 57. & $\begin{array}{l}\text { Primary Healthcare Research } \\
\text { Network-General Practice } \\
\text { (PHReNet) }\end{array}$ & Australia & 2001 & $\begin{array}{l}\text { Comino } 2002^{70} \\
\text { Comino et al } 2002^{62} \\
\text { Mehmet et al } 2004^{269} \\
\text { Magin et al } 2011^{143}\end{array}$ \\
\hline 58. & $\begin{array}{l}\text { Continuity Research Network } \\
\text { (CORNET) }\end{array}$ & USA & 2002 & $\begin{array}{l}\text { Serwint } 2001^{114} \\
\text { Serwint et al } 2006^{175} \\
\text { Wasserman et al } 2011^{55}\end{array}$ \\
\hline 59. & $\begin{array}{l}\text { Oregon Rural Practice-Based } \\
\text { Research Network (ORPRN) }\end{array}$ & USA & 2002 & $\begin{array}{l}\text { Nagykaldi et al } 2006^{245} \\
\text { Fagnan et al } 2007^{156} \\
\text { ORPRN }{ }^{115}\end{array}$ \\
\hline 60. & $\begin{array}{c}\text { Midwest Nursing Centers } \\
\text { Consortium Research } \\
\text { Network (MNCCRN) }\end{array}$ & USA & 2002 & $\begin{array}{l}\text { Anderko et al } 2005^{270} \\
\text { Anderko et al } 2005^{139} \\
\text { Anderko et al } 2006^{53}\end{array}$ \\
\hline 61. & $\begin{array}{l}\text { South Australian Primary Health } \\
\text { Care Research Network } \\
\text { (SARNet) }\end{array}$ & Australia & 2002 & $\begin{array}{l}\text { Waters et al } 2004^{63} \\
\text { Ried et al } 2006^{100} \\
\text { Aims and objectives for the SARNet } \\
\quad \text { Research Network } 2006^{271} \\
\text { Ried et al } 2007^{65} \\
\text { Farmer et al } 2005^{272}\end{array}$ \\
\hline
\end{tabular}




\begin{tabular}{|c|c|c|c|c|}
\hline & PBRN & Country & $\begin{array}{c}\text { Year of } \\
\text { Foundation }\end{array}$ & $\begin{array}{c}\text { Peer-Reviewed Articles and Review } \\
\text { Resources }\end{array}$ \\
\hline 62. & $\begin{array}{l}\text { Mecklenburg Area Partnership } \\
\text { for Primary Care Research } \\
\text { (MAPPR) }\end{array}$ & USA & 2003 & $\begin{array}{l}\text { Dulin } 2005^{107} \\
\text { Dulin et al } 2010^{273} \\
\text { Dulin et al } 2011^{157} \\
\text { Dulin et al } 2012^{274} \\
\text { MAPPR }^{275}\end{array}$ \\
\hline 63. & $\begin{array}{l}\text { Electronic Primary Care } \\
\text { Research Network (ePCRN) }\end{array}$ & $\begin{array}{l}\text { USA and United } \\
\text { Kingdom }\end{array}$ & 2004 & $\begin{array}{l}\text { Peterson et al } 2006^{23} \\
\text { Fontaine et al } 2007^{38} \\
\text { Delaney et al } 2012^{39} \\
\text { Peterson et al } 2012^{40}\end{array}$ \\
\hline 64. & $\begin{array}{l}\text { Massachusetts School Nurse } \\
\text { Research Network } \\
\text { (MASNRN) }\end{array}$ & USA & 2004 & $\begin{array}{l}\text { Vessey } 2007^{166} \\
\text { Pulcini et al } 2008^{276}\end{array}$ \\
\hline 65. & $\begin{array}{l}\text { CONTinuous Morbidity } \\
\text { Registration Epidemiologic } \\
\text { NeTwork (CONTENT) }\end{array}$ & Germany & 2005 & $\begin{array}{l}\text { Laux et al } 2005^{150} \\
\text { Chmiel et al } 2011^{187}\end{array}$ \\
\hline 66. & ResoPrim Project & Belgium & 2005 & De Clercq et al $2009^{277}$ \\
\hline 67. & $\begin{array}{l}\text { UK Clinical Research Network } \\
\text { (UKCRN) and National } \\
\text { Institute for Health Research } \\
\text { (NIHR) CRN }\end{array}$ & United Kingdom & 2006 & $\begin{array}{l}\text { Department of Health } 2006^{278} \\
\text { Department of Health } 2006^{27} \\
\text { Sullivan et al } 2007^{75} \\
\text { Cooke et al } 2008^{50} \\
\text { Pickstone et al } 2008^{85} \\
\text { National Institute for Health Research } \\
2012^{279} \\
\text { National Institute for Health Research } \\
2014^{135} \\
\text { National Institute for Health Research } \\
2014^{280} \\
\text { Local Clinical Research Networks } 2016^{281}\end{array}$ \\
\hline 68. & GRACE-01 & International & 2006 & $\begin{array}{l}\text { Butler et al } 2009^{42} \\
\text { Nuttal et al } 2011^{43}\end{array}$ \\
\hline 69. & DARTNet & USA & 2007 & $\begin{array}{l}\text { Pace et al } 2009^{21} \\
\text { Maro et al } 2009^{282} \\
\text { Pace et al } 2009^{188} \\
\text { Libby et al } 2010^{116} \\
\text { Pace et al } 2014^{153}\end{array}$ \\
\hline 70. & $\begin{array}{l}\text { Greater Rochester-PBRN (GR- } \\
\text { PBRN) }\end{array}$ & USA & 2007 & Gibson et al $2010^{102}$ \\
\hline 71. & $\begin{array}{l}\text { OCHIN Practice-Based } \\
\text { Research Network (OCHIN } \\
\text { PBRN) }\end{array}$ & USA & 2007 & $\begin{array}{l}\text { DeVoe et al } 2011^{90} \\
\text { DeVoe et al } 2012^{92} \\
\text { DeVoe and Sears } 2013^{110} \\
\text { Arkind et al } 2015^{283}\end{array}$ \\
\hline 72. & $\begin{array}{l}\text { Victorian Primary Care Practice- } \\
\text { Based Research and Education } \\
\text { Network (VicReN) }\end{array}$ & Australia & 2007 & $\begin{array}{l}\text { Soós et al } 2010^{66} \\
\text { Australian Primary Care Research Network } \\
\text { APCReN }{ }^{21}\end{array}$ \\
\hline 73. & $\begin{array}{l}\text { Canadian Primary Care Sentinel } \\
\text { Surveillance Network } \\
\text { (CPCSSN) }\end{array}$ & Canada & 2008 & $\begin{array}{l}\text { Birtwhistle et al } 2009^{126} \\
\text { Birtwhistle } 2011^{159} \\
\text { Peckham and Hutchison } 2012^{284} \\
\text { Coleman et al } 2015^{285}\end{array}$ \\
\hline
\end{tabular}




\begin{tabular}{|c|c|c|c|c|}
\hline & PBRN & Country & $\begin{array}{l}\text { Year of } \\
\text { Foundation }\end{array}$ & $\begin{array}{c}\text { Peer-Reviewed Articles and Review } \\
\text { Resources }\end{array}$ \\
\hline 74. & $\begin{array}{l}\text { European Academy of Pediatrics } \\
\text { Research in Ambulatory } \\
\text { Settings network } \\
\text { (EAPRASnet) }\end{array}$ & International & 2008 & Del Torso et al $2010^{44}$ \\
\hline 75. & $\begin{array}{l}\text { TARGet Kids Toronto Area } \\
\text { Research Group }\end{array}$ & Canada & 2008 & $\begin{array}{l}\text { Morinis et al } 2012^{149} \\
\text { Abdullah et al } 2015^{286} \\
\text { Carsley et al } 2015^{148}\end{array}$ \\
\hline 76. & $\begin{array}{l}\text { FIRE Project (Family Medicine } \\
\text { ICPC-Research Using } \\
\text { Electronic Medical Records) }\end{array}$ & Switzerland & 2009 & $\begin{array}{l}\text { Chmiel et al } 2011^{187} \\
\text { Rizza et al } 2012^{287} \\
\text { Zellweger et al } 2014^{288}\end{array}$ \\
\hline 77. & $\begin{array}{l}\text { Centricity Health Care User } \\
\text { Research Network (CHURN) }\end{array}$ & USA & N/A (2009?) & $\begin{array}{l}\text { Lieberman } 2006^{82} \\
\text { Gill et al } 2010^{289} \\
\text { Gill et al } 2012^{185}\end{array}$ \\
\hline 78. & $\begin{array}{l}\text { West of Ireland Research and } \\
\text { Education Network } \\
\text { (WestREN) }\end{array}$ & Ireland & 2009 & Kavanagh et al $2010^{122}$ \\
\hline 79. & $\begin{array}{l}\text { Electronic Practice Based } \\
\text { Research Network (e-PBRN) }\end{array}$ & Australia & 2010 & $\begin{array}{l}\text { Liaw et al } 2011^{103} \\
\text { Taggart et al } 2012^{152} \\
\text { e-PBRN }\end{array}$ \\
\hline 80. & $\begin{array}{l}\text { Scalable Architecture for } \\
\text { Federated Translational } \\
\text { Inquiries Network } \\
\text { (SAFTINet) }\end{array}$ & USA & 2010 & $\begin{array}{l}\text { Schilling et al } 2013^{165} \\
\text { Kwan et al } 2013^{291} \\
\text { Sills } 2015^{88} \\
\text { Kwan et al } 2016^{93}\end{array}$ \\
\hline 81. & $\begin{array}{l}\text { Community Health Applied } \\
\text { Research Network (CHARN) }\end{array}$ & USA & 2010 & Likumahuwa et al $2013^{108}$ \\
\hline 82. & VA WH-PBRN (USA) & USA & 2010 & $\begin{array}{l}\text { Frayne et al } 2013^{82} \\
\text { Pomernacki et al } 2019^{292}\end{array}$ \\
\hline 83. & $\begin{array}{l}\text { WWAMI Region Practice and } \\
\text { Research Network (WPRN) }\end{array}$ & USA & 2011 & $\begin{array}{l}\text { Baldwin et al } 2012^{18} \\
\text { Stephens et al } 2012^{95} \\
\text { Cole et al } 2014^{115} \\
\text { Cole et al } 2016^{293}\end{array}$ \\
\hline 84. & $\begin{array}{l}\text { Illawarra and Southern Practice } \\
\text { Research Network (ISPRN) }\end{array}$ & Australia & 2011 & Dijkmans-Hadley et al $2015^{67}$ \\
\hline 85. & PBRN-OSH & Sweden & 2011 & Jensen et al $2020^{83}$ \\
\hline 86. & $\begin{array}{l}\text { Irish Primary Care Research } \\
\text { Network (IPCRN) }\end{array}$ & Ireland & 2012 & $\begin{array}{l}\text { Galvin et al } 2015^{294} \\
\text { Dillon et al } 2015^{154} \\
\text { IPCRN }^{127}\end{array}$ \\
\hline 87. & $\begin{array}{l}\text { Home Visiting Applied Research } \\
\text { Collaborative/Home Visiting } \\
\text { Research Network (HARC/ } \\
\text { HVRN) }\end{array}$ & USA & 2012 & Duggan et al $2013^{79}$ \\
\hline 88. & $\begin{array}{l}\text { Swiss Primary Care Active } \\
\text { Monitoring Network (SPAM) }\end{array}$ & Switzerland & 2012 & Selby et al $2015^{176}$ \\
\hline 89. & $\begin{array}{l}\text { Developmental Disabilities } \\
\text { Practice-Based Research } \\
\text { Network (DD-PBRN) }\end{array}$ & USA & 2013 & Tyler and Werner $2014^{81}$ \\
\hline 90. & $\begin{array}{l}\text { Australian Chiropractic Research } \\
\text { Network (ACORN) }\end{array}$ & Australia & 2015 & $\begin{array}{l}\text { Adams et al } 2015^{295} \\
\text { Adams et al } 2016^{80} \\
\text { Adams et al } 2017^{296} \\
\text { ACORN }^{250}\end{array}$ \\
\hline 91. & $\begin{array}{l}\text { Tutka Primary Care Research } \\
\text { Network (TUTKA) }\end{array}$ & Finland & 2015 & Koskela $2017^{118}$ \\
\hline
\end{tabular}




\begin{tabular}{|c|c|c|c|c|}
\hline & PBRN & Country & $\begin{array}{c}\text { Year of } \\
\text { Foundation }\end{array}$ & $\begin{array}{c}\text { Peer-Reviewed Articles and Review } \\
\text { Resources }\end{array}$ \\
\hline 92. & $\begin{array}{l}\text { University of Limerick } \\
\text { Education and Research } \\
\text { Network for General Practice } \\
\text { (ULEARN-GP) }\end{array}$ & Ireland & 2018 & O'Regan et al $2020^{89}$ \\
\hline 93. & $\begin{array}{l}\text { Pacific People's Health Advisory } \\
\text { Group (PPHAG) PBRN }\end{array}$ & $\begin{array}{l}\text { Samoa, Tonga, Cook } \\
\text { Islands, Niue, and } \\
\text { New Zealand }\end{array}$ & 2018 & Lamont et al $2020^{45}$ \\
\hline
\end{tabular}

PBRN, practice-based research network.

consistent across academia-initiated and practitioner-driven activities by members who recognize the importance of practice-based research, which improves primary care practice. Furthermore, the UK and Australian networks explicitly stated the specific purpose of research capacity building in primary care. ${ }^{51,52,60-75}$ Later-generation PBRNs demonstrated more specific goals at their establishment, which defined their aims and partnerships. ${ }^{79-83}$ We present PBRN goals and aims in Appendix Table 2.

As the PBRNs worked toward accomplishing their mission, they developed "ties" and "properties" that helped sustain their internal environment, but they also encountered a number of barriers and challenges, some of them were incidental, while some others were structural. These facilitators and barriers were mapped in relationship to specific key elements and are presented in the following and also summarized in Table 4.

\section{Practitioner Participation and Motivation}

We found the following 5 key elements to be linked to the subtheme of "Practitioner Participation and Motivation" (see also Table 3). Most PBRNs were established on a core of research-motivated and experienced clinician members. Especially in the early networks, volunteer practitioner ("bottomup") ${ }^{7,84}$ support was instrumental.

The recruitment of members followed various paths. Some networks recruited a decisively selective group of practices, others tended to create either a representative or a convenience sample. Some sought specific practice or practitioner characteristics or PBRN-related criteria, especially in relation to research experience or interest in a specific research topic. In general, membership brought a set of benefits and obligations, which in some networks were more binding, while others applied a flexible membership model. The idea of providing value-added benefits to members was at the heart of most networks.

PBRN member recruitment often leveraged prior relationships with academia through training or research, relationships within professional organizations, connections established via social or professional venues, and various incentives.

Across the board, PBRN membership typically encompassed either general practitioners (GPs)/family physicians (FPs) or other primary care professionals, separately or together with GPs/FPs. Since the 1990s, numerous networks engaged multiple types of primary care disciplines, including allied health professionals and various levels of expertise. ${ }^{63,70,85,86} \mathrm{In}$ the early years, mainly individual practices were involved, while later, membership was expanded to larger healthcare organizations. ${ }^{87-89}$

Our analysis suggested 5 levels of member engagement on the research participation continuum: (1) practitioner-research leaders, who initiated, designed, and drove research; (2) champion members, who were active participants in all/most steps of research; (3) regular collaborators, who participated in research that was initiated, designed, and driven by others; (4) research advisors, who interacted with researchers and/or contributed data without conducting research; and (5) informed research users, who were interested in using research results without participating or contributing.

Common barriers for practitioner engagement and participation included lack of protected time, low interest in research topics, limited research skills, competing priorities, and maintaining practice efficiency. ${ }^{44,46,89-94}$ Obstacles to recruitment 
also included previous negative experiences with academic interactions. ${ }^{89,95}$

Practitioner focus on patient care excellence tended to form the cornerstone of PBRN activities. Practitioners were interested in research topics that were closely related to their daily work and were applicable to real-world conditions. ${ }^{9,18,36,60,69,79,80,92,96-108}$ As members, they aimed to contribute to new knowledge, implement research findings, and engage in healthcare policy or advocacy.

Member motivation was associated with the presence of a research culture in the clinic and the appreciation for research that members considered highly important in general practice. ${ }^{50,60,79,89,109}$ PBRN membership was perceived as professionally stimulating, increasing job satisfaction, supporting collegiality and peer learning, and facilitating professional development.

Networks that aligned their objectives with the needs of individual practitioners relied more on nonmaterial incentives, eg, a shared vision, participation in a learning community, dissemination of value-added resources, and diffusing knowledge. Such approaches created a solid foundation and strong incentive for PBRN research. 39,66,67,69,78,81,82,86,99,105,108,110-118.

Other nonmaterial incentives included simple projects at the start-up period, professional and practice benefits, and research assistance. Material incentives

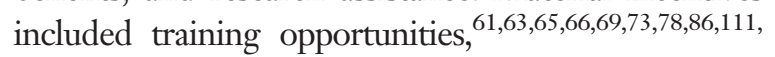
119,120 small research grants, ${ }^{10,52,61,63,65,73,78,86,121-125}$ and professional credits. ${ }^{46,78,80,125-130}$

Member financial support/remuneration has been applied broadly; ${ }^{60,61,65,73-75,80,92,93,99,108,121,122,131-135 ~}$ however, in some cases professional credits proved to be enticing ${ }^{126}$ or preferable. $46,73,80,102,125,127,129,130$

Ongoing mentorship combined with practitioner empowerment built strong personal relationships, even when these were established through a "topdown approach," and member compensation was limited. ${ }^{7,9,65,66,136}$

\section{Academic Participation and Attitudes}

Seven key elements were linked to the subtheme of "Academic Participation and Attitudes" (see Table 3).

The development of PBRNs was linked strongly to the development of academic centers of excellence in general practice/family medicine and coevolving with the primary care profession. $6,7,47,56,70,137-140$ Many networks were initiated and hosted by academic institutions, in part, by leveraging past professional relationships. A number of PBRNs also received infrastructure and technology support (financial and in kind) from academic organizations. In some countries, especially in the UK and Australia, most networks were developed based on national strategies and were supported by academic departments. ${ }^{51,63,65-67,73,136,141-143}$

A few networks included only academic professionals, while nonacademic practitioners had a minimal role, at least initially. ${ }^{129,140,144}$ However, some early networks expressed unease with strictly academically propagated PBRNs. ${ }^{54,145}$

Our study confirmed the notion that the history of PBRNs is inseparable from the development of family medicine/general practice as a distinct discipline. In countries where PBRNs were developed earlier (eg, UK and the Netherlands), these networks emerged together with the academic family medicine discipline. ${ }^{6,7}$ Based on our data, it seems that in those countries where the discipline was developed at a later stage, research that was able to inform the expansion of family medicine/general practice was also delayed. ${ }^{89,146}$ Likewise, in some countries where the discipline was not well supported until more recently, the development of PBRNs also seemed to have lagged significantly. ${ }^{76}$

Academic professionals recognized the importance of practice-based research for the discipline, professional growth, academic education, and careers and have often encouraged the work of PBRNs. They were also inspired and skillful leaders who contributed to the organization, expertise, research quality, reputation, and funding of networks. Academic expertise had a palpable influence on the prioritization of research as well. 9,46-48,57,60,66,75,86,90,91,119,122,125,136,137,140,144,147-149

Academically supported PBRN databases allowed the management of a broader research portfolio and more focus on high-impact health conditions ${ }^{7,23,95,106,126,140,147,148,150-153}$ or facilitated increasing sophistication in primary care research, resulting in a definitive effect on practice improvement. $^{7,21,93,109,126,129,140,147,149,152-154}$

Academic educators frequently linked medical and resident training with PBRN activity, instilling research skills into future members. Through QI cycles and quality assurance in patient care, academics fostered an environment of excellence and facilitated knowledge transfer to learners, contributing to the growth of practitioners. ${ }^{50,52,93,109,112,130,137,154-156}$

Academic departments benefited from working with PBRNs by increasing their publication output, 
Table 3. Overarching Thematic Framework for the Establishment of Practice-Based Research Networks Focusing on the Theme of the Internal Environment Described in This Article

Theme Subtheme Key Elements

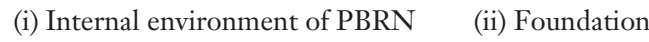

(ii) Practitioner participation and motivation

(iii) Academic participation and attitudes

(iv) Network infrastructure and operations

(i) Patients and community stakeholders (i) Setting up mission, purposes, goals, objectives, and aims

(i) Recruitment

(ii) Membership

(iii) Levels of member engagement

(iv) Intrinsic motivators to participate and benefits for practitioners

(v) Extrinsic motivators to participate and benefits for practitioners

(i) Type of affiliation and advantages-disadvantages of affiliation

(ii) The role of academics and academic departments in developing, hosting, and sustaining the network

(iii) Academic contribution to governance and leadership

(iv) Contribution of academic research expertise

(v) Academic support for research culture development and practitioner empowerment

(vi) Academic initiative to link medical students and residents to PBRN activity

(vii) Benefits for academia from PBRN collaboration

(i) Initial partnerships to establish PBRNs and centers of operations

(ii) Infrastructural funding

(iii) Key activities at establishment

(iv) Relationship building between academics and practitioners in the field

(v) Governance

(vi) Organizational leadership

(vii) Methodology of prioritizing the research agenda

(viii) Topics of PBRN research

(ix) Data gathered from networks and data management

(x) QI activities

(xi) Learning environment

(xii) Communication

(i) Patient-centeredness and community engagement in PBRNs

(ii) Relationship building with patient or community groups as an essential part of research

(iii) QI activities guided by patient feedback

(iv) Involving patients or community members in PBRN governance

(v) Integrating CBPR methodology into PBRN research

(vi) Community engaged research methodology in PBRN research

(vii) Motivation of community members for research participation

(viii) Community engagement in health policy making through PBRN activity 
Table 3. Continued

\begin{tabular}{|c|c|c|}
\hline Theme & Subtheme & Key Elements \\
\hline \multirow{24}{*}{ (iii) External environment } & \multirow[t]{3}{*}{ (ii) Other health care stakeholders } & $\begin{array}{l}\text { (i) Identification, engagement, and contribution of } \\
\text { health care stakeholders }\end{array}$ \\
\hline & & (ii) Relationship building with health care stakeholders \\
\hline & & $\begin{array}{l}\text { (iii) Other aspects of working with health care } \\
\text { stakeholders }\end{array}$ \\
\hline & (i) National health system & $\begin{array}{l}\text { (i) The impact of primary health care structure on } \\
\text { PBRN development }\end{array}$ \\
\hline & \multirow{5}{*}{$\begin{array}{l}\text { (ii) Institutional/governmental } \\
\text { support, national/state policy } \\
\text { and regulatory environment }\end{array}$} & (i) Decision-makers \\
\hline & & (ii) National policy \\
\hline & & (iii) Regulatory environment \\
\hline & & (iv) Interaction with policy-makers \\
\hline & & $\begin{array}{l}\text { (v) Community impact on public health policy-makers } \\
\text { through PBRN }\end{array}$ \\
\hline & \multirow[t]{2}{*}{ (iii) Professional organizations } & $\begin{array}{l}\text { (i) National professional organization contribution } \\
\text { and support }\end{array}$ \\
\hline & & $\begin{array}{l}\text { (ii) International professional organization } \\
\text { contribution }\end{array}$ \\
\hline & (iii) External funders & (i) External funder contributions \\
\hline & \multirow{7}{*}{$\begin{array}{l}\text { (iv) Leveraging previous research } \\
\text { and PBRN experience and } \\
\text { interacting with other networks }\end{array}$} & (i) International experience \\
\hline & & (ii) National experience \\
\hline & & (iii) Leveraging previous research expertise \\
\hline & & (iv) Leveraging PBRN practice models \\
\hline & & (v) Leveraging experience from peer networks \\
\hline & & (vi) Interacting with other networks \\
\hline & & (vii) Developing networks of PBRNs \\
\hline & \multirow[t]{5}{*}{ (v) HIT and HIT vendors } & (i) HIT applications sustain the infrastructure \\
\hline & & $\begin{array}{l}\text { (ii) HIT applications facilitating or supporting the } \\
\text { PBRN operation }\end{array}$ \\
\hline & & (iii) HIT vendors contribute to sustainability \\
\hline & & (iv) HIT vendor in the partnership of the network \\
\hline & & (v) Challenges from the variety of EHR systems \\
\hline
\end{tabular}

EHR, electronic health record; HIT, health information technology; PBRN, practice-based research network; QI, quality improvement.

strengthening professional training, acquiring grants, establishing fellowships, using or generating PBRN data for scholarly research, and making academic research more community focused and more relevant to primary care. ${ }^{6,47,57,108,124,137,140,157}$

\section{Network Infrastructure and Operations}

We found 12 key elements linked to the subtheme of "Infrastructure and Operations" presented in the following in groups, according to their relevance (see also Table 3).

\section{Initial Partnerships to Establish PBRNs and Centers of Operations}

In most PBRNs, academic institutions provided the backbone of network infrastructure, and they also became the center of operation. However, in some cases, professional organizations played this pivotal role. ${ }^{46,84,120,124,144,158-160}$ Some PBRNs were affiliated with research institutes, ${ }^{47,76,158,161}$ some developed as community-based associations, ${ }^{81,107,110}$ in 1 case, without academic affiliation. ${ }^{111}$ Other PBRNs had more than 1 linkage, ${ }^{23,75,90,108,126}$ of which 1 was a HIT vendor. ${ }^{91}$ Some operated as affiliates of other PBRNs ${ }^{96,112,162}$ or developed as networks of PBRNs, ${ }^{21,60,75,108,126,163}$ or as subsets of networks, ${ }^{152}$ or incorporated previous PBRNs, ${ }^{164}$ or established multiple linkages combining the above affiliations. ${ }^{144}$ The maturity of PBRNs was clearly associated with more sophisticated research infrastructure development, ${ }^{21,39,60,75,133,153}$ including federated or "meta" networks (networks of networks). ${ }^{60,75,87,108,126,153,162,165}$ Information about various organizations that initiated and supported PBRNs is presented in Appendix Table 1. 


\section{Facilitators}

\section{Practitioner Participation}

\section{Recruitment}

- Identification of key issues of successful recruitment (using tools such as surveys, panels, forums, professional events, site visits, or face-to-face meetings)

- Development and implementation of a recruitment strategy

- Leveraging prior relationships with university faculty (personal/professional relationships, teaching practices, residency programs)

- Leveraging previous research experience or PBRN experience

- Recruiting members of existing PBRNs

- Leveraging the potential of recently retired clinicians

- Leveraging the experience of practitioner champions or research-motivated practitioners

Membership

- Identifying practitioner motivation through surveys

- Personal motivators for PBRN membership

- Practitioner scientific interest, self-motivation, and commitment

- Flexibility in research participation (time, level of effort, methods) or protected time for research and research training

- Expanding membership to all primary care professionals

- Tailoring research to practitioner interests and encouraging practitioner empowerment

- Engagement in development of research ideas and research prioritization and proposals

- Research with direct impact on practice improvement

- Higher degree of education that facilitates PBRN activity

- Professional benefits and career development linked to participation

- Educational opportunities

- Participation in QI activities

- Participation in research that is valued or what the practitioners perceive as rewarding

- Financial and other incentives

- Integrating new knowledge from research into teaching and linking research with practitioner growth

- Relevant and easily applicable projects

- Development of an integral relationship between practice and research

- Structural benefits of data sharing

- Direct incentives for investing time and effort into innovations

- Research participation that is made motivating or even fun

- On-site, hands-on research assistance

- Other support or benefits/perks incorporated into membership

Membership in Large Networks/Networks of Networks

- Access to more robust resources and benefits derived from economies of scale

- Reaching a large sample size

- Enabling research on unexplored/understudied topics

- Access to large, geographically dispersed, and demographically diverse populations allowing research that cannot be conducted otherwise

- Access to technological, administrative, and scientific resources and expertise through a shared infrastructure

- More rapid diffusion of learning and resources

- Rich diversity of member experiences and backgrounds

Academic-Practitioner Partnership

- Availability of highly research-motivated academics who can help initiate the network

- Knowledge and resources that reside within the academic discipline

- Academic contribution to the development of a real-world research laboratory

- Academic research expertise, scientific rigor, and fundraising potential

- Academic contribution to research capacity building and practitioner empowerment including mentoring and supervising emerging researchers

- Publications that enhance the primary care discipline

- Better fundraising potential by leveraging the reputation of academics

- Academic contributions to infrastructural funding and in-kind support (including academic and PBRN staff, logistics, administration, technology)

- Academic engagement in the governance of PBRN

- Academic support for career development (fellowships, grants, support for further education)

- Academic initiatives to link medical students and residents to PBRN activity ("pipelining")

- Development of PBRNs that can supply data for external research

- Practice-based research infrastructure may become cost-effective over time

- Low-cost research assistance by involving medical learners

- Cost-effective research by leveraging longitudinal data flowing from the membership

- Networks that can be built more rapidly through academic connections

Infrastructure and Operations

Infrastructure Funding

- Dedicated funding for infrastructure or long-term funding commitment (eg, from national agencies, national professional organizations or health organizations, international governing bodies)

- Contributions from members 
- Dedicated funding for research capacity building

- Development of business models for research and QI activities

Relationship Building between Academics and Practitioners in the Field

- Development of shared vision and common identity

- Sustainable relationship building through on-site visits

- Development of long-lasting collaborative relationships within and beyond the PBRN

- Multidirectional communication, participatory membership model, appreciation of each other's preferences, values, and culture

- Fostering research relationships by establishing partnerships along common interests, collegiality, and maintaining enthusiasm

- Establishing collaborations across various disciplines and levels of seniority

- Developing relationships of trust and respect between clinician members and academics and between members, governing boards, and practice managers/staff

- Peer support from practitioners-champions (in research) to novice practitioner-researchers

- Linking academicians with novice practitioner-researchers through mentoring

- Satisfaction emerging from the achievements of small start-up projects

- Developing strong bonds with academic mentors

- Skill development based on mutual support and shared resources that add value to network products

- Leveraging prior relationships with academia

- Leveraging relationships established during previous QI activities or training

- Partnering for shared learning and best practice implementation

- Building on the ties between residents and community preceptors

- Linking students to network activities

- Linking practitioner research capacity building to asking timely research questions and the integration of practice-based research and QI outcomes into practice

Governance and Organizational Leadership

- Setting up a network upon a core of practice-based research motivated and experienced members

- Governance that provides benefits for all members

- Leaders who are champions and possess knowledge, energy, enthusiasm, and commitment to promoting PBRNs or practitioners with strong bonds to academic faculty

- Reputation/track record of recognized academics involved in organizational leadership that help sustain the network

- Strong leadership that applies close monitoring and frequent multidirectional communication

Data Collection and Management

- Data that are representative of the populations of interest

- Data interoperability that facilitates collaborative medicine and the implementation of multiple functions such as clinical decision tools

- Data that can support QI activities

- "Big data" aggregation that allows population-level information on primary care delivery and building capacity for multiple concurrent (or longitudinal) studies

QI Activities

- A specific QI-informed mission that becomes an incentive for PBRN membership

- Social and collaborative learning aspects of QI

- Development of combined research and QI methodology promotes faster research translation

- The impact of QI activities on daily practice through the implementation of best practices

- Supporting QI activities using well-designed HIT tools

Learning Environment

Training

- Training activities as a bridge to building relationships between practitioners and academics

- Linking professional development with PBRN activity and providing dedicated funding to academic departments to participate in PBRN activity

- Dedicated funding and supportive initiatives for training

- Engagement in PBRN activity during and as a follow-up to residency

Fostering Learning Communities

- Building learning communities as one of the main objectives of a PBRN

- Member motivation to share resources and to learn from and share practice-based knowledge and best practices

- Member motivation to participate in the development and sharing of practice innovation and/or transformation

- Member motivation to experience an exchange of knowledge and expertise between academia and practitioners

Communication

- Open and frequent communication using multiple means of synchronous and asynchronous methods

- On-site visits of practitioner champions/exemplars/peers when they may exchange hands-on experience and advice and teach by example

- Frequent on-site visits for research assistance to maintain interest and enthusiasm

- Facilitating problem solving in everyday practice as part of a community

- Events that promote interaction between members (academic-practitioner/practitioner-practitioner), intellectual exchange, and matching

- Breaking down practitioner isolation

- Sharing information about the progress of research (feedback, eg, via newsletters)

- Frequent meetings of the oversight bodies

- Empowering practitioners through ongoing communication 


\section{Barriers}

Clinical Practices

- Clinician and staff turnover

- The burden (time, effort, and cost) of research

- Larger practice size may result in increased research demands

- Competing organizational priorities and workflow changes

- Concerns for lost productivity due to research

- Research ethical oversight-related challenges

- Attracting and maintaining practice interest

- Lack of support for research activities by practice leadership

- Lack of cooperation from the clinic staff

- Lack of research champions in the practice

- Limited research support by experts

- Low research capacity resulting in low engagement in research

- Reorganization or transformation of practices

- Limited practice space available for research activity

- Negative research experiences in the past

Practitioners

- Not valuing practitioner contributions to research

- Time constraints to participate in PBRN activities

- Competing priorities between providing clinical services and research participation

- Sustained participation in network activities (membership retention)

- Moderate motivation for research

- Barriers related to professional role (eg, nurses have no access to clinician records)

- Lack of research skills and support to develop research skills

- Lack of understanding the research methodology and low scientific rigor in research procedures

- Restricted career opportunities for FPs/GPs and other primary care professionals

- Lack of skilled mentorship

- Insufficient access to a pool of scientific knowledge and resources necessary for research and evidence-based practice

- Lack of academic connections or knowing who to turn to for information

- Lack of remuneration for practitioner time spent with research

- Poor self-image of FP/GP when envisioning their role and their position in the health care system or seeing themselves as researchers-lack of confidence in their ability as researchers

Academia

- A delayed development of family medicine/general practice as a distinct discipline

- Lower capacity of primary care academics to attract external funding

- Academia-driven PBRN research, which may not be important for the practitioners in the field

- Academic-dominated research topics and top-down research processes

Financial Barriers

- Lack of continuity in administrative and/or overall infrastructural funding and dependence on project-based grant funding for infrastructure support

- Discrepancies between network mission and funder interest

- Lack of systematic support to cover infrastructure cost

- Lack of financial compensation for PBRN member participation in research

- Limited funding for practice-based research

- A vicious circle where outside project-related funding is difficult to obtain until the network has a track record, but it is difficult to develop a track record without outside start-up funding

Relationship Building

- Criticizing instead of supporting low-performing practices in research projects

- Low trust between academics and practitioners

- A fear of displacement of practitioners by academics in research

PBRN Structure

- Creation of a sense of identity

- Geographic dispersion of networks as a logistical challenge

- Lower generalizability of research due to small numbers of participating practices

- Challenges related to local and national realities, cultures and structures, and the additional length and cost of processes that define wide-scale activity in large networks

- Complexity of maintaining a multilevel infrastructure in international PBRNs

Research Data Concerns

- Research data quality pertaining to recording (documentation), coding, and confidentiality

- The importance of patient data privacy for the primary care practitioner

- Setting agreements/rules about research data ownership, security, use, and sharing

- Health data quality as it relates to the quality of documentation

- Maintaining data quality in longitudinal studies

- Data duplication as it relates to overlapping care episodes and care sites

- Small network size may affect the validity of outcomes

- Retrospective collection/analyses of recorded data 
- No uniform diagnostic and classification criteria or terminology for health conditions across the network

- Variable primary care service coding practices

- Representativeness of practices, practitioners, and patient population

- Selection bias when establishing patient database

- Voluntary membership may affect the quality of data

Research Study Design

- Interpretation bias may occur in research where different cultures and education are involved in international networks

- Multipractice studies require more personnel time, travel, equipment, and supplies

- Research may be more difficult in international networks that interact with populations associated with different language, means, and social context

- Increased complexity of research coordination, lengthened timelines, and higher research costs in large networks

- Identifying appropriate research study designs for specific studies that are also sensitive to the network environment

- The model of health care delivery affects research planning and sufficient subject recruitment and retention

- Restricted opportunities to frame and translate research results when practitioners have no strong participation in research

Communication

- Risk for communication gaps between practitioners and academics in large networks where communication happens through conveners

- Communication clarity may be challenged by time constraints

- Lack of good communication and understanding during research activities

- Problems deriving from distance communication during research studies

FP, family physician; GP, general practitioner; HIT, health information technology; PBRN, practice-based research network; QI, quality improvement.

\section{Key Activities at Establishment, Infrastructural}

\section{Funding}

PBRNs were established through specific key activities that defined the nature of their network. Key activities at the establishment of PBRNs included those that initiated the formation of the network and transformed ideas and mission statements into activities. Some PBRNs followed a common pathway/approach to start their operations, eg, conducting a survey to establish the profile of their practices and practitioners or the routine collection of data in their practices. Representative key activities are illustrated with quotes from the literature in Appendix Table 3.

PBRNs received infrastructural funding from a variety of external sources; however, the most common infrastructural support came from hosting academic institutions. ${ }^{10,18,46,52,66,113,124,125,140}$ In some countries (eg, Australia and the UK), strategic infrastructural investments and enduring research capacity-building programs originated from national entities. ${ }^{6,52,63,66,69,73-75,100}$ In some PBRNs, member dues and other in-kind contributions added to the infrastructure. ${ }^{35,52,84,124,130,166}$

Many networks recognized funding instability as a major challenge to sustainability. This compelled a number of PBRNs to develop business models to support their infrastructure longitudinally. We identified some business models that networks developed within the first decade following their establishment and during the time frame of our cross-sectional review. These models varied from contracting with external researchers who had long-term projects that ensured payments to practitioners or practices involved in these projects, ${ }^{78,124,167}$ to developing a diversified research portfolio $^{60,115}$ or contributing with intellectual capital and infrastructure on a cost-recovery basis, to projects sponsored by major funding organizations. ${ }^{52,66} \mathrm{We}$ also encountered more sophisticated business models that provided access to "big data" or other research data resources, which generated revenues for the network. ${ }^{153}$

\section{Relationship Building between Academics and Practitioners in the Field}

PBRNs based relationship building on the need to establish a shared identity among their members. Networks typically aimed at building long-term, constructive, collaborative, and reciprocal relationships and fostering collegiality, respect, trust, and mutual appreciation between academics and practitioners.

Synergistic relationships, which became pivotal for the long-term development of PBRNs, were implemented through all types of interactions between academic professionals and network members. Further, "conveners" that sustained the ties between them, such as practice facilitators, research coordinators, and assistants, were actively involved in these relationships. Thus, interpersonal multidirectional relationships 
were shown to be fundamentally important to the development of PBRNs. PBRN relationship-building activities are presented in Appendix Table 5, along with the steps of synthesizing this key element.

PBRNs reinforced relationships through training and education, applying multidisciplinary approaches and engaging key practitioners, practice managers, clinician champions, ${ }^{45,92,108}$ research assistants, and practice facilitators. ${ }^{168}$ Practice facilitation became a key component of many PBRN projects, supporting multidirectional communication between practices and network leadership and providing value-added assistance.

Dynamic practitioner-academic interactions fostered the emergence of a new model of primary care where research and QI are integral to the practice. This new model and vision of primary care, which has been developing since the early 2000s in some PBRNs, ${ }^{51,52,60,61,68-75}$ was expressed in a recent survey. ${ }^{89}$

\section{Governance, Leadership, Communication}

Strong leadership, multidirectional communication, and participatory governance that produces reciprocal benefits for all members were linked to PBRN growth already at the network establishment phase. ${ }^{43,60,90,92,}$ 124,125,153,157,167,169 The initial governance structure and multidirectional relationships leaders developed have influenced the network structure, how the network evolved in the following years, and the very first activities they engaged in.

Our data suggested that many networks were established around a recognized "research-enthusiast" and committed leader, with interest in improving primary care practice, developing new knowledge, and, in some cases, influencing policy. Leaders were either professionals ${ }^{73}$ who had senior academic positions ${ }^{169}$ and/or clinicians with long track records. ${ }^{67,124}$ Some also had previous PBRN experience with other networks. ${ }^{115,125}$ The components of key element "Organizational Leadership" are presented in Appendix Table 6 together with the steps of synthesizing this key element.

PBRNs used various pathways of a/synchronous communication to meet their goals for intellectual exchange, research capacity building, research prioritization, translation and dissemination of research results, and relationship building. On-site visits and personal communication were considered the most effective and motivating for research engagement. Conferences were used to generate new ideas and discuss their implementation.

Early PBRNs typically implemented an informal and low-cost governance model. We encountered a few networks with minimally structured governance, which were led by a director, ${ }^{84}$ while large single,

\section{Table 5. Suggestions for Developing New PBRNs}

Recruitment

- Identify key issues of successful recruitment strategies (using tools such as surveys, panels, forums, professional events, on-site discussions)

- Capitalize on opportunities for fostering participation within the network, eg, quality improvement activities, practice evaluations, practice transformation, data quality assurance

- Leverage prior relationships with trusted and well-known academic faculty (personal/professional relationships, teaching practices, residency programs) and previous research experience or PBRN experience

Relationship Building

- Make research easy for the busy practitioner-eg, use research assistants or practice facilitators, pragmatic research designs, and incentivize practitioners when their effort is requested ("value proposition")

- Build reciprocal long-lasting collaborative relationships based on trust and let these to be the context of decision-making in the network

- Develop member groups with matched interests

- Value member participation in research in many ways and choose those that they most appreciate, eg, provide professional credits

Research Capacity Building

- Support the research capacity building and professional development of primary care practitioners with diverse opportunities that may respond to all educational preferences varying from online workshops and training to academic educational curricula

- Foster learning communities across the members of the network

Communication

- Support open and frequent and multidirectional communication using multiple means of synchronous and asynchronous approaches

- Offer community practitioners on-site (or virtual) visits with peers where exemplars may demonstrate the benefits and/or feasibility of research in their practice

Funding for Infrastructure

- Ensure sufficient funding for infrastructure through national agencies, local organizations, and the academic institution and develop a strategic plan for a business model with diversified portfolio for the future

PBRN, practice-based research network. 
international or federated networks and networks of PBRNs incorporated a more sophisticated and extensive leadership structure. ${ }^{41,43,44,60,75,92,96,108,126,132,153}$

Some networks operated as (semi)independent or nonprofit organizations, but there was limited information regarding their relationship to host organizations and how independently they operated.

Based on available data, PBRN governance models could be characterized as top-down, bottom-up, or a mixed model that engaged the entire organization, which some referred to as a "whole system approach." 66,86

Governing bodies of PBRNs tended to incorporate a mixture of member-practitioners, academics, or solely academic professionals, depending on their structure.

Typically, governance consisted of a leadership group with research expertise, which offered guidance to research proposals, and/or an oversight group, which contributed to planning and monitoring. In larger networks, subgroups/committees were established to attend to larger-scale issues. Administrative structures and day-to-day operations varied in size and complexity, depending on the robustness of the network.

Methodology of Prioritizing the Research Agenda and Topics of PBRN Research

We found that governance type was also linked to idea generation and research prioritization activities. Competing agenda was indicated by statements stressing that practitioner priorities were important. ${ }^{9,35,96,111,112,122,170-172}$ In some publications, we also found information about leadership processes for cocreating the research agenda, ${ }^{81,83,86,99,110,125,132,173}$ data-driven research, ${ }^{21,90,153}$ evidence reviews, ${ }^{47,72,130}$ and the ranking of project ideas based on network priorities. $^{35,99,110,115,132}$ Networks reported challenges when there were gaps between the interests of research funders and PBRN stakeholders, including divergence between the goals of granting agencies and interests of PBRNs.

We identified 5 levels of research outcomes based on the subjects of interest-patient-level, clinician-level, practice/health system-level, community/population-level, and PBRN-level-including work on the research capacity of the network. Many PBRN studies incorporated multiple levels of outcomes, ${ }^{52,60,84,94,116,130}$ which were closely linked to the types of data PBRNs collected.
Data Gathered from Networks, Data Management, and QI Activities

Some publications contained information about research data sources, data governance practices and ownership, data use and purpose, scope and representativeness, value (including capacity of data), and information about infrastructure for data management support, database development, warehousing, and interoperability. Ensuring data quality through ongoing improvement efforts was fundamental for PBRNs to operate as "real-world" research laboratories producing knowledge and resources that could be disseminated widely in primary care settings. Aggregation and systematic analyses of data emanating from large collaborations, eg, federated or "meta" networks, contributed to the generalizability of results and deeper research innovations. ${ }^{23,36,55,80,92,96,125,126,153}$

The issue of representativeness of the network was a concern in many PBRNs from the start. To prevent variations from national standards, some PBRNs developed confirmatory surveys to measure the external validity of their research, 3,97,122,127,132,140,155, 156,174-181 while some smaller/local networks were representative of the patient population of their area, ${ }^{152,156,182,183}$ or their data allowed extrapolation to a national population. ${ }^{129,137}$

QI was among the main objectives of many PBRNs, even before the year 2000. ${ }^{52,112}$ Our results indicate that QI has been a significant incentive for participation, and it was leveraged to improve clinical guideline implementation, stimulated the development of new methodologies, ${ }^{112,184}$ such as "best practices research," played an important role in the translation of research into practice, helped identify research topics relevant to gaps in practice, and was also linked to collaborative learning.

PBRNs reported that QI activities enhanced the quality of healthcare in network practices. ${ }^{7,18,51,53,106,112}$ Numerous networks applied HIT to facilitate QI activities, such as quality feedbacks, clinical decision tools, and learning communities, and had a robust effect on QI implementations and QI capacity. ${ }^{21,74,95,103,105,133,185}$

\section{Learning Environment}

The learning environment was an integral part of the infrastructure and operation of PBRNs. Many findings indicate that colearning helped build a primary care research culture among PBRNs, espe-

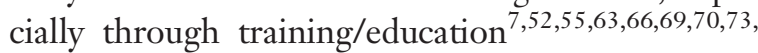


$75,78,79,81,109,111,179,186,187$ or learning community activities. $^{13,39,67,86,88,90,99,153,188}$

General training included educational courses, continuing medical education, annual training programs, higher degree education, and using interactive teaching methods, such as workshops, courses, and webinars. Mentoring, advising, research assistance, and QI training were frequently provided in the context of specific projects. $7,38,43,46,51,52,66,74,76,78$, $86,99,101,106,109,111,112,115,120,132,139,160,169,171,189$

Training activities were targeted mainly to primary care practitioners interested in research, but they were also provided for emerging academic researchers. Residency and practitioner training programs linked to PBRN activities represented other components of the learning environment.

Research capacity building activities were pronounced among the priorities of UK and Australian networks and varied from simple research training courses to degree credits and higher-level education, allowing the more widespread use of clinical evidence gleaned from practice-based research. ${ }^{9,52,59,61 \text {, }}$ $63,69,70,75,78,100$ An example of research training is presented in Appendix Table 4.

More recent networks tended to emphasize the learning community aspect of PBRNs and considered it fundamental to the network's operation, but the seminal idea was rooted in early networks. ${ }^{54,111-113}$ The function involved sharing resources and peer learning and the dissemination of best practices and QI methods based on facilitated member interaction.

\section{Discussion}

This article presents the findings of a seminal scoping review across the widest possible geographical and temporary scope, and it maps key elements contributing to the establishment of PBRNs in primary care settings. Our study examined a wide variety of publications spanning 5 decades. Our approach allowed us to explore key elements of establishing PBRNs, but it did not aim at a deep analysis of the underlying reasons.

Our synthesis yielded $57 \mathrm{key}$ elements (see Table 3), of which 25 are discussed in this article. These belong to the subthemes of "Foundation," "Practitioner Participation and Motivation," "Academic Participation and Attitudes," and "Network Infrastructure and Operations" and are linked to the theme of "Internal Environment of PBRN." Our lists of facilitators and barriers were distilled from knowledge we derived from our synthesis, and they may be useful for those who plan to build PBRNs in the future.

The key elements presented in this review are in line with a study published in 2005 on infrastructural requirements of PBRNs in the American context. ${ }^{190}$ They are also coherent with network dimensions that create social and intellectual capital that were presented in an evaluation tool/kit by Harvey et al in 2000, ${ }^{191}$ although this article applies a different nomenclature. Harvey's study also underscores the existence of common features among PBRNs across all geographies.

In the subtheme "Foundation," we linked mission, purpose, goals, objectives, and aims; however, not all PBRNs communicated their vision and goals clearly in discoverable publications, which does not imply a lack of goals. In this review, we did not investigate whether networks modified their mission during their trajectory or if they became incorporated into larger networks, but their continuity suggests that they may have reached at least some of their initial goals.

Our review suggests that network member profiling surveys, ${ }^{44,89,98,122,140,155,156,169}$ gauging practitioner motivation $51,55,56,78,79,102,127,138,145$ or training needs, ${ }^{63,67,69,70,100}$ and assessing the external validity of research ${ }^{97,179-181}$ were common in the early phase of networks, underscoring the importance of membership and/or population characteristics, practitioner motivation, and the research capacity of the network.

We found a shift in later-generation PBRNs toward more specific goals articulated at their establishment, which expressed their partnership interests. $^{79-83}$ These trends indicate an increasing sophistication of PBRNs, either through broadening their membership, which reflects their transformation in the primary healthcare environment, or through research specialization. ${ }^{13,85,192}$ The evolution of the goals of new networks over time may indicate that PBRNs adjusted to the emerging needs of communities for better primary healthcare practice.

Specific network objectives and pathways of starting networks were dependent on available resources that fostered PBRN activity in each country and network. Most of these resources were influenced by external factors, which in turn could alter resources that are internal to the PBRNs. These connections will be reviewed in a subsequent article.

The development of large networks often incorporated an objective to ensure the viability of 
emerging PBRN partners. ${ }^{21,75,96,108,126}$ These networks had access to a variety of populations, leveraged wider interests, engaged in multiple types of research, and focused on research topics that were broadly generalizable. This trend seems to have developed around 2010, and it is consistent with the findings of other studies that show that there is a tendency toward multinetwork collaborations, especially when they leverage advanced HIT. ${ }^{13,133}$ As a further expansion of PBRNs, the establishment of PBRN "meta-networks" led to a transformation into "communities of solutions"193 supported by Centers for Primary Care Practice-Based Research and Learning (P30 Centers), in the USA, ${ }^{194}$ and the extension of the clinical research network approach to all healthcare, in the UK. ${ }^{195}$

In these transformations, the focus of the research partnership was gradually extended from individual practitioner to practice, then clinic, and finally to the broader PBRN membership even in the early phases of PBRN development. These seem to parallel a similar methodological evolution, which progressed from studies addressing existing knowledge gaps of primary care to more sophisticated comparative effectiveness research based on large primary care data sets. This transition was anchored in increased research capacity and technological innovations that enabled additional functions, such as accredited evaluations, ${ }^{126,153}$ advanced clinical decision support, ${ }^{93,95,96,153}$ and learning communities. ${ }^{88,90,153}$ In many PBRNs, practitioners seemed to be more poised to improve the quality of care than to do academic research. These findings are in line with a recent survey. ${ }^{196}$

\section{Importance of Communication, Learning Environment, and Relationship Building}

Our analyses, which were anchored in social network theory, ${ }^{29,197}$ indicated the highest levels of associations in the following areas: (1) communication; (2) learning environment; and (3) relationship building between academics and practitioners in the field. These key elements included numerous components describing facilitators as well. The first and second areas indicate that PBRNs evolved as learning organizations applying multidimensional communication, which enabled them to shorten the time of spreading innovations among stakeholders, underscoring that research is not the only activity in the scope of PBRNs. ${ }^{198,199}$ The third area in the internal environment of PBRNs was linked to key elements for relationship building between academics and practitioners in the field and reflects features of these relationships that propagated the establishment of PBRNs.

Our findings are also convergent with previous studies that present key elements of high-quality practice organizations in primary care. ${ }^{200,201}$ This may indicate that practices engaged in PBRN activity are endowed with properties that enable them to improve care quality or that QI is organically linked to PBRN activity. The richness of data related to communication, learning environment, and relationship building in PBRNs, using multidirectional and multiple means communication, suggests more intense interactions and knowledge exchange among PBRN members.

\section{The Impact of PBRNs on Primary Care Practice and Professionals}

Our findings demonstrate a reciprocal relationship between the development of PBRNs and the generation of new knowledge for primary healthcare improvement, the enhancement of the discipline of primary care, and the acceleration of primary care practice reform through transformative collaborations. Although our review suggests that practices that participate in PBRN research may be somewhat different, and therefore may not be representative of primary care in general, ${ }^{41,97,122,148,174,181,202}$ in some networks, participation seemed to enable the implementation of care innovations. Through their broader impact on healthcare, policy, and education, members may have also accelerated innovation transfer to other practices. ${ }^{203-207}$

Based on our findings, we formulated 5 levels of member engagement on the research participation continuum (see Table 3), including literature-concordant "research leaders," "network champions," "regular collaborators," "advisors," and "informed research-product users." The latter describes practitioners who are influenced by PBRN activity passively ("listeners"). ${ }^{69,100,208,209}$ This may be noteworthy, since academic funders typically do not support the dissemination and "consumption," only the "production," of knowledge and resources.

Our findings indicate that the 50-year development of PBRNs gave rise to a new thinking and way of practicing general medicine, which gradually integrated research into community practice. This notion might be called "researcher-in-community," which describes practitioners who pose questions emerging from daily practice to a dedicated 
network of like-minded colleagues, supported by academic researchers. Their aim is to answer practical questions through practice-based research by bringing the university to community practice and incorporating the community into academia.

This is analogous to the model of "researcherin-residence," $210-212$ an arrangement that may provide additional benefits through broader crosspollination, learning, and diffusion of healthcare innovations. ${ }^{19,203,213}$

\section{Governance Models}

Our analyses indicated "top-down," "bottom-up" or mixed ("whole system") governance models in PBRNs. ${ }^{66,142}$ We found other typologies for PBRN governance in a study from the $\mathrm{UK}^{214}$ and in a publication from Institute for Health Policy Studies (IHPS), in the UK. ${ }^{215}$ There was limited information on governance models PBRNs adopted over the period of their establishment. Some articles suggest that a mixed-type model tended to develop in most networks over time. For example, the Nijmegen Family Practice Academic Network started as a top-down network, but practitioner empowerment resulted in stronger bottom-up governance. ${ }^{9,10}$

\section{Reciprocal Benefits between PBRN Practices and Academic Departments}

The key elements "Learning Environment" and "Academic Contribution to PBRNs" reflected strong support academicians provided to facilitate the professional growth of primary care practitioners.

Our synthesis established 6 key elements that describe the contributions of academia and 1 element that points to benefits that academic institutions received from PBRNs (see Table 3). It is important to note that this is not a quantitative measure of academic benefits, which included publications, enhanced graduate education, grants supported by PBRN data, excellence in teaching medical students and training residents, and better proximity to community, which were facilitated by working with PBRNs. This reflects the reciprocity between academician and practitioner benefits from PBRN participation.

\section{Business Models of Supporting the Work of PBRNs}

Financial instability was another significant challenge for PBRNs. Prior research has underscored the importance of infrastructural and research funding for PBRN operation. ${ }^{11,190,216-218}$ To address ongoing infrastructural support, some networks developed a business model at the time of their establishment ${ }^{52,66,82,124,153}$ or later. ${ }^{172}$ The PBRN infrastructure has been promoted in the USA through training and technical assistance provided by the Agency for Healthcare Research and Quality, ${ }^{219}$ while in the UK, a diverse research portfolio elicited by the needs of academia and industry has been driving research in primary care settings. ${ }^{75}$

\section{Geographical Variations in PBRN Development in the Internal Environment}

We have not seen substantial geographical variations in the "Internal Environment" of PBRNs (the focus of this article) by region or country. However, we observed a clear and strong thrust toward research capacity building in primary care settings among the UK and Australian networks. These networks tended to attribute similar importance to practice-based evidence and evidencebased practice in family medicine/general practice and primary care, compared with networks from other countries. Dutch networks were characterized by the development of registries of data recorded by FPs. Data collection capacity and modalities defined the use of study methodologies in different countries. Examples include sentinel surveillance networks and relevant studies in the UK, Australia, Belgium, the Netherlands, or the Dutch registries and their observational studies, and card studies plus flow charts in American networks.

International networks shared similar infrastructural problems with large national networks in the USA and UK, including study coordination, network logistics, challenges with the management of large data sets, and the costs of big-scale activity. In addition, international networks encountered other problems that emerged from differences between the local and/or national environment (eg, different ethical and regulatory frameworks across different countries); interpretation bias (eg, local differences in understanding of key research concepts); and challenges from different structures of member networks depending on varying levels of development and organization.

In the UK, Dutch, Canadian, and Australian networks, we observed more top-down PBRN governance, although it was not always communicated explicitly. In the American networks, there was 
more emphasis on practitioner engagement and empowerment (participatory networks). Various governance types defined pathways of practitioner empowerment as well. In this way, top-down networks more commonly implemented audit cycles, educational and degree courses, and academic appointments, whereas more bottom-up type networks more frequently promoted shared resources and learning communities. However, top-down networks also developed learning communities, eg, through the audit cycle sessions of the Dutch networks, and, vice versa, bottom-up networks in the USA promoted the professional development of their members through degree programs.

Financial incentives showed similar patterns. In the UK and Australia, providing PBRN member financial incentives was more common practice, but this type of incentive expanded over time, together with professional credits. Typically, the use of financial incentives seemed more common where top-down governance was prevalent, while the importance of intellectual exchange and development of new knowledge was a superior motivator in bottom-up networks. The use of financial incentives expanded in the last category of networks over time, underscoring the value of the time and effort of practitioners and also indicating a movement from single-practitioner practices, where the practitioner's membership was based on personal motivation, to larger organizations where financial motivators may play a greater role.

\section{Suggestions for Developing New PBRNs}

Our review indicated a clear emphasis on specific activities and practices that led to the development of new PBRNs. We summarize these in Table 5.

\section{Limitations}

According to our knowledge, this is a seminal and novel scoping review and a mapping of what can be gleaned from the international literature about the establishment of PBRNs in primary care across multiple countries and over a period of more than 50 years. Our ongoing work may be a foundation for future studies on the development of PBRNs; however, this article was limited to the key elements of the main theme "Internal Environment." Future studies will explore other domains, including the external environment and those spanning the internal and external environments.

We relied only on English-language sources since our team did not have the capacity to review scientific papers in several languages. However, most of the PBRN literature is in English, which favors our approach.

Our decision to review up to 10 years of each network's development can be challenged, since some networks may not need 10 years to develop a mature operation. However, we observed that some pioneer networks developed more gradually without well-tried templates, so we wanted to ensure that we can capture this important process.

The list of PBRNs that met our inclusion criteria is more limited than those identified in the $\mathrm{USA}^{220}$ Australia, ${ }^{221}$ the UK, ${ }^{70}$ and Canada ${ }^{222}$ and in sources that refer only to specific PBRN activities. We excluded articles that did not contain sufficient information on PBRN establishment. We also omitted data that we found exclusively on PBRN websites without any supporting literature. In some cases, our search of the "gray literature" was extended by communicating with key informants or authors. This approach may result in the omission of some less accessible information.

Scoping reviews may carry some bias of various kinds because a critical appraisal of the included literature's quality is often beyond their scope. Selection bias may occur, if not all available data on a topic are identified or included. In this study, we implemented an inductive thematic analysis methodology. Themes, subthemes, and key elements emerged from the data. However, we purposefully leveraged some well-established a priori knowledge about PBRNs that had a guiding effect on the development of our thematic model.

\section{Conclusions}

PBRNs have emerged through reciprocal relationships and interactions between academicians and primary care professionals. They evolved not only as research communities but also as learning organizations with multidirectional communication that shares the new knowledge and best practice innovations across the membership. They had a marked impact on the landscape of primary healthcare of the academic disciplines and became an integral part of primary healthcare practice in their countries. Although there are country- and PBRN-specific features, most facilitators and barriers of developing PBRNs, as viewed from their internal environment, are shared throughout the world and over 5 decades. 
To see this article online, please go to: bttp://jabfm.org/content/ 34/4/762.full.

\section{References}

1. Agency for Healthcare Research and Quality [Internet]. Practice-based research networks; 2016. Available from: https://pbrn.ahrq.gov.

2. Mold JW, Pasternak A, McCaulay A, PracticeBased Research Subcommittee of North American Primary Care Research Group Committee on Advancing Science of Family Medicine, et al. Definitions of common terms relevant to primary care research. Ann Fam Med 2008;6:570-1.

3. Robinson G, Gould M. What are the attitudes of general practitioners towards research? Br J Gen Pr 2000;50:390-2.

4. Thomas P, Griffiths F, Kai J, O'Dwyer A. Networks for research in primary health care. $\mathrm{Br}$ Med J 2001;322:588-90.

5. Green LA, Hickner J. A short history of primary care practice-based research networks: from concept to essential research laboratories. J Am Board Fam Med 2006;19:1-10.

6. Fleming DM, Norbury CA, Crombie DL. Annual and seasonal variation in the incidence of common diseases. Occas Pap R Coll Gen Pract 1991;1-24.

7. Van Weel C. The continuous morbidity registration Nijmegen: background and history of a Dutch general practice database. Eur J Gen Pract 2008;14(Suppl. 1):5-12.

8. Smith H. The Federation of Primary Care Research Networks: a national initiative to enhance networking locally. Prim Heal Care Res Dev 2000;1:3-4.

9. Van Weel C, Smith H, Beasley JW. Family practice research networks: experiences from 3 countries. J Fam Pract 2000;49.

10. Gunn JM. Should Australia develop primary care research networks? Med J Aust 2002;177:62-6.

11. Pirotta M, Temple-Smith M. Practice-based research networks. Aust Fam Physician 2017;46:793-5.

12. Van Weel C. General practice research networks: gateway to primary care evidence. Med J Aust 2002;177:62-3.

13. Rhyne RL, Fagnan LJ. Practice-based research network (PBRN) engagement: 20+ years and counting. J Am Board Fam Med 2018;31:833-9.

14. Willis CD, Riley BL, Herbert CP, Best A. Networks to strengthen health systems for chronic disease prevention. Am J Public Health 2013;103: e39-e48.

15. Kennedy ED, Chester P, Majeed A, Wallace P, Matthews DR. Networks offer new opportunities for diabetes research. Prim Care Diabetes 2010; 4:3-8.

16. Tapp H, Dulin M. The science of primary healthcare improvement: potential and use of community-based participatory research by practice-based research networks for translation of research into practice. Exp Biol Med 2010;235:290-9.

17. Dusek JA, Abrams DI, Roberts R, et al. Patients Receiving Integrative Medicine Effectiveness Registry (PRIMIER) of the BraveNet practice-based research network: study protocol. BMC Complement Altern Med 2015;16.

18. Baldwin LM, Keppel GA, Davis A, GuirguisBlake J, Force RW, Berg AO. Developing a practice-based research network by integrating quality improvement: challenges and ingredients for success. Clin Transl Sci 2012;5:351-5.

19. Gaglioti AH, Werner JJ, Rust G, Fagnan LJ, Neale AV. Practice-based research networks (PBRNs) bridging the gaps between communities, funders, and policymakers. J Am Board Fam Med 2016;29.

20. Krist AH, Green LA, Phillips RL, NAPCRG Health Information Technology Working Group, et al. Health information technology needs help from primary care researchers. J Am Board Fam Med 2015;28:306-10.

21. Pace WD, Cifuentes M, Valuck RJ, Staton EW, Brandt EC, West DR. An electronic practice-based network for observational comparative effectiveness research. Ann Intern Med 2009;151:338.

22. Nagykaldi Z, Fox C, Gallo S, et al. Improving collaboration between primary care research networks using Access Grid technology. Inform Prim Care 2008;16:51-8.

23. Peterson KA, Fontaine P, Speedie S. The electronic Primary Care Research Network (ePCRN): a new era in practice-based research. J Am Board Fam Med 2006;19:93-7.

24. Booth M, Hill G, Moore MJ, Dalla D, Moore MG, Messenger A. The new Australian Primary Health Networks: how will they integrate public health and primary care? Public Heal Res Pract 2016;26.

25. Australian Government Department of Health and Ageing. Primary Health Care Research, Evaluation and Development (PHCRED) strategy phase three: 2010-2014; 2010.

26. Westfall JM, Mold J, Fagnan L. Practice-based research-"blue highways" on the NIH roadmap. JAMA 2007;297:403-6.

27. Department for Health. Best research for best health: introducing a new national health research strategy; 2006.

28. Arksey H, O'Malley L. Scoping studies: towards a methodological framework. Int $\mathrm{J}$ Soc Res Methodol Theory Pract 2005;8.

29. Moren-Cross J, Lin N. Social networks and social integration. In: Binstock R, et al. editors. Handbook of aging and the social sciences. Academic Press; 2006. p. 111-5. 
30. Thomas P, Graffy J, Wallace P, Kirby M. How primary care networks can help integrate academic and service initiatives in primary care. Ann Fam Med 2006;4:235-9.

31. Brass DJ, Galaskiewicz J, Greve HR, Tsai W. Taking stock of networks and organizations: a multilevel perspective. Acad Manag J 2004;47.

32. Braun V, Clarke V. Using thematic analysis in psychology. Qual Res Psychol 2006;3.

33. Maguire M, Delahunt B. Doing a thematic analysis: a practical, step-by-step guide for learning and teaching scholars. All Irel J Teach Learn High Educ 2017;8.

34. Vaismoradi M, Turunen H, Bondas T. Content analysis and thematic analysis: implications for conducting a qualitative descriptive study. Nurs Heal Sci 2013;15.

35. Green LA, Wood M, Becker L, et al. The Ambulatory Sentinel Practice Network: purpose, methods, and policies. J Fam Pract 1984;18.

36. Iverson DC, Calonge N, Miller RS, Niebauer LJ, Reed FM. The development and management of a primary care research network. Fam Med 1988;20: 1978-87.

37. Rosser WW, Green L. Update from ASPN. Can Fam Physician 1989;35.

38. Fontaine P, Mendenhall TJ, Peterson K, Speedie SM. The "Measuring Outcomes of Clinical Connectivity" (MOCC) trial: investigating data entry errors in the electronic Primary Care Research Network (ePCRN). J Am Board Fam Med 2007;20.

39. Delaney BC, Peterson KA, Speedie S, Taweel A, Arvanitis TN, Richard HF. Envisioning a learning health care system: the electronic primary care research network, a case study. Ann Fam Med 2012;10.

40. Peterson KA, Delaney BC, Arvanitis TN, et al. A model for the electronic support of practice-based research networks. Ann Fam Med 2012;10.

41. Culpepper L, Froom J. The international primary care network: purpose, methods, and policies. Fam Med 1988;20.

42. Butler CC, Hood K, Verheij T, et al. Variation in antibiotic prescribing and its impact on recovery in patients with acute cough in primary care: prospective study in 13 countries. BMJ 2009;338: b2242.

43. Nuttall J, Hood K, Verheij TJ, et al. Building an international network for a primary care research program: reflections on challenges and solutions in the set-up and delivery of a prospective observational study of acute cough in 13 European countries. BMC Fam Pract 2011;12.

44. del Torso S, van Esso D, Gerber A, et al. European Academy of Paediatrics Research in Ambulatory Setting Network (EAPRASnet): a multi-national general paediatric research network for better child health. Child Care Health Dev $2010 ; 36$.

45. Lamont R, Fishman T, Sanders PF, 'Ofanoa M, Goodyear-Smith F. View from the canoe: codesigning research Pacific style. Ann Fam Med 2020;18:172-5.

46. Clothier HJ, Fielding JE, Kelly HA. An evaluation of the Australian Sentinel Practice Research Network (ASPREN) surveillance for influenzalike illness. Commun Dis Intell 2005;29.

47. Schweikardt C, Verheij RA, Donker GA, Coppieters Y. The historical development of the Dutch Sentinel General Practice Network from a paper-based into a digital primary care monitoring system. J Public Heal 2016;24.

48. Volmink JA, Furman SN. The South African Sentinel Practitioner Research Network Organization, Objectives, Policies and Methods; 1991.

49. Fleming DM. Weekly returns service of the Royal College of General Practitioners. Commun Dis Public Heal 1999;2:96-100.

50. Cooke J, Nancarrow S, Dyas J, Williams M. An evaluation of the "designated research team" approach to building research capacity in primary care. BMC Fam Pract 2008;9.

51. Abbott S, Gunnell C. Developing R\&D capacity in primary care nursing: report of a research project. Prim Health Care Res Dev 2005;6:95-100.

52. Carter Y. Research opportunities in primary care. Radcliffe Medical Press; 1998.

53. Anderko L, Lundeen S, Bartz C. The Midwest Nursing Centers Consortium Research Network: translating research into practice. Policy Polit Nurs Pract 2006;7:101-9.

54. Nelson EC, Kirk JW, Bise BW, et al. The cooperative information project: part 2: some initial clinical, quality assurance, and practice management studies. J Fam Pract 1981;13.

55. Wasserman R, Serwint JR, Kuppermann N, Srivastava R, Dreyer B. The APA and the rise of pediatric generalist network research. Acad Pediatr 2011;11:195-204.

56. Solberg LI, Cole PM, Seifert MH. The Minnesota Academy of Family Physicians' Research Network: a vehicle for practice-based research. Minn Med 1986;69.

57. Middelkoop BJC, Bohnen AM, Duisterhout JS, Hoes AW, Pleumeekers HJCM, Prins A. Rotterdam General Practitioners Report (ROHAPRO): a computerised network of general practices in Rotterdam, The Netherlands. J Epidemiol Community Health 1995;49:231-3.

58. Davies J, Heyman B, Bryar R, et al. The research potential of practice nurses. Heal Soc Care Community 2002;10:370-81.

59. Davies J, Heyman B, Bryar R, et al. Building practice nurse research capacity. Pract Nurs 2002;13:449-53. 
60. Sullivan F, Hinds A, Pitkethly M, Treweek S, Wilson P, Wyke S. Primary care research network progress in Scotland. Eur J Gen Pract 2014;20.

61. Hannay DR. Evaluation of a primary care research network in rural Scotland. Prim Heal Care Res Dev 2006;7.

62. Comino E, Zwar NA, Hermiz OH. PHReNet: a general practice research network in South Western Sydney, Australia; 2002.

63. Waters RL, Weston KM, Farmer E [Internet]. Linking primary health care researchers in South Australia: a network strategy; 2004. Available from: https://ro.uow.edu.au/cgi/viewcontent.cgi? article $=1564 \&$ context $=$ medpapers .

64. Ried K, Farmer EA, Weston KM. Setting directions for capacity building in primary health care: a survey of a research network. BMC Fam Pract 2006;7.

65. Ried K, Farmer EA, Weston KM. Bursaries, writing grants and fellowships: a strategy to develop research capacity in primary health care. BMC Fam Pract 2007;8:13.

66. Soós M, Temple-Smith M, Gunn J, JohnstonAta'Ata K, Pirotta M. Establishing the Victorian primary care practice based research network. Aust Fam Physician 2010;39.

67. Dijkmans-Hadley B, Bonney A, Barnett SR. Development of an Australian practice-based research network as a community of practice. Aust J Prim Health 2015;21.

68. Robertson S, Hornby C, Jones R. Joint working to develop R\&D capacity in three rural primary care trusts. Prim Health Care Res Dev 2005;6:1-4.

69. Trent Focus Group. For the promotion of research and development in primary health care: annual report 1996-97; 1997.

70. Comino E [Internet]. The Winston Churchill Memorial Trust of Australia Churchill Fellowship 2002: primary health care research (networks) in the United Kingdom. Available from: http://nswcfa. churchilltrust.com.au/media/fellows/Comino_ Elizabeth_2002-1.pdf.

71. Cooke J, Owen J, Wilson A. Research and development at the health and social care interface in primary care: a scoping exercise in one National Health Service region. Heal Soc Care Community 2002;10.

72. Graffy J, Hines M, Fosam H. Annual Report for ELENoR; 2002.

73. Pitkethly M, Sullivan F N. Four years of TayRen, a primary care research and development network. Prim Heal Care Res Dev 2003;4.

74. Porcheret M, Hughes R, Evans D, et al. Data quality of general practice electronic health records: the impact of a program of assessments, feedback, and training. J Am Med Informatics Assoc 2004;11.

75. Sullivan F, Butler C, Cupples M, Kinmonth AL. Primary care research networks in the United Kingdom. Br Med J 2007;334:1093-4.
76. Visentin GR. The multiple meaning of a research project in general practice. Eur J Clin Nutr 2005;59:S89-S92.

77. Okkes IM, Groen A, Oskam SK, Lamberts H. Advantages of long observation in episode-oriented electronic patient records in family practice. Methods Inf Med 2001;40:229-35.

78. Smith HD, Dunleavey J. Wessex primary care research network: a report on two years progress. Southampt Heal J 1996;3:43-7.

79. Duggan A, Minkovitz CS, Chaffin M, et al. Creating a national home visiting research network. Pediatrics 2013;132:S82-S89.

80. Adams J, Steel A, Moore C, Amorin-Woods L, Sibbritt D. Establishing the ACORN National Practitioner Database: strategies to recruit practitioners to a national practice-based research network. J Manipulative Physiol Ther 2016;39:594-602.].

81. Tyler CV, Werner JJ. Community-engagement strategies of the Developmental Disabilities PracticeBased Research Network (DD-PBRN). J Am Board Fam Med 2014;27.

82. Frayne SM, Carney DV, Bastian L, et al. The VA women's health practice-based research network: amplifying women veterans' voices in VA research. J Gen Intern Med 2013;28:504-9.

83. Jensen IB, Brämberg EB, Wåhlin C, et al. Promoting evidence-based practice for improved occupational safety and health at workplaces in Sweden: report on a practice-based research network approach. IJERPH 2020;17:5283-15.

84. Dovey SM, Tilyard MW. The computer research network of the Royal New Zealand College of General Practitioners: an approach to general practice research in New Zealand. Br J Gen Pract 1996;46.

85. Pickstone C, Nancarrow SA, Cooke JM, et al. Building research capacity in the allied health professions. Evid Policy 2008;4:53-68.

86. Thomas $\mathrm{P}$, While A. Increasing research capacity and changing the culture of primary care towards reflective inquiring practice: the experience of the West London research network (WeLReN). J Interprof Care 2001;15.

87. Lieberman MI [Internet]. Medical Quality Improvement Consortium (MQIC) presentation; 2006. Available from: https://www.amia.org/sites/amia.org/ files/2006-Policy-Meeting-Medical-2006-PolicyMeeting-Quality-Improvement-Consortium.pdf.

88. Sills MR [Internet]. SAFTINet overview for EDRC: presented to the Emergency Department Research Committee, Department of Pediatrics, University of Colorado School of Medicine; 2015 [cited 2020 June 29]. Available from: https://www. slideshare.net/MarionSills/saftinet-overview-for-edrc.

89. O'Regan A, Hayes P, O'Connor R, et al. The University of Limerick Education and Research 
Network for General Practice (ULEARN-GP): practice characteristics and general practitioner perspectives. BMC Fam Pract 2020;21:25.

90. DeVoe JE, Gold R, Spofford M, et al. Developing a network of community health centers with a common electronic health record: description of the Safety Net West Practice-Based Research Network (SNW-PBRN). J Am Board Fam Med 2011;24.

91. Ornstein SM, Jenkins RG. The Practice Partner Research Network: description of a novel national research network of computer-based patient records users. Carolina Heal Serv Policy Rev 1997;4:145-51.

92. DeVoe JE, Likumahuwa S, Eiff MP, et al. Lessons learned and challenges ahead: report from the OCHIN Safety Net West Practice-Based Research Network (PBRN). J Am Board Fam Med 2012;25: $560-4$.

93. Kwan BM, Sills MR, Graham D, et al. Stakeholder engagement in a patient-reported outcomes (PRO) measure implementation: a report from the SAFTINet practice-based research network (PBRN). J Am Board Fam Med 2016;29:102-15.

94. Rodnick JE, Francisco S. Papers by family physicians that have influenced the way i practice. J Fam Pract 1999; 48. Available from: https://www. mdedge.com/familymedicine/article/183548/ papers-family-physicians-have-influenced-way-ipractice.

95. Stephens KA, Lin C-P, Baldwin L-M, et al. LC Data QUEST: a technical architecture for community federated clinical data sharing. AMIA Jt Summits Transl Sci 2012;2012:57-62.

96. Slora EJ, Wasserman RC. PROS: a research network to enhance practice and improve child health. Pediatr Ann 2010;39:352-61.

97. McCloskey B, Grey M, Deshefy-Longhi T, Grey LJ. APRN practice patterns in primary care. Nurse Pract 2003;28:39-44.

98. Pearce KA, Love MM, Barron MA, Matheny SC, Mahfoud Z. How and why to study the practice content of a practice-based research network. Ann Fam Med 2004;2.

99. Kuo GM, Steinbauer JR, Spann SJ. Conducting medication safety research projects in a primary care physician practice-based research network. J Am Pharm Assoc 2008;48.

100. Ried K, Farmer EA, Weston KM. Setting directions for capacity building in primary health care: a survey of a research network. BMC Fam Pract 2006;7:1-11.

101. Vessey JA. A practice-based research network to improve the quality of school nursing practice. J Sch Nurs 2007;23.

102. Gibson K, Szilagyi P, Swanger CM, et al. Physician perspectives on incentives to participate in practice- based research: a Greater Rochester practice-based research network (GR-PBRN) study. J Am Board Fam Med 2010;23.

103. Liaw ST, Taggart J, Dennis S, Yeo A. Data quality and fitness for purpose of routinely collected dataa general practice case study from an electronic practice-based research network (ePBRN). AMIA Annu Symp Proc 2011;2011:785-94.

104. Green LA, Hames CG, Nutting PA. Potential of practice-based research networks: experiences from ASPN. J Fam Pract 1994;38.

105. Kwan BM, Graham D, Sills M, et al. SAFTINet: Scalable Architecture for Federated Translational Inquiries Network methods for the collection of patient reported outcomes in a safety net-oriented practice based research network: a SAFTINet demonstration project patient-reported outcome; 2015.

106. Boydell L, Grandidier H, Rafferty C, McAteer C, Reilly P. General practice data retrieval: The Northern Ireland project. J Epidemiol Community Health 1995;49:22-5.

107. Dulin MF. The creation of PBRN to study health care delivery to a transitioning community (HS16023); 2005.

108. Likumahuwa S, Song H, Singal R, et al. Building research infrastructure in community health centers: a Community Health Applied Research Network (CHARN) report. J Am Board Fam Med 2013;26.

109. Metsemakers JFM, Hoppener P, Knottnerus JA, Kocken RJJ, Limonard CBG. Computerized health information in the Netherlands: a registration network of family practices. Br J Gen Pract 1992;42.

110. DeVoe JE, Sears A. The Ochin community information network: bringing together community health centers, information technology, and data to support a patient-centered medical village. J Am Board Fam Med 2013;26:271-8.

111. Sardell A. Clinical networks and clinician retention: the case of CDN. J Community Health 1996;21:437-51.

112. Mold JW, Peterson KA. Primary care practicebased research networks: working at the interface between research and quality improvement. Ann Fam Med 2005;3.

113. Mold JW, Barton ED. OAFP starts practice-based resource/research network. J Okla State Med Assoc 1996;89.

114. Serwint JR. Multisite survey of pediatric residents' continuity experiences: their perceptions of the clinical and educational opportunities. Pediatrics 2001;107:e78.

115. Fagnan LJ. ORPRN "Blue Highways" reflections; 2018.

116. Libby AM, Pace W, Bryan C, et al. Comparative effectiveness research in DARTNet primary care 
practices: point of care data collection on hypoglycemia and over-the-counter and herbal use among patients diagnosed with diabetes. Med Care 2010;48(Suppl.).

117. Cole AM, Stephens KA, Keppel GA, Lin CP, Baldwin LM. Implementation of a health data-sharing infrastructure across diverse primary care organizations. J Ambul Care Manage 2014;37:164-70.

118. Koskela TH. Building a primary care research network-lessons to learn. Scand J Prim Health Care 2017;35.

119. Davies J, Heyman B, Bryar R, et al. Building practice nurse research capacity. Pract Nurs 2002;13.

120. Graham DG, Spano MS, Stewart TV, Staton EW, Meers A, Pace WD. Strategies for planning and launching PBRN research studies: a project of the Academy of Family Physicians National Research Network (AAFP NRN). J Am Board Fam Med 2007;20.

121. Burge SK, Hill JH. The medical student summer research program in family medicine. Fam Med 2014;46:45-8.

122. Kavanagh KE, O'Brien N, Glynn LG, Vellinga A, Murphy AW. WestREN: a description of an Irish academic general practice research network. BMC Fam Pract 2010;11.

123. Trent Focus Group. For the promotion of research and development in primary health care: annual report 2000-2001; 2001.

124. Beasley JW, Cox NS, Livingston BT. Development and operation of the Wisconsin Research Network. Wis Med J 1991;90.

125. Pearls of Research [Internet]. American Academy of Family Physicians. Practice-based research networks in the 21st century; 1998. Available from: https://www.aafp.org/dam/AAFP/documents/patient_ care/nrn/pearlsofresearch.pdf.

126. Birtwhistle R, Keshavjee K, Lambert-Lanning A, et al. Building a pan-Canadian primary care sentinel surveillance network: initial development and moving forward. J Am Board Fam Med 2009;22.

127. Croughan-Minihane MS, Thom DH, Petitti DB. Research interests of physicians in two practicebased primary care research networks. West J Med 1999;170:19-24.

128. IPCRN [Internet]. Irish Primary Care Research Network [cited 2017 May 17]. Available from: http://www.ipcrn.ie/.

129. Sayer GP, McGeechan K, Kemp A, et al. The general practice research network: the capabilities of an electronic patient management system for longitudinal patient data. Pharmacoepidemiol Drug Saf 2003;12.

130. Nelson EC, Kirk JW, Bise BW, et al. The Cooperative Information Project: part 1: a sentinel practice network for service and research in primary care. J Fam Pract 1981;13.
131. Williamson HA, Hector MG, LeFevre M, White RD. Establishing a rural family practice research network. Fam Med 1988;20.

132. Wasserman RC, Slora EJ, Bocian AB, et al. Pediatric Research in Office Settings (PROS): a national practice-based research network to improve children's health care. Pediatrics 1998;102:1350-7.

133. Peterson KA, Lipman PD, Lange CJ, Cohen RA, Durako S. Supporting better science in primary care: a description of practice-based research networks (PBRNs) in 2011. J Am Board Fam Med $2012 ; 25$.

134. Love MM, Pearce KA, Williamson MA, Barron MA, Shelton BJ. Patients, practices, and relationships: challenges and lessons learned from the Kentucky Ambulatory Network (KAN) CaRESS clinical trial. J Am Board Fam Med 2006;19: 75-84.

135. National Institute for Health Research, Clinical Research Network. LCRN guidance suite: provision of infratsructure support for research delivery in primary care settings. Vol V2.0.; 2014.

136. Laurence CO, Beilby JJ, Marley JE, Newbury J, Wilkinson D, Symon B. Establishing a practice based primary care research network: the University Family Practice Network in South Australia. Aust Fam Physician 2001;30.

137. Schers H, Bor H, van den Hoogen H, van Weel C. What went and what came? Morbidity trends in general practice from the Netherlands. Eur J Gen Pract 2008;14:13-24.

138. Osborn EH, Petitti DB. Physician interest in collaborative research. J Am Board Fam Pract 1988;1.

139. Anderko L, Bartz C, Lundeen S. Practice-based research networks: nursing centers and communities working collaboratively to reduce health disparities. Nurs Clin North Am 2005;40.

140. Sloane PD, Callahan L, Kahwati L, Mitchell CM. Development of a practice-based patient cohort for primary care research. Fam Med 2006;38.

141. Trent Focus Group. For the promotion of research and development in primary health care: annual report 1999-2000; 1999.

142. Thomas P, Griffiths F, Kai J, O’Dwyer A. Primary care networks for research in primary health care. Br Med J 2001;322:588-90.

143. Magin PJ, Marshall MJ, Goode SM, Cotter GL, Pond CD, Zwar NA. How generalisable are results of studies conducted in practice-based research networks? A cross-sectional study of general practitioner demographics in two New South Wales networks. Med J Aust 2011;195.

144. De Clercq E, Vandenberghe H, Jonckheer P, Bastiaens H, Lafontane MF, Van Gasteren V. Assessment of a three-year experience with a Belgian primary care data network. Stud Health Technol Inform 2002;93. 
145. Marley J. Establishing a rural research network. Med J Aust 1992;156.

146. Volmink J. SASPREN-a new development in family practice research in South Africa. South African Med J 1996;86.

147. Truyers C, Goderis G, Dewitte H, Akker MV, Buntinx F. The Intego database: background, methods and basic results of a Flemish general practice-based continuous morbidity registration project. BMC Med Inform Decis Mak 2014;14.

148. Carsley S, Borkhoff CM, Maguire JL, et al. Cohort profile: the Applied Research Group for Kids (TARGet Kids!). Int J Epidemiol 2015;44.

149. Morinis J, Maguire J, Khovratovich M, McCrindle BW, Parkin PC, Birken CS. Paediatric obesity research in early childhood and the primary care setting: the TARGet Kids! research network. IJERPH 2012;9:1343-54.

150. Laux G, Koerner T, Rosemann T, Beyer M, Gilbert K, Szecsenyi J. The CONTENT project: a problem-oriented, episode-based electronic patient record in primary care. Inform Prim Care 2005;13.

151. Metsemakers JFM, Knottnerus JA, Van Schendel GJ, Kocken RJJ, Limonard CBG. Unlocking patients' records in general practice for research, medical education and quality assurance: the Registration Network Family Practices. Int J Biomed Comput 1996;42:1-2.

152. Taggart J, Liaw ST, Dennis S, et al. The University of NSW electronic practice based research network: disease registers, data quality and utility. Stud Heal Technol Inform 2012;178.

153. Pace WD, Fox C, White T, Graham D, Schilling LM, West DR. The DARTNet Institute: seeking a sustainable support mechanism for electronic data enabled research networks. eGEMs 2014; 2:6.

154. Dillon P, O'Brien KK, McDonnell R, et al. Prevalence of prescribing in pregnancy using the Irish primary care research network: a pilot study. BMC Pregnancy Childbirth 2015;15.

155. Boffin N, Bossuyt N, Vanthomme K, Van Casteren V. Readiness of the Belgian network of sentinel general practitioners to deliver electronic health record data for surveillance purposes: results of survey study. BMC Fam Pract 2010;11.

156. Fagnan LJ, Morris C, Shipman SA, Holub J, King A, Angier H. Characterizing a practice-based research network: Oregon rural practice-based research network (ORPRN) survey tools. J Am Board Fam Med 2007;20.

157. Dulin MF, Tapp H, Smith HA, Urquieta D. H B, Furuseth OJ. A community based participatory approach to improving health in a Hispanic population. Implement Sci 2011;6.

158. Fleming DM, Crombie DL. The incidence of common infectious diseases: the weekly returns service of the Royal College of General Practitioners. Health Trends 1985;17.

159. Birtwhistle RV. Canadian Primary Care Sentinel Surveillance Network: a developing resource for family medicine and public health. Can Fam Physician 2011;57.

160. Wasserman RC, Croft CA, Brotherton SE. Preschool vision screening in pediatric practice: a study from the Pediatric Research in Office Settings (PROS) network. Pediatrics 1992;89:834-8.

161. Lobet MP, Stroobant A, Mertens R, et al. Tool for validation of the network of sentinel general practitioners in the Belgian health care system. Int J Epidemiol 1987;16:612-8.

162. AAFP [Internet]. Affiliated PBRNs-National Research Network [cited 2020 Aug 13]. Available from: https://www.aafp.org/patient-care/nrn/nrn/ pbrns.html.

163. PBRN Resource Center A. Centers for Primary Care Practice-Based Research and Learning: nurture partnerships, method development, and trans-network collaborations; n.d.

164. Lindbloom EJ, Ewigman BG, Hickner JM. Practice-based research networks: the laboratories of primary care research. Med Care 2004;42 (Suppl).

165. Schilling LM, Kwan BM, Drolshagen CT, et al. Scalable Architecture for Federated Translational Inquiries Network (SAFTINet) Technology Infrastructure for a Distributed Data Network. eGEMs 2013;1:11.

166. Vessey JA, the Founding Oversight Board Members of MASNRN. Development of the Massachusetts School Nurse Research Network (MASNRN): a practice-based research network to improve the quality of school nursing practice. J Sch Nurs 2007;23:65-72.

167. LeBailly S, Ariza A, Bayldon B, Binns HJ. The origin and evolution of a regional pediatric practicebased research network: practical and methodological lessons from the Pediatric Practice Research Group. Curr Probl Pediatr Adolesc Health Care 2003;33.

168. Nagykaldi Z, Mold JW, Aspy CB. Practice facilitators: a review of the literature. Fam Med 2005; 37:581-8.

169. Deshefy-Longhi T, Swartz MK, Grey M. Establishing a practice-based research network of advanced practice registered nurses in southern New England. Nurs Outlook 2002;50:127-31.

170. Christoffel KK, Binns HJ, Stockman JA, et al. Practice-based research: opportunities and obstacles. Pediatrics 1988;82.

171. Solberg LI, Mayer TR, Seifert M, Cole PM. The Minnesota AFP research panel: a model for collaborative practicing family physician research. Fam Med 1983;15:139-42. 
172. Hayes H, Parchman ML, Howard R. A logic model framework for evaluation and planning in a primary care practice-based research network (PBRN). J Am Board Fam Med 2011;24.

173. Williams RL, McPherson L, Kong A, Skipper B, Weller N. Internet-based training in a practicebased research network consortium: a report from the primary care multiethnic network (PRIME Net). J Am Board Fam Med 2009;22.

174. Volmink J, Laubscher J, Furman S. The SASPREN primary care survey-who consults the family doctor? South African Med J 1996;86.

175. Serwint JR, Thoma KA, Dabrow SM, for the CORNET Investigators, , et al. Comparing patients seen in pediatric resident continuity clinics and National Ambulatory Medical Care Survey practices: a study from the Continuity Research Network. Pediatrics 2006;118:e849-e858.

176. Selby K, Cornuz J, Senn N. Establishment of a representative practice-based research network (PBRN) for the monitoring of primary care in Switzerland. J Am Board Fam Med 2015;28.

177. Galliher JM, Bonham AJ, Dickinson LM, Staton EW, Pace WD. Representativeness of PBRN physician practice patterns and related beliefs: the case of the AAFP National Research Network. Ann Fam Med 2009;7:547-54.

178. Slora EJ, Thoma KA, Wasserman RC, Pedlow SE, Bocian AB. Patient visits to a national practice-based research network: comparing pediatric research in office settings with the National Ambulatory Medical Care Survey. Pediatrics 2006;118:e228-e234.

179. De VP. Home violence in South Africa: surveillance during 1996 by SASPREN, a sentinel network of general/family practitioners: SASPREN news. South Africa Fam Pract 1998;19.

180. Green LA, Miller RS, Reed FM, Iverson DC, Barley GE. How representative of typical practice are practice-based research networks? A report from the Ambulatory Sentinel Practice Network Inc (ASPN). Arch Fam Med 1993;2: 939-49.

181. Nutting PA, Baier M, Werner JJ, Cutter G, Reed FM, Orzano AJ. Practice patterns of family physicians in practice-based research networks: a report from ASPN. J Am Board Fam Pract 1999;12: 278-84.

182. Van den Akker M, Buntix F, Metsemakers JFM, Roos S, Knottnerus JA. Multimorbidity in general practice: prevalence, incidence, and determinants of co-occurring chronic and recurrent diseases. J Clin Epidemiol 1998;51.

183. Gourlay ML, Lewis CL, Preisser JS, Mitchell CM, Sloane PD. Perceptions of informed decision making about cancer screening in a diverse primary care population. Fam Med 2010;42: 421-7.
184. Mold J, Gregory ME. Best practices research. Fam Med 2003;35:131-4.

185. Gill JM, Chen YX, Grimes A, Klinkman MS. Using electronic health record-based tools to screen for bipolar disorder in primary care patients with depression. J Am Board Fam Med 2012;25: 283-90.

186. Venmans LMAJ, Hak E, Gorter KJ, Rutten GEHM. Incidence and antibiotic prescription rates for common infections in patients with diabetes in primary care over the years 1995 to 2003. Int J Infect Dis. 2009;13.

187. Chmiel C, Bhend H, Senn O, et al. The FIRE project: a milestone for research in primary care in Switzerland. Swiss Med Wkly 2011;141:1-7.

188. Pace WD, West DR, Valuck RJ, Cifuentes M, Staton EW. Distributed Ambulatory Research in Theurapeutics Network (DARTNet): summary report; 2009.

189. Slawson DC, Herman JM, Bennett JH. Single community research networks: the HARNET experience. Arch Fam Med 1993;2:725-8.

190. Green LA, White LL, Barry HC, Nease DE, Hudson BL. Infrastructure requirements for practice-based research networks. Ann Fam Med 2005;3.

191. Harvey J, Fenton E, Sturt J. Evaluation of primary care R\&D networks in North Thames region: final report; 2002.

192. Tierney WM, Oppenheimer CC, Hudson BL, et al. A national survey of primary care practicebased research networks. Ann Fam Med 2007;5.

193. Griswold KS. Communities of solution: the Folsom report revisited. Ann Fam Med 2012;10:250-60.

194. Primary Care MultiEthnic Network (PRIMENet) [Internet]. 2020. [cited 2020 Nov 29]. Available from: http://www.prime-net-consortium.org/.

195. Darbyshire J, Sitzia J, Cameron D, et al. Extending the clinical research network approach to all of healthcare. Ann Oncol 2011;22.

196. Binienda J, Neale AV, Wallace LS. Future directions for practice-based research networks (PBRNs): a CERA survey. J Am Board Fam Med 2018;31.

197. Mayo M, Meindl JR, Pastor JC. Shared leadership in work teams: a social network approach. In: Shared leadership: reframing the hows and whys of leadership. London: SAGE; 2003.

198. Burt RS. Social contagion and innovation: cohesion versus structural equivalence. Am J Sociol 1987;92.

199. Liu W, Sidhu A, Beacom AM, Valente TW. Social network theory. In: The international encyclopedia of media effects. Hoboken (NJ): Wiley; 2017. p. 1-12.

200. Crossland L, Janamian T, Jackson CL. Key elements of high-quality practice organisation in primary health care: a systematic review. Med J Aust 2014;201. 
201. Solberg LI, Hroscikoski MC, Sperl-Hillen JAM, Harper PG, Crabtree BF. Transforming medical care: case study of an exemplary, small medical group. Ann Fam Med 2006;4.

202. Van Weel C. Longitudinal research and data collection in primary care. Ann Fam Med 2005;3.

203. Beasley JW, Starfield B, Van Weel C, Rosser WW, Haq CL. Global health and primary care research. J Am Board Fam Med 2007;20.

204. Nagykaldi Z. Practice-based research networks at the crossroads of research translation. J Am Board Fam Med 2014;27:725-9.

205. Schwartz A, Young R, Hicks PJ, Learn FA. Medical education practice-based research networks: facilitating collaborative research. Med Teach 2016;38.

206. Werner JJ, Stange KC. Praxis-based research networks: An emerging paradigm for research that is rigorous, relevant, and inclusive. J Am Board Fam Med 2014;27.

207. Etz RS, Hahn KA, Gonzalez MM, Crabtree BF, Stange KC. Practice-based innovations: more relevant and transportable than NIH-funded studies. J Am Board Fam Med 2014;27.

208. Del MC., Askew D. Building family/general practice research capacity. Ann Fam Med 2004;2.

209. Dwan KM, Magin PJ. The desire for research in general practice. Aust Fam Physician 2008;37:871-3.

210. Marshall M, Pagel C, French C, et al. Moving improvement research closer to practice: the researcher-in-residence model. BMJ Qual Saf 2014;23:801-5.

211. Marshall M, Eyre L, Lalani M, et al. Increasing the impact of health services research on service improvement: the researcher-in-residence model. J R Soc Med 2016;109:220-5.

212. Marshall M [Internet]. Negotiating evidence; the researcher-in-residence model; 2016. Available from: https://piru.ac.uk/assets/files/Marshall Researcher in Residence.pdf.

213. Cadwallader JS, Lebeau JP, Lasserre E, Letrilliart L. Patient and professional attitudes towards research in general practice: the RepR qualitative study. BMC Fam Pract 2014;15.

214. SDO. NHS Service Delivery and Organization, R\&D Programme. Key lessons for network management in health care; 2005.

215. Exworthy M, Day P, Robinson R, Peckham S, Evans D [Internet]. Primary care research networks; 1997 [cited 2020 Oct 13]. Available from: https:// uwe-repository.worktribe.com/output/1102793.

216. Beasley JW, Starfield B, Van Weel C, Rosser WW, Haq CL. Global health and primary care research. J Am Board Fam Med 2007;20:518-26.

217. Beasley JW, Hahn DL, Wiesen P, Plane MB, Manwell L. The cost of primary care research. J Fam Pract 2000;49:985.
218. Hahn DL. Physician opportunity costs for performing practice-based research. J Fam Pract 2000;49.

219. Agency for Healthcare Research and Quality PRC [Internet]. Practice-based research network business opportunities with ACOs and other health care systems: training and technical assistance; 2015. Available from: https://pbrn.ahrq.gov/sites/default/files/ docs/page/Primer-for-PBRN-Business-Opportunities. pdf.

220. Agency for Healthcare Research and Quality [Internet]. PBRN registry, practice-based research networks, Agency for Healthcare Research and Quality; 2019. [cited 2020 Oct 13]. Available from: https://pbrn.ahrq.gov/pbrn-registry.

221. APCReN [Internet]. Available from: www.apcren. org.au.

222. Jones C [Internet]. An environmental scan of practicebased research networks; 2006. Available from: https:// www.yumpu.com/en/document/read/23017131/ an-environmental-scan-of-practice-based-researchnetworks.

223. Van den Bosch WJ. Forty years family-based morbidity data in general practice. Scand J Prim Health Care 1993;11:31-2.

224. Nelson E. Functional health status levels of primary care patients. JAMA 1983;249:3331.

225. Main DS, Lutz LJ, Barrett JE, Matthew J, Miller RS. The role of primary care clinician attitudes, beliefs, and training in the diagnosis and treatment of depression: a report from the Ambulatory Sentinel Practice Network Inc. Arch Fam Med 1993;2:1061-6.

226. Boffin N, Moreels S, Casteren VV [Internet]. The Belgian Network of Sentinel General Practices between 2007 and 2012: a short report; 2013. Available from: https://www.wiv-isp.be/Epidemio/ epien/medven/D_2013_2505_40.pdf.

227. Ariza AJ, Binns HJ, Christoffel KK. Evaluating computer capabilities in a primary care practicebased research network. Ann Fam Med 2004;2.

228. LaBresh KA, Lazorick S, Ariza AJ, et al. Implementation of the NHLBI Integrated Guidelines for Cardiovascular Health and Risk Reduction in Children and Adolescents: rationale and study design for Young Hearts, Strong Starts, a cluster-randomized trial targeting body mass index, blood pressure, and tobacco. Contemp Clin Trials 2014;37.

229. Froom J, Culpepper L. Otitis media in day-care children: a report from the International Primary Care Network. J Fam Pract 1991;32.

230. Okkes IM, Polderman GO, Fryer GE, et al. The role of family practice in different health care systems: a comparison of reasons for encounter, diagnoses, and interventions in primary care populations in the Netherlands, Japan, Poland, and the United States. J Fam Pract 2002;51. 
231. Kljakovic M, Seddon T, Reinken J, McLeod D. The rise and fall of a general practice information network. N Z Fam Physician 1992;73-6.

232. Leitch S. New Zealand needs a practice based research network. J Prim Health Care 2016;8:9.

233. Shaughnessy AF, Cincotta JA, Adelman A. Family for the Harrisburg Area Research Network (HARNET). Practice patients' attitudes toward firearm safety as a preventive medicine issue: a HARNET study. J Am Board Fam Pract 1999;12:354-9.

234. Knottnerus J, Metsemakers J, Hoppener P, Limonard C. Chronic illness in the community and the concept of social prevalence. Fam Pract 1992;9:15-21.

235. de Lusignan S, van Weel C. The use of routinely collected computer data for research in primary care: opportunities and challenges. Fam Pract $2006 ; 23$.

236. Tilyard MW, Dovey SM, Spears GF. Biases in estimates from the RNZCGP computer research group. N Z Med J 1995;108.

237. Rodnick JE. Research fellowships: a road less traveled. Fam Med 1999;31.

238. Hall J, Martin IR. The Dunedin RNZCGP Research Unit Computer Research Network: an update to 2003 and beyond. N Z Fam Physician 2003;30:181-5.

239. Hak E, Van Essen GA, Buskens E, Stalman W, De MR. Is immunising all patients with chronic lung disease in the community against influenza cost effective? Evidence from a general practice based clinical prospective cohort study in Utrecht, The Netherlands. J Epidemiol Community Health 1998;52:120-5.

240. Hak E, Van Essen GA, Stalman WAB, De MR. Improving influenza vaccination coverage among high-risk patients: a role for computer-supported prevention strategy? Fam Pract 1998;15:138-43.

241. Middelkoop BJ, Bohnen AM, Duisterhout JS, Pleumeekers HJ, Prins A. A computerized network of general practices in Rotterdam, The Netherlands. Am J Public Health 1994;84:1852-3.

242. Noël PH, Zeber JE, Pugh MJ, Finley EP, Parchman ML. A pilot survey of post-deployment health care needs in small community-based primary care clinics. BMC Fam Pract 2011;12.

243. Hayes H, Burge S. Creating a practice-based research network from scratch: where do I begin? Progress in Community Health Partnerships 2012;6:369-80.

244. STARNet [Internet]. About STARNet, Institute for Integration of Medicine and Science [cited 2020 June 28]. Available from: https://iims. uthscsa.edu/STARNet/about.

245. Nagykaldi Z, Mold JW, Robinson A, Niebauer L, Ford A. Practice facilitators and practice-based research networks. J Am Board Fam Med 2006;19: 506-10.
246. Van Casteren VFA, Bossuyt NHE, Moreels SJS, et al. Does the Belgian diabetes type 2 care trajectory improve quality of care for diabetes patients? Arch Public Heal 2015;73.

247. Nemeth LS, Wessell AM, Jenkins RG, Nietert PJ, Liszka HA, Ornstein SM. Strategies to accelerate translation of research into primary care within practices using electronic medical records. J Nurs Care Qual 2007;22:343-9.

248. Wessell AM, Liszka HA, Nietert PJ, Jenkins RG, Nemeth LS, Ornstein S. Achievable benchmarks of care for primary care quality indicators in a practice-based research network. Am J Med Qual 2008;23:39-46.

249. Etz RS, Keith RE, Maternick AM, et al. Supporting Practices to Adopt Registry-Based Care (SPARC): protocol for a randomized controlled trial. Implement Sci 2015;10:1-9.

250. ACORN [Internet]. ACORN, Department of Family Medicine, VCU School of Medicine [cited 2020 June 28]. Available from: https://familymedicine.vcu.edu/ research/family-medicine-research/acorn/.

251. Thiru K, de Lusignan S, Sullivan F, Brew S, Cooper A. Three steps to data quality. JHI 2003;11:95-102.

252. Albright TL, Parchman M, Burge SK. Predictors of self-care behavior in adults with type 2 diabetes: an RRNeST study. Fam Med 2001;33:354-60.

253. Hill JH, Burge S, Haring A, Young RA. Communication technology access, use, and preferences among primary care patients: from the Residency Research Network of Texas (RRNe'T). J Am Board Fam Med 2012;25.

254. RRNET [Internet]. About RRNeT, Institute for Integration of Medicine and Science [cited 2020 June 28]. Available from: https://iims.uthscsa.edu/ RRNeT/about.

255. Westfall JM, VanVorst RF, Main DS, Herbert C. Community-based participatory research in practice-based research networks. Ann Fam Med 2006;4.

256. Frew EJ, Hammersley V, Wolstenholme J, Whynes DK. Collaborating with a primary care-based research network. J Eval Clin Pract 2001;7:339-42.

257. Hammersley VS, Hippisley-Cox J, Wilson A, Pringle M. A comparison of research general practices and their patients with other practices - a cross-sectional survey in Trent. Br J Gen Pract 2002;52:463-8.

258. Trent Focus Group. For the promotion of research and development in primary health care: annual report 2001-2002; 2002.

259. Graffy J. News from ELENoR. ELENoR NEWS 2003 (April).

260. Hayward RA, Porcheret M, Mallen CD, Thomas E. Recruiting patients and collecting data for an observational study using computerised record pop-up prompts: the PROG-RES study. Prim Health Care Res Dev 2013;14:21-8. 
261. Zwar NA, Weller DP, McCloughan L, Traynor VJ. Supporting research in primary care: are practice-based research networks the missing link? Med J Aust 2006; 185.

262. Olsen DP, Dixon JK, Grey M, Deshefy-Longhi T, Demarest JC. Privacy concerns of patients and nurse practitioners in primary care-an APRNet study. J Am Acad Nurse Pract 2005;17.

263. Deshefy-Longhi T, Swartz MK, Grey M. Characterizing nurse practitioner practice by sampling patient encounters: an APRNet study. J Am Acad Nurse Practitioners 2008;20:281-7.

264. Chuan TN, Gan GL. Primary care research-a blueprint for action for Singapore. Asia Pac J Public Health 2001;13:49-53.

265. Trinh L, Macartney K, McIntyre P, Chiu C, Dey A, Menzies R. Investigating adverse events following immunisation with pneumococcal polysaccharide vaccine using electronic general practice data. Vaccine 2017;35:1524-9.

266. Sinclair-Lian N, Rhyne RL, Alexander SH, Williams RL. Practice-based research network membership is associated with retention of clinicians in underserved communities: a research involving outpatient settings network (RIOS Net) study. J Am Board Fam Med 2008;21.

267. Williams RL, Shelley BM, Sussman AL. The marriage of community-based participatory research and practice-based research networks: can it work? A research involving outpatient settings network (RIOS Net) study. J Am Board Fam Med 2009;22.

268. Sloane P, Donahue K, Daaleman T, Mitchell CM [Internet]. North Carolina Family Medicine Research Network (NC-FP-RN), grant final report; 2005. Available from: https://www.science.gov/scigov/ desktop/en/service/link/track? redirectUrl=https\% 3A\%2F\%2Fntrl.ntis.gov\%2FNTRL\%2Fdashboard \%2FsearchResults\%2FtitleDetail\%2FPB2007107879. xhtml\&collectionCode $=$ NTIS\&searchId $=65 \mathrm{~b} 6 \mathrm{e} 4 \mathrm{c} 3-$ 63cb-4c1f-ad52-4c5d4e561228\&type=RESULT\& signat.

269. Mehmet S, Comino E, Traynor VJ, Zwar NA. PHReNet: running a primary health care network: issues and challenges; 2004.

270. Anderko L, Bartz C, Lundeen S. Wellness for a lifetime: improving lifestyle behaviors of lowincome, ethnically diverse populations. Ann Fam Med 2005;3.

271. Ried K, Farmer EA, Weston KM. Aims and objectives for the SARNet research network. BMC Fam Pract 2006;7.

272. Farmer E, Ried K, Weston KM. Primary Health Care Research Evaluation and Development Program, annual report; 2005.

273. Dulin MF, Ludden TM, Tapp H, et al. Geographic information systems (GIS) demonstrating primary care needs for a transitioning Hispanic community. J Am Board Fam Med 2010;23.

274. Dulin MF, Tapp H, Smith HA, et al. A trans-disciplinary approach to the evaluation of social determinants of health in a Hispanic population. BMC Public Health 2012;12.

275. MAPPR [Internet]. Home page [cited 2020 June 28]. Available from: https://www.mapprnc.org/.

276. Pulcini J, Sheetz A, Desisto M. Establishing a practice-based research network: lessons from the Massachusetts experience. J School Health 2008;78:172-4.

277. De Clercq E, Van Casteren V, Jonckheer P, Burggraeve P. Primary healthcare research network: the Belgian ResoPrim recommendations. In: Studies in health technology and informatics. Amsterdam: IOS Press; 2009.

278. Department of Health, Research and Development Directorate. Best research for best health: a new national health research strategy; 2006.

279. National Institute for Health Research, Clinical Research Network. Five year strategic plan for research delivery: 2012-2017; 2012.

280. National Institute for Health Research, Clinical Research Network [Internet]. Income distribution from NIHR CRN industry portfolio studies; 2014.

281. Local Clinical Research Networks [Internet]; 2016. Available from: http://www.nihr.ac.uk/nihr-in-yourarea/local-clinical-research-networks.htm.

282. Maro JC, Platt R, Holmes JH, et al. Design of a national distributed health data network. Ann Intern Med 2009;151:341.

283. Arkind J, Likumahuwa-Ackman S, Warren N, et al. Lessons learned from developing a patient engagement panel: an OCHIN report. J Am Board Fam Med 2015;28:632-8.

284. Peckham S, Hutchison B. Developing primary care: the contribution of primary care research networks. Healthc Policy 2012;8.

285. Coleman N, Halas G, Peeler W, Casaclang N, Williamson T, Katz A. From patient care to research: a validation study examining the factors contributing to data quality in a primary care electronic medical record database. BMC Fam Pract 2015;16:11.

286. Abdullah K, Thorpe KE, Mamak E, et al. Optimizing early child development for young children with non-anemic iron deficiency in the primary care practice setting (OptEC): study protocol for a randomized controlled trial. Trials 2015;16.

287. Rizza A, Kaplan V, Senn O, et al. Age- and gender-related prevalence of multimorbidity in primary care: the Swiss FIRE project. BMC Fam Pract 2012;13:113.

288. Zellweger U, Bopp M, Holzer BM, Djalali S, Kaplan V. Prevalence of chronic medical 
conditions in Switzerland: exploring estimates validity by comparing complementary data sources. BMC Public Health 2014;14:1-12.

289. Gill JM, Klinkman MS, Chen YX. Antidepressant medication use for primary care patients with and without medical comorbidities: a national electronic health record (EHR) network study. J Am Board Fam Med 2010;23:499-508.

290. Electronic Practice Based Research Network, Centre for Primary Health Care and Equity [cited 2020 June 28]. Available from: https://cphce.unsw. edu.au/research/informatics-and-ehealth/electronicpractice-based-research-network.

291. Kwan BM, Graham DG, Sills MR, et al [Internet]. Methods for the collection of patient reported outcomes in a safety net-oriented practice based research network: a SAFTINet demonstration project. Poster presentation, AcademyHealth Annual Research Meeting, June 24, 2013 [cited 2020 June 29]. Available from: https://www. slideshare.net/MarionSills/academy-health-proposter-final-2013-0620.

292. Pomernacki A, Carney DV, Kimerling R, et al. Lessons from initiating the first Veterans Health
Administration (VA) Women's Health Practicebased Research Network (WH-PBRN) study. J Am Board Fam Med 2015;28:649-57.

293. Cole AM, Stephens KA, Keppel GA, Estiri H, Baldwin L-M. Extracting electronic health record data in a practice-based research network: processes to support translational research across diverse practice organizations. eGEMs 2016;4: 1206.

294. Galvin S, Callan A, Cormican M, et al. Improving antimicrobial prescribing in Irish primary care through electronic data collection and surveillance: a feasibility study. BMC Fam Pract 2015;16.

295. Adams J, Steel A, Chang S, Sibbritt D. Helping address the national research and research capacity needs of Australian chiropractic: introducing the Australian Chiropractic Research Network (ACORN) project. Chiropr Man Ther 2015;23.

296. Adams J, Peng W, Steel A, et al. A cross-sectional examination of the profile of chiropractors recruited to the Australian Chiropractic Research Network (ACORN): a sustainable resource for future chiropractic research. BMJ Open 2017;7: e015830.e015830. 


\section{Appendix}

\section{Appendix Table 1. Types of Organizations That Initiated and Supported PBRNs at Their Establishment and Relevant Quotations}

Type of Organization
A professional organization initiated the network
A special interest group within the national professional
organization initiated the network
organization initiated the network

An academic department initiated the network

More than one academic department initiated the network

An academic department initiated the network and based the operations

An academic department together with a regional health authority initiated the network

A professional organization and the academic department initiated the network

A clinical and translational science institute affiliated to a university initiated the network

The academic department together with HIT vendors initiated the network

\section{Quotations}

"PROS is a program of the American Academy of Pediatrics." (Wasserman et al 2011)

"The RNZCGP Computer Research Network is a development of the Dunedin RNZCGP Research Unit. This unit was established in 1984 by a single $\$ 7000$ grant from the RNZCGP, and is maintained by further research grants from peerreviewed research funding agencies and the pharmaceutical industry." (Dovey and Tilyard 1996)

"CORNET is the practice-based research network (PBRN) of pediatric resident continuity practices that developed from the APA Continuity Special Interest Group (SIG). In 1995, the Task Force of the Continuity SIG presented a workshop at the APA national meeting. In preparation for this workshop, more than 70 manuscripts of research studies completed in pediatric residency continuity practices were collated." (Wassermann et al 2011)

"Recognizing that collaborative research networks were needed in California, the Division of Family and Community Medicine at the University of California, San Francisco (UCSF), discussed a proposal for collaborative research at its annual meeting." (Osborn and Petitti 1988)

"In 1996, a joint proposal for funding a new network of research and development general practices was put to the regional $R \& D$ directorate by the three heads of departments of general practice in South Thames, Professors Sean Hilton (St George's), Roger Jones (UMDS) and Roger Higgs (King's), in collaboration with the two postgraduate deans of general practice education, Drs Ri Hornung and Alan Ruben." (Carter 1998, p. 85)

"UPRNet is a program of Michigan State University College of Human Medicine's Upper Peninsula campus, from which we receive infrastructure support.” (Pearls of Research 1998)

"The North Staffordshire General Practice (GP) Research Network was established by the Primary Care Sciences Research Centre (PCSRC) at Keele University, the North Staffordshire Health Authority, and local general practices in 1997." (Porcheret et al 2004)

"The Oklahoma Academy of Family Physicians in collaboration with the University of Oklahoma Health Sciences Center established a primary care practice-based research network with thirteen family practice offices currently participating." (Mold and Barton 1996)

"The University of Rochester's CTSA-funded Clinical and Translational Science Institute established the Greater Rochester PBRN (GR-PBRN).” (Gibson et al 2010)

"As part of an effort by the Community Outreach and Research Translation Core of the University of Washington's CTSA (the Institute of Translational Health Sciences-ITHS) to build a PBRN in the Washington, Wyoming, Alaska, Montana, Idaho (WWAMI) states, seven clinical practices in the University of Washington's (UW) Family Medicine Residency Network (FMRN) participated in a study of clinical importance to the practices that simultaneously built research capacity and infrastructure at the sites." (Baldwin et al 2012)

"The PPRNet activities will be conducted under a set of operational procedures that are consistent with contracts between the Medical University of South Carolina (MUSC), 
"FIMMG (FederazioneItaliana Medici di MedicinaGenerale), CSeRMEG (Centro Studi e Ricerca in MedicinaGenerale), CoS (ConsorzioSanità), Ass. Cu.M.I.

(AssociazioneCulturaleMedicaInterdisciplinare), AMISI (Associazione per la MedicinaIntegrativa e la Sanità Integrata) and Istituto di RicercheFarmacologiche 'Mario Negri' supported and stimulated the interest in practice-based research activity. This collaborative will be the basis of the research infrastructure." (Visentin 2005)

The network was built upon existing networks

"The Scottish Primary Care Research Network was finally built upon existing networks of teaching and training practices centered on research active departments of general practice and primary care. This meant that a climate already favorable to research existed and several of the necessary skills were available." (Sullivan et al 2014)

A national federation of PBRNs in collaboration with a PBRN and HIT infrastructure from a university initiated the network

"The ePCRN integrates the practice-based research expertise from the community practices of the Federation of Practicebased Research Networks (FP-BRN) with the advanced "Grid" electronic infrastructure of the University of Minnesota (UM), and the Midlands Research Practices Consortium (Mi- dReC), one of the largest PCRNs in the United Kingdom.” (Peterson et al 2006)

A group of community health centers initiated the network

A public health agency and a national professional organization initiated the network

A group of community stakeholders and a PBRN shared resource initiated the network

A professional organization initiated the network and based its operations

A professional organization initiated the network and the academic department based the center of operations: 
Appendix Table 1. Continued

Type of Organization

Quotations

A professional organization and an academic department based the center of operations

An academic department based the center of operations

"We have also established a central office at the CFPC [College of Family Physicians of Canada] for the project manager/director and support staff. The chair of the board of CPCSSN is currently at Queen's University, where the central repository is housed. In the future, however, the chair may be at another network so the funding for the office of the chair will float." (Birtwhistle et al 2009)

"The University Family Practice Network is composed of five practices and is managed jointly by the Department of General Practice." (Laurence et al 2001)

"The Primary Health Care Research Network (PHReNet) is being established by the University of NSW as part of the NSW Primary Health Care Research Capacity Building Program. This program is funded by the Commonwealth Department of Health and Aged Care to develop and support research and evaluation in general practice and primary health care in Australia." (Mehmet et al 2004)

"KAN is administered through the Department of Family and Community Medicine at the University of Kentucky in Lexington." (Love et al 2006)

HIT, health information technology; PBRN, practice-based research network. 


\begin{tabular}{ll}
\hline Missions & Quotations \\
\hline
\end{tabular}

"to explore the morbidity pattern in the Dutch population as far as it could be diagnosed in GP care, to signal diseases as well as shifts in disease patterns." (Schweikardt et al 2016)

"to meet the need for a community based research 'laboratory' for child health research focused on issues central to the delivery of preventive pediatric care and across the spectrum of health and illness." (LeBailly et al 2003)

"to facilitate practice-based research partnerships between academic researchers and community based clinical teams that can lead to improved primary care clinical outcomes." (Jame et al 2015)

"to improve the health of children and enhance primary care practice by conducting national collaborative practice-based research." (Slora et al 2006)

"to conduct and disseminate practice-based research that results in new knowledge and improves the health of patients in South Texas." (Hayes et al 2011)

"to conduct practice-based research designed to improve health care in the United States." (Ornstein and Jenkins 1997)

"to inform and influence decisions along the continuum of service to patients, from research to practice and policy." (http://acornpbrn.org/mission/, accessed November 8, 2019)

"to conduct and facilitate practice-based research relevant to APRN primary care practice, develop culturally competent, evidence-based practice models for APRNs, and enhance the translation of research findings into primary care practice." (Deshefy-Longhi et al 2002)

"to improve the quality and safety of health care in primary care settings by identifying and solving problems commonly encountered in practice." (Kuo et al 2008)

"to generate new knowledge about basic pediatric issues of prevention and medical effectivenessknowledge that can have a significant impact on the health of children." (Del Torso et al 2010)

"Its mission is to support primary care research and education in order to improve the quality of care delivered to patients in the community in the West of Ireland." (Kavanagh et al 2010)

Purposes

Quotations

"Its purpose is the international study of problems and concerns presented at the level of the primary care to improve the understanding, organization, and implementation of appropriate health care for people throughout the world." (Culpepper and Froom 1988)

"for the purpose of facilitating research on chronic disease and related health care problems commonly addressed in primary care settings." (Sloane et al 2006)

"to demonstrate the impact of nursing centers on the health of communities; foster understanding, recognition, and use of nursing centers for essential primary health care; provide a forum for communication and collaboration among consortium members; and support the growth of nursing centers nationally." (Anderko et al 2005)

"to offer a managed approach to hosting high quality research in the health service and to assuring recruitment and retention of study participants." (Sullivan et al 2007)

"to improve the health and health care of underserved, low-income, multiethnic populations of the South-west." (Sinclair-Lian et al 2008)

"to participate in clinical research for the benefit of their patients and to enhance the discipline of general practice through research training and activity." (IPCRN, accessed May 17, 2017)

"to study problems as they present in the primary care setting and to increase the knowledge base regarding how modern primary care medicine is practiced." (Iverson et al 1988)

"offers epidemiological information to the health service and the possibility of scientific research by the university departments." (Middelkoop et al 1995)

Goals/Focuses

Quotations

"To screen and facilitate the increasing number of researcher requests for Academy support in approaching family physicians about participation in their projects. To encourage and support individual or group research projects by its members. To train members in research methodology. To develop and coordinate research support resources for members." (Solberg et al 1986)

"The main goal of the Transition Project is the analysis of the content of family practice in great clinical detail, for epidemiological purposes and to support quality assessment, health care policy, medical education and research." (Okkes et al 2001)

"Focusing on research strategies for integrating epidemiological research, community-based primary care research and outcomes assessment in practices serving the medically underserved. .. To involve larger numbers of clinicians at health centers in community-based research." (Sardell 1996)

"In our network the focus is on an intensive contact monitoring of patient diagnoses." (Hak et al 1998)

"The SPAM network, with its focus on processes of care in PC and national representation, should be complementary to other efforts." (Selby et al 2015)

"WH-PBRN specializes in multisite women's health research and recruitment of women to multisite, practice-based research studies." (Frayne et al 2013)

"The chief goal of the Registration Network Family Practices is to establish a computerized database containing certain patient characteristics and all relevant health problems excluding minor, temporary illnesses.” (Metsemakers et al 1996) 
"Investing in people. Recognizing that meaningful change is effected by motivated individuals and not systems alone. Creating an environment in which research is seen as a positive attribute and a necessity for the development of the profession.Preparing a structured support system for fostering research. Developing an education and career structure for practice-based researchers, including attachments and appointments, and help towards higher degrees and diplomas. Being part of an integrated drive towards research and development and to ensure representation for primary care researchers at policy making and resource allocation level." (Carter 1998, p. 77)

"The overall CORNET research goals are to study the health care of minority and underserved children, to examine health care disparities, and to study resident education, with comparisons of physician behaviors between pediatric residents and pediatricians in practice." (Serwint et al 2006)

"The overall goals of TARGet Kids! are:

1. to establish a 'proof-of concept' community-based primary care research network;

2. to learn from the 'proof-of-concept' experience and to scale up to a provincially-based network with sentinel sites to ensure representativeness;

3. to build partnerships between child health researchers, community-based practitioners and public health researchers and practitioners;

4. to build a platform to advance evidence for community-based prevention and health promotion;

5. to build a platform to advance population-level child health surveillance." (Carsley et al 2015)

"Create a trusted, valued multi-state community of safety net stakeholders and researchers to lead and participate in a learning community to address evidence-gaps relevant to the safety net populations -with special emphasis upon those populations served by Medicaid and State Child Health Insurance Program (SCHIP”). (Sills 2015)

"The goals of CHARN are to:

- Foster practice-based collaboration among personnel, practitioners, and researchers at various clinics and centers;

- Create infrastructure for pooling patient data across different sites;

- Train CHC personnel in research methods and protocols;

- Develop and conduct study protocols;

- Expand the research agenda via additional funding; and

- Develop improved approaches for transferring research findings into practice." (Likumahuva et al 2013)

"Goals of building GP research in the community. Develop professional development opportunities for GP supervisors and GP registrars. Goals of improving GP clinical academic's professional development." (Dijkmans-Hadley et al 2015)

"Its goal is to promote the translation of research findings into policy and practice." (Duggan et al 2013)

Objectives

Quotations

"To improve on knowledge of infectious diseases gained from the national notification system. The difference between notification and true incidence has been emphasized; To estimate the importance of other infectious diseases in general practice; To inquire into the field of health problems observed in general practice." (Lobet et al 1987)

"The Primary Care Cooperative Information Project consists of a network of 44 free-standing primary care practices that are working with medical school faculty to (1) establish a professional environment that can help, attract, retain, and educate primary care physicians in a rural area, (2) develop practice based quality assurance systems, (3) improve management efficiency and heighten clinical cost consciousness in the daily practice of medicine, and (4) build a better system for continuing education based on practice self-study and cross-practice research." (Nelson et al 1981, Part 1)

"Its objectives are to (1) develop a national home visiting research agenda, (2) advance the use of innovative research methods, and (3) provide a research environment that is supportive of the professional development of emerging researchers interested in home visiting." "An overarching goal is to promote the translation of research into policy and practice." (Duggan et al 2013)

"Support community physicians research. Support research interests of family physicians. Conduct collaborative research among family physicians. Train physicians in research methods. Provide access to community practices for (academic) investigators." (van Weel et al 2000)

"to develop an epidemiological database for diseases to a central unit for Northern Ireland of morbidity within the community as presented to general practitioners. To support epidemiological research in general practice." (Boydell et al 1995)

"The objectives of the network are: (i) to monitor trends in acute and chronic illness seen in primary care; (ii) to investigate the role of psychosocial factors in illness and disease; (iii) to examine aspects of medical practice, eg, the use of drugs, tests and procedures; (iv) to promote cost-effective management of medical problems in the community; and (v) to establish a databank for undergraduate and postgraduate training of primary care providers." (Volmik et al 1996) 
"The objectives are to co-ordinate research projects in general practice, to assist legitimate organizations and individuals undertaking research projects, to facilitate appropriate feasible and high-quality research being undertaken in practices, and to develop the skills and confidence of practices undertaking such research." (Frew et al 2001).

"1. Develop an infrastructure for CPCSSN that will underpin the operations of a robust, longitudinal data collection and maintenance of a primary care data repository on chronic disease.

2. Demonstrate the ability to extract relevant data from multiple EMRs in multiple primary care practice sites.

3. Create a usable CPCSSN database that will be a searchable data repository for primary care researchers and will be the basis for reports for government and others about chronic disease in Canada." (Birtwhistle et al 2009)

"to share data extracted from health information systems to facilitate professional collegiality and coordination of health services, quality monitoring and research and development to improve health documentation, patient care and health outcomes in an integrated health neighborhood." (Electronic Practice Based Research Network, accessed January 7, 2020)

"Establish and maintain a broad, safety-net focused, research partnership and learning community to govern relationships, establish priorities, provide data quality oversight, and evaluate the purpose and value of the community's effort." (Sills 2015)

Aims

Quotations

"We aimed to develop a practical, ethical, long-term means of undertaking research in general practice by adjusting research methods to the everyday procedures of general practice teams, rather than asking doctors and nurses to change the way they recorded care in order to accommodate research requirements." (Dovey and Tilyard 1996)

"Its aim has always been to provide an efficient and effective support network for all interested healthcare researchers in what are now the three North Cumbria PCT's; Carlisle \& District PCT, Eden Valley PCT and West Cumbria PCT.” (Robertson et al 2005)

"The aim of the network is to promote a research and development culture through primary care in order to secure high quality, evidence-based, clinical care." (Smith and Dunleavey 1996)

"The network aims to operate as a complex adaptive learning system (a whole system approach) by resolving a number of seeming paradoxes: There is a need for simultaneous 'top down', 'bottom up' and 'coalition' led research. . The 'whole system' is big but resources permit only a small number of people to be involved at any one time. . There is a need to harness individual enthusiasm but multidisciplinary working, quality and equity also need to be assured. . Research needs to be focused and rigorous but reflective inquiring practice is a goal for all involved in primary care development." (Thomas and While 2001)

"The overall aim of research networks is to support and promote high quality research aimed at improving the quality and cost-effectiveness of services offered by the NHS as well as securing lasting improvements to health nationally and internationally." (Sullivan et al 2014)

"Known as ASPIRE or 'A Singhealth Polyclinics Initiative for Research Excellence', the committee aims to develop a comprehensive research program consistent with the vision and mission of the Singhealth network and to cultivate research culture in the polyclinics." (Chuan and Gan 2001)

"The aims of the PCRN were: 1) To develop a culture of research in primary care in South West Scotland. 2) To provide research training. 3) To provide support for researchers in primary care. 4) To develop and conduct non-commercial research which would inform the provision of primary care." (Hannay 2006)

"The major aim of the work of the MNCCRN is to discover new knowledge that will inform primary care practice, health professional education, and health care policy." (Anderko et al 2006)

"One of the main aims of GRACE was to establish a multi-disciplinary network of research to address a complex problem and to establish an enduring European-wide primary care research network for future research." (Nuttall et al 2011)

"To spur the development of important and high-quality primary care research that is relevant to clinical practice. To influence primary care policy making through its research." (Soos et al 2010).

"Our aim is to improve the evidence for population health and primary prevention using a research platform embedded in primary care practice." (Carsley et al 2015)

"The ongoing FIRE project (Family Medicine ICPC-Research using Electronic Medical Record) aims to embed standardized collection of research data by means of an EPR into routine clinical practice." (Chmiel et al 2011)

"The aims of the Tutka network include developing research activity and capacity by learning, by researching together, by creating important research questions from the point of view of primary care health care professionals, by involving health centers in data collection, and by linking to external research projects." ('Tuomas Koskela 2017)

GP, general practitioner. 


\begin{tabular}{ll}
\hline Key Activities & Name of PBRN, Nationality, and Quotations
\end{tabular}

Initiating networks with routine collection of data

Initiating networks through specific projects

Initiating networks focusing activities on capacity building

The Nijmegen Family Practice Academic Network (NL): "The Nijmegen network collects patientrelated data on an ongoing basis." (van Weel 2000) "In a practice-based setting, data were collected concerning health problems patients presented to their general practitioner." (van Weel 2008)

The Transition Project (Thanshis) (NL):

"54 FPs in 23 practices distributed over the Netherlands routinely collected and coded data for all face to face (direct) encounters with their listed patients." (Okkes et al 2001)

$\operatorname{GPDRP}(U K)$ :

"The project is a sentinel network of 23 general practices in Northern Ireland that report the incidence of a list of selected diseases to a central unit for analysis." (Boydell et al 1995)

$R N H(N L)$ :

"This is a continuous and computerized database in which 42 general practitioners, working in 15 different practices in the south of the Netherlands, are participating. All relevant health problems are registered. A health problem is defined as 'anything that has required, does or may require health-care management and has affected or could significantly affect a person's physical or emotional well-being." " (van den Akker et al 1998)

ASPN (USA and Canada):

"ASPN routinely collects and maintains data in four areas of network operations. First, all ASPN practices annually submit a report, which describes their active patient population,...ASPN collects data that update the characteristics of the practices and individual clinicians in ASPN...ASPN has replicated the National Ambulatory Medical Care Survey (NAMCS) in all practices and instituted by policy that requires NAMCS in all practices joining the network. Finally, ASPN practices report data on specific topics on a 'weekly return card."' (Green et al 1994)

CSeRMeG PBRN (Italy):

"A research project that is becoming the paradigm of the Italian research on General Practice. It started from a survey showing that treatment and control of cardiovascular risk is still far from optimal even in very high-risk patients. A group of general practitioners, coordinated by Istituto Mario Negri, wrote the protocol of the study with various proposals: Creating a research network." (Visentin 2005)

GRACE-01 (International):

"We aimed to set up a European-wide primary care research network to deliver an ambitious observational study during one winter period. We succeeded in establishing a clinical platform for the GRACE 01 study, and many of the PCNs [primary care networks] have continued to recruit patients into subsequent GRACE studies. We achieved recruitment targets in many PCNs in GRACE 01. GRACE 01 continues to generate data that has clinical relevance." (Nuttall et al 2011) Tutka (Finland):

"The first study, focusing on the non-acute use of ECG in primary health care, has been carried out and infrastructure for future studies has been established." (Koskela et al 2017)

Trent Focus Collaborative Research Network (UK):

"The network commenced its activities with a detailed needs assessment exercise to identify the research skills and needs of practitioners." (Comino 2002)

WeLReN (UK):

"The evidence suggests that it is possible to operate a primary care research network in a way that develops coalitions of interest from different parts of the health care system as well as both "top down' and 'bottom up' led projects." (Thomas and While 2001)

"The network aims to operate as a complex adaptive learning system (a whole system approach)." (Thomas and While 2001)

TayRen (UK):

"An early priority was to increase the research skills across the network by investing in a broad range of training, from critical appraisal skills, searching for evidence, managing data to detailed research methodology." "As research expertise within the network increased, more novice researchers could be integrated into the network, have access to training in research skills and gain experience by working within project teams." (Pitkethly and Sullivan 2003)

The Dumfries and Galloway Primary Care Research Network (UK):

"All primary care professionals working in the region were offered an initial grant to buy time for research training to develop their own research ideas." (Hannay 2006)

Initiating networks developing SFBayCRN (ex-UCSF) (USA): a survey 

survey to identify training needs and subsequent training
Initiating networks with a
Initiating networks leveraging health information technology developments or aggregating electronic health data

\section{EAPRASnet (International):}

"Every pediatrician joining the network has been asked to complete a recruitment survey. The aims of the survey were to characterize pediatricians' demographics, practice arrangements and patients' demographics, to define main incentives for research, and to learn what pediatricians view as unsolved issues that need to be studied." (Del Torso et al 2010)

WestREN (Ireland):

"In September 2009 all member practices were issued with a questionnaire with two objectives: to describe the structure and characteristics of the member practices and to compare the results to the national profile of Irish general practice.” (Kavanagh et al 2010)

CORNET (USA):

"the Task Force undertook a research study in 1999 that included a multi-site evaluation of pediatric residents' continuity experiences. CORNET was born when 42 continuity practices expressed interest and 36 programs completed the study, with over 1100 resident responses-a powerful demonstration of the potential and power of collaboration." (Wasserman et al 2011)

GR-PBRN (USA):

"Before engaging practices in PBRN-related research, we surveyed physicians about practice-based research to assess facilitating factors regarding physician participation in practice-based research and to compare the perspectives of internists, family physicians, and pediatricians" (Gibson et al 2010)

SPAM (Switzerland):

"The Quality and Costs of Primary Care in Europe (QUALICOPC) survey served as a starting-point for creating the SPAM network." (Selby et al 2015)

$W \operatorname{ReN}(\mathrm{UK})$ :

"Before setting-up the network a survey was conducted of GPs in Wessex to estimate the level of interest in research and the perceived barriers to participation in research activity." (Smith and Dunleavey 1996)

"WReN has identified primary care teams interested in research and provided training in research methods, provision of research support and opportunities for collaborative research" (Smith and Dunleavey 1996)

SARNet (Australia):

"We designed a survey questionnaire to assess network members' research experience and interest in developing further skills." (Ried et al 2006)

"At the time of joining SARNet, members are sent a survey asking their specific interests and needs for research and evaluation training. Data from these returned surveys are now being used when planning courses and activities to be undertaken or repeated." (Waters et al 2004)

PPRNet (USA):

"The Practice Partner Research Network (PPRNet), a practice-based research network consisting solely of physicians that use Physician Micro Systems Practice Partner, CPR system.” (Ornstein and Jenkins 1997) "PPRNet involvement is voluntary and offered to all practices that use Practice Partner's EMR.” (Wessell et al 2008)

ePCRN (USA and UK):

"The electronic infrastructure of the ePCRN is being built on a web-enabled distributed database technology that makes use of cutting-edge web technologies such as the OGSA and WSRF. This allows creation of distributed clinical information systems located at the site of practice that can be appropriately and securely linked together. Exciting possibilities for this technology include the potential for patient eligibility searches across wide geographic areas, real-time video conferencing, implementation of medical record communication standards, and real-time clinician access to standard clinical performance measures." (Peterson et al 2006)

DARTNet (USA):

"A federated network links geographically and organizationally separate databases so that a single database query can return results from multiple databases while maintaining the privacy and confidentiality of patient data." (Pace et al 2009)

CPCSSN (Canada):

"In 2008, PHAC [Public Health Agency of Canada] issued a request for proposal for a primary care sentinel surveillance system for chronic disease." "All of these academic primary care research networks had associated family medicine practices that used EMRs...Because of the work involved with assessing data extraction capabilities from individual EMRs, each network was restricted to recruiting up to 10 practices using the same EMR.” (Birtwhistle et al 2009)

IPCRN (Ireland):

"Through participation in the IPCRN, the extraction of anonymised patient prescribing records is possible through the integration of an electronic tool for remote data extraction into the General Practitioner's (GP) patient management software system." (Galvin et al 2015)

Initiating networks developing TARGet Kids! (Canada):

a patient cohort
The development of an open longitudinal cohort of children enrolling from early childhood and following-up until adolescence. "The Applied Research Group for Kids (TARGet Kids!) is an 


Key Activities Name of PBRN, Nationality, and Quotations

Initiating networks following other approaches or combinations of approaches ongoing open longitudinal cohort study enrolling healthy children (from birth to 5 years of age) and following them into adolescence." (Carsley et al 2015)

$N C-F M-R N(U S A)$ :

"This paper describes the development of a different type of primary care research laboratory—a cohort of adult patients recruited from a representative sample of primary care offices and maintained for use on multiple projects. The cohort, the North Carolina Health Project (NCHP) research cohort, was developed by faculty of the University of North Carolina (UNC), in collaboration with the North Carolina Academy of Family Physicians, for the purpose of facilitating research on chronic disease and related health care problems commonly addressed in primary care settings. As such, it may represent a new model of primary care research infrastructure development — different from, and complementary to, traditional PBRNs.” (Sloane et al 2006)

HARNET (USA): Peer intellectual exchange and development of research questions

"The HARNET came into existence as an outgrowth of the Harrisburg (Pa) Hospital Family Practice Residency Program. In 1988, clinicians from six local practices (four suburban and semirural private practices and two residency-based family practice centers in urban and semirural areas) met to discuss their mutual interest in practice-based research. Clinicians from these practices teach in the family practice residency program. Initial discussions held at monthly faculty meetings centered on a list of clinical research questions arising from the members' practices." (Slawson et al 1993)

$C D N$ (USA): Development of a peer network for implementation of better practice and to start a big-scale research project

"Since the mid-1980s, clinicians working in community and migrant health centers formed clinical networks to provide administrative and clinical training, regular interaction with peers, and opportunities for participation in policy formulation. The subject of this article is the most developed of the regional clinical networks, the Clinical Directors Network of Region II (CDN)," (Sardell 1996)

"During its ten-year history, CDN has responded to the needs articulated by clinicians at health centers. It has provided managerial training and clinical education, strategies for increased involvement of clinicians in health center management and opportunities for engagement in community-based primary care research...

During the 1990s, CDN's annual conferences dealt with both clinical and managerial issues, focusing on strategies for integrating epidemiological research, community-based primary care research and outcomes assessment in practices serving the medically underserved. These conferences were linked to research activities in which CDN was involved and were part of efforts to involve larger numbers of clinicians at health centers in community-based research. CDN has, since 1989, functioned as a practice-based research network." (Sardell 1996)

COOP (USA): Developing a forum of intellectual exchange and common software

"The core of the COOP project is development of a medical information system in all practices that is tailored to the requirements of each, yet contains a basic data set common to all participants in the network." (Nelson et al 1981, Part 1)

"As a forum for intellectual exchange, the COOP has enabled clinicians to serve as sources of information for each other, which has affected clinical practice." (Mold and Peterson 2005)

ASPIRE (Singapore): Developing a forum of communication for potential researchers

"It [the network] serves as a forum of communication for potential researchers, a platform to exchange research ideas and a base for methodology capacity building and collaborations with external research agencies." (Chuan and Gan 2001)

MAFPRN (USA): Developing a research panel

"In 1978 the MAFP's Committee. . .decided the participation in practical research was one of the best ways for practitioners to continue their educational growth. In order to foster this participation, the committee formed a small research panel of interested practitioners. . This research panel's goals included (1) increased research acceptance and skills by practicing doctors, (2) development of a list of practitioners interested in research, (3) development of a technique for multiclinic collaborative projects, and (4) completion of several practical demonstration studies that would produce information about the problems and activities of practitioners." (Solberg et al 1983)

$R R N e T$ (USA): Linking residents to practice-based research activity

"Each year, RRNeT recruited medical students through various events and assisted them with applications to the dean's program, focusing on the current RRNeT study. Since 2006, RRNeT recruited 40 UTHSCSA medical students, four to eight per year." (Burge and Hill 2014)

OKPRN (USA): Sharing resources

"OKPRN currently includes thirteen family practice offices across Oklahoma connected by computerized e-mail and a mission to share resources, support decision-making in private practice, and conduct research." (Mold and Barton 1996)

SPCRN (UK): Leveraging previous PBRN experience and active in training and teaching practices

"The Scottish Primary Care Research Network was finally built upon existing networks of teaching and training practices centered on research active departments of general practice and primary care. This meant that a climate already favorable to research existed and several of the necessary skills were available." (Sullivan et al 2014)

OCHIN (ex-Safety Net West) (USA): Development of patient-centered medical village (community centers network) with a shared EHR enabling data aggregation and colearning 
"One model of shared IT resources and learning is a "patient-centered medical village. . the OCHIN Community Health Information Network is an example of this model; community practices have come together collectively to form an organization that leverages shared IT expertise, resources, and data, providing members with the means to fully capitalize on new technologies that support improved care." (DeVoe et al 2013)

"The opportunity to harness data from many practices was another major facilitator of our PBRN's development and echoes others' observations about the power of networks to collect data on large numbers of diverse patients. Our PBRN's data on a large patient population is in one shared and linked EHR which is centrally maintained and housed at OCHIN. This unique data resource helped to catalyze the formation of our PBRN and obtain some early grants to conduct secondary data analyses." (DeVoe et al 2012)

"The collaborative and its member groups also provide a structured environment with peer mentors and a shared EHR to enable practices to come together, share their individual innovations, and spread them across the network." (DeVoe et al 2013)

CHARN (USA): Providing research capacity and infrastructure

"CHARN offers opportunities to bridge clinical practice and academic environments to improve research infrastructure and capacity." (Likumhuva et al 2013)

ISPRN (Australia): Development of relationships and communication pathways

"The framework developed by Barnett et al (2012) was found to be more useful in its application to ISPRN, which had a better balance of face-to-face interaction than online interaction, when the seven principles were collapsed into five...: (1) the establishment of a recognized leader (to promote and facilitate research idea development); (2) the development of relationships (between network members and stakeholders); (3) the evolution of communication pathways (through various mediums); (4) the collaboration of $\mathrm{CoP}$ members involved in developing shared goals and objectives; and (5) the role of evaluation in improving the CoP." (Dijkmans-Hadley et al 2015)

$D D-P B R N$ : Collaborative management, problem solving, and cocreation in training

"The idea of a DD-PBRN slowly emerged following years of affiliation between constituent members. ..It developed in the context of a series of success experiences in which future PBRN members engaged in tasks beyond the scope of their usual daily work, for example, co-creating training and clinical resources and educating health professionals." (Tyler and Werner 2014)

"self-advocates, family members, and service providers began to see a role for themselves as vitally important educators of physicians. Many became involved in ongoing training of resident physicians at their local family medicine residency training programs. They recognized that the education of health professionals was a concrete means of ensuring and advocating for better health care." (Tyler and Werner 2014)

"Mutual respect and understanding further developed between members of these 3 communities through collaborative management of complex client situations in which extensive communication and problem-solving between groups were required." (Tyler and Werner 2014)

$H V R N$ : Advances of implementation science and input of stakeholders

"Advances in dissemination and implementation science and comparative effectiveness research can and should be applied to home visiting. These advances include conceptual frameworks, operationalization of framework components, approaches to match administrative data, and development of designs and analytic techniques to test multilevel factors for the dissemination, implementation, and sustainment of innovations."

"In summary, a rigorous program of research is needed to advance the field of home visiting. Such a program should draw on advances in implementation science, input from stakeholders, and the experience of practice-based research networks." (Duggan et al 2013)

e-PBRN (Australia): Data extraction from EHRs and an integrated care model implementation

"Electronic health records (EHR) of all patients are extracted routinely from the general practices (3 using MD3, one originally used MD2 and one using Practix) using GRHANITETM and sent encrypted to a secure data warehouse at the University of NSW." (Taggart et al 2012)

"The overarching conceptual framework highlights the socio-ecological complexity that influences the sharing and use of skills, information and resources to maximize the benefit to the patient, community and health system over time. It includes elements identified in the review of integrated care programs. . .Effective integrated care requires a transformational change towards teamwork, information sharing and work practices; a systems approach to managing chronic disease; eHealth; and continuous quality improvement with ongoing monitoring and evaluation. Higher level policy drivers include reforming health care financing to promote and sustain multidisciplinary integrated care." (Liaw et al 2011)

WPRN (USA): Leveraging existing strengths from QI activities and data sharing HIT infrastructure"Developing a practice-based research network (PBRN) with a model that integrates research and QI builds on the existing strengths of QI efforts, adding research incrementally rather than building a research program from the ground up." (Baldwin et al 2012)

WPRN (USA): A HIT infrastructure of data sharing across practices

"Our CTSA efforts at the University of Washington's Institute of Translational Health Sciences (ITHS) include the Locally Controlled Data QUery, Extraction, Standardization and Translation (LC Data QUEST) pilot project aimed at creating data sharing capacity within the Washington, Wyoming, Alaska, Montana, Idaho region across primary care based practices." (Stephens et al 


\begin{tabular}{l} 
Key Activities \\
\hline 2012) \\
ACORN (Australia): Developing a survey across the practitioners and developing a database of \\
research interested practitioners \\
"One major task for the ACORN Project Steering Committee was to decide the method by which \\
to recruit registered chiropractors via the invitation pack (database questionnaire and ACORN \\
national practitioner database consent form)." "the ACORN project initially employs what we call \\
a sub-study model to PBRN design whereby initial data collection is focused exclusively on \\
practitioner-relevant information collected via self-report aimed at establishing a practitioner \\
PBRN database." (Adams et al 2016) \\
ULEARN-GP (Ireland): Developing a profiling survey and in-depth interviews on research \\
engagement on GPs \\
"A profiling survey questionnaire was posted and e-mailed to all practices affiliated with the \\
University of Limerick Graduate Entry Medical School... The profiling questionnaire used in the \\
study gathered demographic details on practices, including details on practice staff, organization, \\
size and academic activity. . GPs affiliated with the University of Limerick-Graduate Entry \\
Medical School were invited by email to participate in an interview." (O'Regan et al 2020) \\
PPHAG PBRN (Samoa, Tonga, Cook Islands, Niue, and New Zealand): Developing a community \\
advisory board to be the basis of the PBRN \\
"Over the next year, Rose recruited a group of Pacific Island community members, and formed the \\
Pacific People's Health Advisory Group (PPHAG). Members were invited from personal and \\
professional networks, reflecting the core values of connectiveness and relationships in Pacific \\
cultures...PPHAG members discussed their areas of possible research interest over the next few \\
months...Co-design and action research were explained-where research is actively done by, \\
with, and for the stakeholders who will benefit from it, such as patients, community members, and \\
clinicians, rather than done on them." (Lamont et al 2020) \\
\end{tabular}

EHR, electronic health record; FP, family physician; GP, general practitioner; HIT, health information technology; PBRN, practice-based research network; QI, quality improvement. 


\section{Appendix Table 4. Example of Practice-Based Research Network Research Training}

Topics of research training
"At the first STaRNet teaching session a research methods resource pack was distributed to each lead practice. This was developed by the STaRNet project team, and included information, references and key articles on: literature reviewing, questionnaires and surveys, qualitative research, epidemiology, clinical trials, evaluating healthcare, health economics research, statistics, ethical issues, writing up and disseminating research, applying for funding and using the Internet in research. A second resource pack was developed on evidence-based healthcare to support the STaRNet lead practices in their work on implementing clinical guidelines and developing evidence-based practice. The pack provided references to key publications and detailed information about groups and resources concerned with evidence-based healthcare and included sections on: an overview of the evidence-based healthcare movement, how to find research evidence, critical appraisal, systematic reviews, guidelines, audit and managing change." (Carter 1998, p. 90-1). 
Appendix Table 5. Example of Synthesis of Key Element "Relationship Building between Academics and Practitioners in the Field"

\begin{tabular}{lll}
\hline Subthemes & Key Elements & Components \\
\hline $\begin{array}{l}\text { Network } \\
\text { infrastructure } \\
\text { and }\end{array}$ & $\begin{array}{c}\text { Relationship } \\
\text { building }\end{array}$ & Long-term relationships \\
operations & $\begin{array}{l}\text { between } \\
\text { academia and }\end{array}$ & \\
& practitioners &
\end{tabular}

Development of common identity

Based on common mission

Collaborative philosophy

Matching practitioners and researchers with common interests

Building research relationships upon the enthusiasm of researchers and practitioners

Collaboration across various disciplines and levels of seniority
Related Quotations

"This entire recruitment process involves relationship building, not just for CaRESS [study] but also for KAN. This defining feature of a PBRN, the long-term relationship with the clinicians, is the context for all our contact and decisions with the practices." (Love et al 2006)

"The organizational model developed for the MNCCRN is one that builds on long-standing relationships with community groups, other health care providers, and organizational linkages that will facilitate trust, increase communication, maximize the use of limited resources, and enhance the dissemination of new knowledge generated to multiple constituencies, including consumers, health professionals, and policy makers." (Anderko et al 2005)

"ASPN conducts an annual convocation of its practices. The primary objectives of this meeting are to get acquainted; share information; develop an "esprit de corps" among network members; review, modify, and approve studies; and generate new study ideas." (Iverson et al 1988)

"We have two meetings a year, because-unlike WReN-we have a very tightly knit group. The doctors and nurses and their support staffs know that they are in UPRNet, and therefore most UPRNet practices participate in most UPRNet studies...we are, after all, a small, regional, highly committed group." (Pearls of Research 1998, p. 72)

"Appropriate resources should be identified for face-to-face meetings/teleconferences and annual events, since getting to know fellow researchers within a network helps to attract commitment and a sense of common purpose and camaraderie. An interactive (rather than didactic) approach to training a multilingual group worked well.” (Nuttall 2011)

"What is not captured in this description of the formal program is the value of WReN members meeting as a group, this is much better reflected in the many compliments received from participants." (Smith and Dunleavey 1996)

"establish annual network meetings, which will provide a sense of 'family' of like-minded practitioners with a common purpose to network members." (Deshefy-Longhi et al 2002)

"CHCs [community health centers] are ideal partners with whom to conduct patient-centered outcomes research because they engage in quality improvement and evaluation with a mission to provide efficient and effective care that advances health and reduces disparities." (Likumahuva et al 2013)

"The collaborative nature of ASPN means that the results are not the property of any one center or any one individual but belong to all involved and should be published under the aegis of ASPN." (Green et al 1984)

"'Matchmaking' providers and researchers with common research interests using as liaisons the PBRN coordinators, community research liaisons to build personal relationships. Likewise, clinic champions operated as liaison for their clinic." (Likumahuva et al 2013)

"building upon the enthusiasm of researchers and clinicians at the geographically dispersed sites will be key, so as to assure that these busy professionals with competing priorities remain engaged over time." (Frayne et al 2013)

"Of particular note is the heartening and consistent multidisciplinary mix of all WeLReN activities but the difference between the doctor:nurse ratio in Theme Group and Expert-Led projects is noteworthy (2:1 vs 6:1). The WeLReN approach facilitates team working across traditional boundaries and across different levels of seniority which may make it easier for research activity to be enhancing of local education and 


\begin{tabular}{llll}
\hline Subthemes & Key Elements & Components & Related Quotations
\end{tabular}

Mutual appreciation between practitioners and academics

Strong bonds between academia and practitioners

Constructive relationship between practitioners and academics

Relationships with key practitioners and practice managers

Collaborative relationship focused on practitioner interest

Maintaining respectful and trusting relationships

Networking and interaction

Efforts to increase trust

Development of trust and boundaries about data sharing

Sharing experiences service development activity, through the desirable development of informal inter-organizational connections." (Thomas and While 2001)

"While a motivating factor of other PBRNs, our two 'different worlds' do not always understand each other, possibly because our PBRN is based in the community rather than an academic setting. Building cohesion among PBRN clinicians and researchers required time to develop relationships so that our clinicians and researchers better appreciate each others' worlds." (DeVoe et al 2012)

"Its success is mainly contributable to the participating GPs' strong academic bonds, to its relatively small size, and to its consistent emphasis on completeness of data and, by organizing monthly meetings, on the assurance of data validity." (Schers 2008)

"The objective of the first set of clinical and management studies presented in the preceding section were to do the following: (1) form a constructive relationship between medical school faculty and community physicians." (Nelson et al 1981, Part 2)

"Other ways that ISPRN has developed relationships over time in the organization and implementation of projects has been through establishing a dual relationship with the practice manager and key GPs involved in the project." (DijkmansHadley et al 2015)

"The first premise is that COOP Project aims to meet the educational, managerial, and research interests of primary care physicians. It is a collaborative effort involving a medical school, community practices, and policy makers, but the direction of the COOP Project is determined by interest of the physicians." (Nelson et al 1981, Part 1)

"the core tenet of successful PBRNs is developing and maintaining respectful and trusting long-term relationships that continue beyond research studies." (Hayes et al 2011)

"Over the course of years, members of the disabilities and service communities slowly developed trusting relationships with a small cadre of physicians who demonstrated expertise and commitment to this population. Mutual respect and understanding further developed between members of these 3 communities through collaborative management of complex client situations in which extensive communication and problem-solving between groups were required.” (Tyler and Werner 2014)

"In addition to opportunities to increase knowledge and skills in clinical and managerial areas, CDN's conferences and workshops also provide opportunities for professional peer networking and interaction. According to CDN activists, sharing experiences and ideas with colleagues who work in similar organizational environments and respond to the needs of similar patient populations helps to enrich professional life." (Sardell 1996)

"Strong leadership and frequent communication meant that NNCs [National Network Coordinators] and NNFs [National Network Facilitators] got to know well and grew to trust the GRACE-01 coordinating team.” (Nuttall 2011)

"Building a PBRN with a common EHR, or the ability to merge data from multiple EHRs into a common repository, requires that trust and boundaries around data sharing be established." (DeVoe et al 2012)

"This unit provided a forum for general practitioners interested in the epidemiology of common infectious diseases to share experiences about the spread and the impact of conditions diagnosed and treated in their practices." (Fleming 1999) 


\begin{tabular}{|c|c|c|}
\hline Subthemes & Key Elements & Components \\
\hline
\end{tabular}

relationships

Fostering collegiality

Support the links between practice and research

Leveraging the prior relationships with academia

Leveraged relationships with teaching practices

Collaborative relationship based on the strengths of each part

Synergies developed during training

Synergy and collaboration developed during research process

Synergy developed through bidirectional collaboration

Cycles of collaborative activity

Collaboration with other research interested groups out of primary health care

Collaboration among all stakeholders
"Another advantage of regional networks is that a more personal relationship with physicians, office staff, and patients is possible. Physicians and their office staff members generally know the PPRG staff personally." (LeBailly 2003)

"Fostering ongoing research relationships and a sense of camaraderie that advances the cause of child research and invigorates participating clinicians." (Slora and Wasserman 2010)

"A shared sense of the importance of the research questions to improving clinical care was the foundation for establishing a common purpose and a spirit of camaraderie." (Nuttall 2011)

"The 3 networks expressed the need to support routine practice, do research, and, at the same time, raise the quality of care in the network. An integral relationship between practice and research is apparent in each of the networks." (van Weel 2000)

"Two rural practices with residency graduates of the University of Missouri expressed an interest in collaborating. In addition, the Department of Family and Community Medicine sponsors two rural satellite practices which are used as educational bases for residents." (Williamson et al 1998)

"The network is both a research and teaching network. Interestingly enough, however, we have done more research than teaching." (Pearls of Research 1988, p. 72)

"The combination of a central university faculty, which has an understanding of research methods and design, statistical analysis, and grant writing, with rural practitioners, who have "real world" practices, values, and clinical institutions, is a good one. This type of collaboration is professionally satisfying and is likely to result in valuable new primary care knowledge." (Williamson et al 1998)

"Since beginning collaborative working in 2002, a synergy has developed between CumbReN and HRDNoW [Health R\&D North West] that has helped build research capacity at an individual and organizational level within the North Cumbria PCTs." (Robertson et al 2005)

"The network enables primary care practitioners with interesting clinical questions to work with expert researchers. From this synergy have developed large R\&D projects of national importance." (Smith and Dunleavey 1996)

"The investigator and one provider then engaged another physician, both of whom were not previously involved with research. Collaboratively, they developed a project to address clinical questions they had encountered in practice." (Likumahuva et al 2013)

"WH-PBRN. . .represents a long-term partnership of clinicians and researchers who together strive to improve the health and health care of women Veterans. Powerful synergies arise from this bi-directional collaboration, which aligns the perspectives and experience of clinicians and researchers." (Frayne et al 2013)

The cycle can itself be viewed as participatory action research in that collaborative cycles of reflection, inquiry, feedback and action occur in each project and throughout the network." (Thomas and While 2001)

"NoReN's activities are geared towards research training, mentoring and fostering collaborative research. Specific activities during 1997 included. . Providing an interface with other local groups, eg, hospital research committees." (Carter 1998 , p. 80-1)

"Collaboration is the key to ACORN's success, relying on strong partnerships with practices, health systems, other universities and PBRNs, community organizations, businesses, insurers, and public health entities. Our relationships help to inform study 


\begin{tabular}{ll}
\hline Subthemes & Key Elements \\
\hline & \\
& \\
& Partnering for shared \\
& learning and best \\
& practices \\
& implementation
\end{tabular}

Development of relationships with vendors (or HIT stakeholders) and members

The relationship with the network is beneficial for the members

Linking through research assistants, research facilitators, clinician champions

Relationship brokering ideas, carry out interventions, interpret and disseminate findings, and ensure that positive transformative methods found are implemented into practice." (ACORN, accessed June 28, 2020)

"Partnering with OCHIN, researchers, and payers, many practices are organizing themselves as Patient-Centered Medical Homes. We envision a synergy between practice transformation and research activities, strengthened by a 'learner's bridge' that provides opportunities for community partners to learn the skills for implementing and evaluating practice interventions... This type of partnership ensures that meaningful activities will be documented and will contribute to the growing fund of knowledge about evidence-based, best practices in primary care. Further, engaging learners in this partnership further strengthens the benefit for spread of innovation and sustainable future change." (DeVoe et al 2011)

"Our system architecture design was a result of partnerships between multiple stakeholders including our CTSA, community practices and tribal partners, and national research communities. Developing the LC Data QUEST data sharing architecture involved significant time and effort in creating and sustaining relationships among all partners involved and required an iterative process to allow stakeholders to give valuable input into system requirements." (Stephens et al 2012)

"Maintaining an engaged and productive network that is able to provide high reliability research activities and attract potential investigators requires a skilled and committed central organizing body to facilitate collaboration, to lessen the burden of research participation for practices, and to govern the network such that that all members receive benefits from participation." (Pace et al 2014)

Clinician champions: "Members of the clinician committee, who are physician champions from participating clinics, may vary from project to project. Physician champions inform their colleagues about the study and help solve logistical problems that arise during the project." (Kuo 2008)

Coinvestigators: "To ensure consistency of intervention and reliability and validity of data, there must be a seasoned coinvestigator at each site who is ultimately responsible for each research study, in collaboration with CNC clinicians." (Anderko et al 2005)

Research assistants/facilitators for research: "These assistants identify and exchange ideas, methods, questions, and challenges between practices within their pod and, through the central office, to the rest of the network; facilitate QI; and assist practices to participate in network-wide projects and for the research results implementation in practice." (Mold and Peterson 2005)

“...the Oklahoma Physicians Resource/ Research Network (OKPRN) uses five full-time equivalent (FTE) facilitators, called practice enhancement assistants (PEAs). The PEAs help member practices participate in individual and network-wide research and quality improvement projects. Initial PEA training includes a comprehensive introduction program followed by project-specific training." (Nagykaldi et al 2005

"Since our network would not be able to depend on much income, it should serve primarily a brokering function, bringing together researchers and interested practitioners for specific studies that are financially supported by the researchers." (Solberg et al 1986)

"In research linking primary care practitioners and hospital-based consultants, complementary strengths can be linked, thereby improving the potential for understanding the natural history of disease." (Christoffel et al 1988) 
Appendix Table 5. Continued

\begin{tabular}{|c|c|c|c|}
\hline Subthemes & Key Elements & Components & Related Quotations \\
\hline & & $\begin{array}{l}\text { Key tips for relationship } \\
\text { building, mentorship, } \\
\text { and leadership }\end{array}$ & $\begin{array}{l}\text { "Cultivate and support; Leaders and collaboration; Share } \\
\text { resources; Build bridges and partnerships; Add value in multiple } \\
\text { differing spheres." (DeVoe et al 2012) }\end{array}$ \\
\hline & & $\begin{array}{l}\text { Challenges deriving } \\
\text { from practice } \\
\text { comparisons }\end{array}$ & $\begin{array}{l}\text { "PBRNs must take precautions to avoid group comparisons so that } \\
\text { 'low performers' are not embarrassed or jeopardized." (Kuo } \\
2008 \text { ) }\end{array}$ \\
\hline & & $\begin{array}{l}\text { Challenges related to } \\
\text { relationships } \\
\text { maintenance }\end{array}$ & $\begin{array}{l}\text { "Maintenance and updating of contact information on cohort } \\
\text { [patient] members requires ongoing effort." "There are, } \\
\text { however, challenges involved in this type of infrastructure } \\
\text { development. They include involvement of practitioners, } \\
\text { minimization of selection bias, and maintenance of funding to } \\
\text { support the network and cohort infrastructure." (Sloan et al } \\
\text { 2006) }\end{array}$ \\
\hline
\end{tabular}


Appendix Table 6. Example of Synthesis of Key Element "Organizational Leadership"

\begin{tabular}{lcc}
\hline Subthemes & Key Elements & Components \\
\hline $\begin{array}{c}\text { Network infrastructure } \\
\text { and operations }\end{array}$ & $\begin{array}{c}\text { Organizational } \\
\text { leadership }\end{array}$ & $\begin{array}{c}\text { Characteristics of a } \\
\text { PBRN leader }\end{array}$
\end{tabular}

Leaders and/or founders with senior academic and clinician background

Leader is academic professor in the department

Leader has previous PBRN experience

Leadership providing critical momentum for capacity development and research activity
Recognized and enthusiastic leaders: "A worthy project such as an APRN research network requires recognized spokespersons in primary care research who are well regarded in both the nursing and medical fields for the importance and integrity of their work. They need to be relatively established in an academic setting that recognizes and supports their research and allows them ready access to other leaders in their field, both nationally and internationally. They must be willing to make the time to start such a project and must have the energy and enthusiasm to see it through. For an APRN research network, they need a clear vision of such a network, a solid perspective of both its promise and limitations, and a sense of humor to communicate that vision to fellow colleagues and staff." (Deshefy-Longhi et al 2002)

"Generally the network has no track record other than the reputation of its director and the members of its planning committee." (Deshefy-Longhi et al 2002)Leaders with engagement and motivation:

"PBRNs also require a champion that has the knowledge, energy, enthusiasm, and commitment to share the PBRN's vision with others." (Deshefy-Longhi et al 2002)

"The former National Association of School Nurse's (NASN) Research Consultant who had worked with other PBRNs served in this capacity." (Vessey et al 2007)

"The network Director is a long-standing GP in the area who now has a senior academic role with the Graduate School of Medicine, University of Wollongong. The Director, as a GP peer, provides an experienced perspective regarding the reality of implementing research within general practice." (Dijkmans-Hadley et al 2015)

"Visible leadership by the university and hospital Chairman of Pediatrics (J.A.S.) has helped to provide authority and prestige to the organization." (Christoffel et al 1988)

"The PPRG was founded in 1984 by Katherine Kaufer Christoffel, MD, MPH, in partnership with leaders in the Department of Pediatrics." (LeBailly 2003)

"In the case of WreN, the initial organizer was a physician in an academic setting who was able to arrange for protected time to facilitate the network development and who had ready access to secretarial and related support services." (Beasley 1991)

"The appointment of a professor of primary care research and development at the Tayside Centre for General Practice coincided with this successful bid." (Pithketly and Sullivan 2003)

"I have been involved with practice-based research for more than 17 years on several levels. I have been an Ambulatory Sentinel Practice Network (ASPN) clinician since 1982, an ASPN board member since 1993, and ASPN's president since 1997." "I cofounded the Michigan Research Network (MiRNet) in 1984.” (Pearls of Research 1998, p. 72)

"The combination of factors-a multi-state network of safety net clinics, an EHR with rich data linked across the network, and support from OCHIN's leadership-provided momentum for developing capacity to improve care quality in the safety net by optimizing practice through research." (DeVoe et al 2011)

“... as described in the quality improvement and practice transformation literature, engaged leadership and a willing champion within each individual practice (eg, quality improvement leader or office manager) helped to maintain momentum, to demonstrate the value of the data for improving quality of care, and to provide audit and feedback to providers and staff." (Kwan et al 2016) 
Appendix Table 6. Continued

\begin{tabular}{|c|c|c|c|}
\hline Subthemes & Key Elements & Components & Related Quotations \\
\hline & & $\begin{array}{l}\text { Leadership with interest } \\
\text { to improve practice } \\
\text { and influence policy }\end{array}$ & $\begin{array}{l}\text { "OCHIN leaders had a vision that extended beyond } \\
\text { supporting the delivery of clinical care in safety net settings. } \\
\text { There was interest in developing resources to improve } \\
\text { practice and to influence policy." (DeVoe et al 2011) }\end{array}$ \\
\hline & & $\begin{array}{l}\text { Key recommendations } \\
\text { for leadership }\end{array}$ & $\begin{array}{l}\text { "Cultivate and support; Leaders and collaboration; Share } \\
\text { resources; Build bridges and partnerships; Add value in } \\
\text { multiple differing spheres." (DeVoe et al 2012) }\end{array}$ \\
\hline
\end{tabular}

EHR, electronic health record; HIT, health information technology; QI, quality improvement. 